\title{
COMBINED USE OF TURNOVER AND PIVOT FLAP FOR DOUBLE LAYER CLOSURE OF POSTAURICULAR FISTULA
}

\author{
Authors: Mukesh Kumar Sharma (1), Naveen Kumar (2), V. Suman Babu (3) \\ Authors Affiliations: (1) Associate Professor, (3) Assistant Professor, Department Of Burns, Plastic \& \\ Reconstructive Surgery, PGIMER \& Dr. R.M.L. Hospital, New Delhi, (2) Assistant Professor, Department Of Plastic \\ Surgery, Lady Hardinge Medical College And Associated Hospital, New Delhi
}

\begin{abstract}
Repair of post auricular fistula are challenging owing to scarred tissue and poor blood supply in this area. Various techniques including locoregional flap cover and cavity obliteration have been utilized to repair this complicated problem. In our report, we introduce a novel technique using a double layer closure utilising local skin flap successful lasting results. Two young adults of age 18 Male and 21 year female. Size of fistulas were ranging from $1 \times 2$ and $2 \times 2$ $\mathrm{cm}$ respectively in size. Once the fistulous tract was excised two flaps were planned for double layer closure of fistula. First flap for inner lining was turnover flap. Then another local pivot flap is planned to cover the secondary defect or the raw area. It can be either simple rotation flap as in first case or Limberg type local transposition defect ( $2^{\text {nd }}$ case) flap. Both fistulas were healed well.
\end{abstract}

KEYWORDS : Fistula, Post auricular, Flap Closure

\section{INTRODUCTION:}

Postauricular cutaneous mastoid fistula (PCMF),connecting the mastoid cavity with the postauricular skin are often an unusual complication of chronic suppurative otitis media (CSOM), radical mastoid surgery or spontaneous exteriorisation of a cholesteatoma from the mastoid through the post-auricular skin surface1, $2^{3}$. Fistula development may also occur after closure of a post-auricular incision in mastoid surgery due to necrosis or breakdown of poor skin edges4. Persistent post aural discharge and cosmetic concerns are two main reasons for patients asking for medical assistance. Repair of post auricular fistula are challenging owing to scarred tissue and poor blood supply in this area. Various techniques including loco- regional flap cover and cavity obliteration have been utilized to repair this complicated problem. In our report, we introduce a novel technique using a double layer closure utilising local skin flap successful lasting results.

\section{CASE PRESENTATION}

Two patients with past history of mastoid surgery were presented with discharging postauricular fistulas. Both were of young adults of age 18 Male and 21 year female. Size of fistulas were ranging from $1 \times 2$ and $2 \times 2 \mathrm{~cm}$ respectively in size. Patients had undergone preoperative CT scan to rule out any residual pathology or residual disease following the mastoid surgery. During surgery, the post auricular region was cleaned and the fistula and fistulous tract were visualized. Skin around the fistula was incised, then the incision was extended upward in the temporal-mastoid-occipital area to expose an adequate portion of fibro-muscular-periosteal tissue. The fistulous tract was traced which was leading up to mastoid antrum and was excised. Fistulous tract was curetted, the antrum cleared of granulation tissue. The fistulous tract was 
excised and abdominal free fat is used to obliterated the antrum. Two flaps were then planned for double layer closure of fistula. First flap for inner lining was turnover flap. The blood supply of this turn over flap was medial intact subdermal plexus. A circumferential incision was made all around the fistula. The width of turnover flap was same as that of the width of the fistula. The flap was raised in the subcutaneous plane and at the medial portion of flap, subdermal plexus was left intact. Flap was then turned inward so that skin part of flap face inside of fistula and sutured to each other leaving raw surface exposed. That was the first layer and the inner lining of fistula. Then another local pivot flap is planned to cover the secondary defect or the raw area. It can be either simple rotation flap as in first case ( FIGURE 1\&2) or Limberg type local transposition defect $\left(2^{\text {nd }}\right.$ case) flap(FIGURE 3\&4). The advantage of the rotation flap and the Limberg type transposition flap was that there was no secondary defect and skin graft was not needed. Laxity of post auricular skin was utilised for same. Even if there was any secondary defect due to transposition flap then it could be skin grafted. A mastoid dressing was done. $1^{\text {st }}$ dressing was done on $3 r d$ post op day. Sutures were removed on $14^{\text {th }}$ post op day. Both fistulas were healed well. Patients were advised to do gentle massaging of the scar. The scars were well hidden behind the ears. The longest follow up was at $12^{\text {th }}$ month with no significant complints

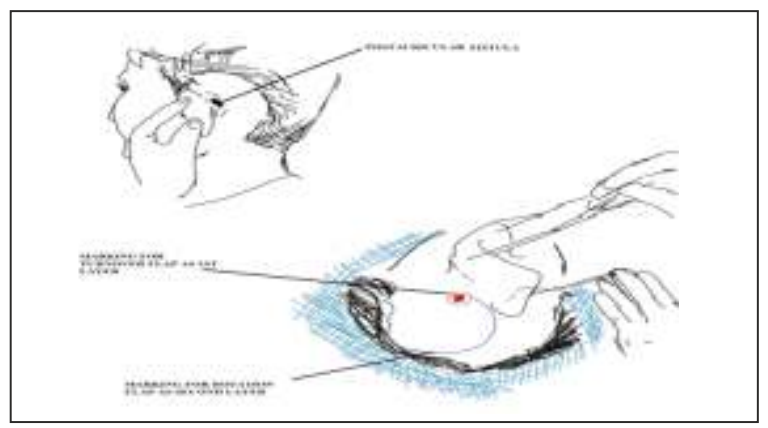

FIGURE 1- LINE DIAGRAM OF PLANNING AND FLAP MARKING OF CASE 1

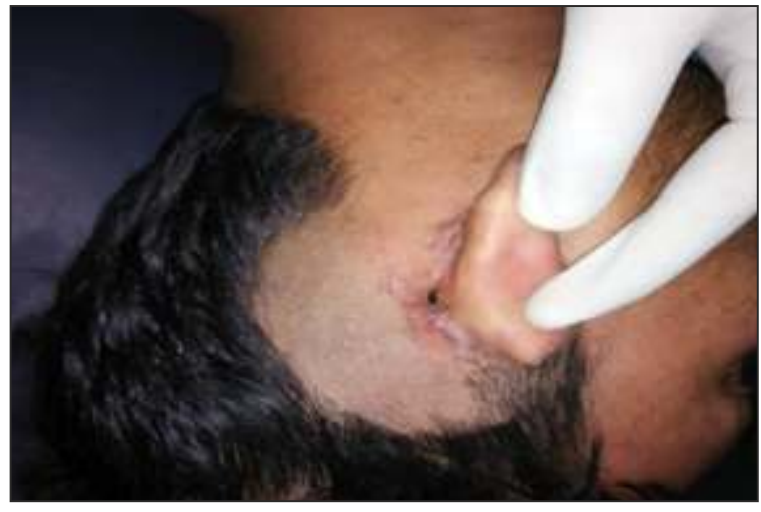

FIGURE 2A- IMAGE SHOWING POSTAURICULAR FISTULA RIGHT SIDE IN CASE 1

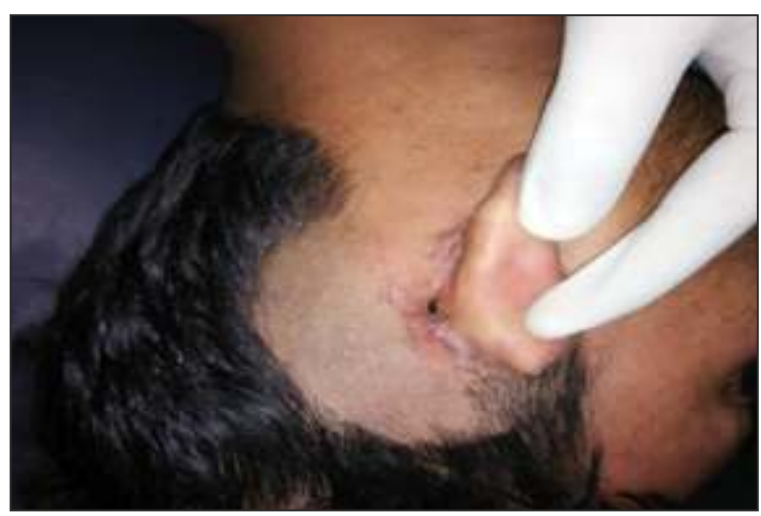

FIGURE 2B - IMAGE SHOWING PLANNING WITH FLAP MARKING

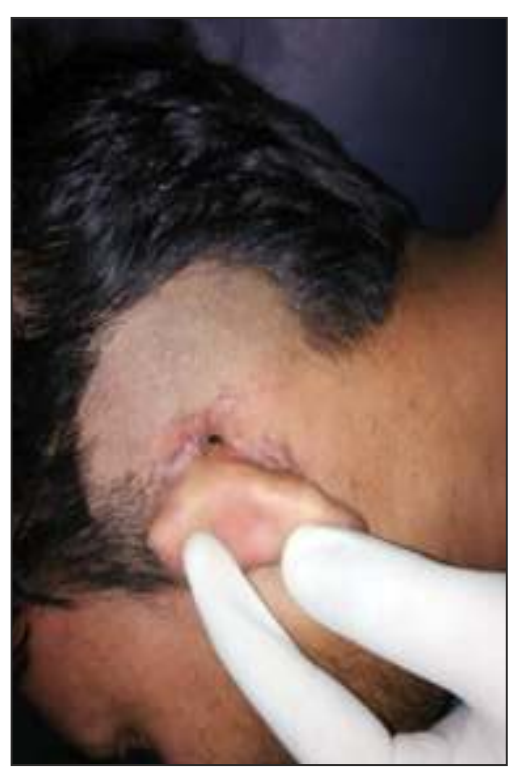

FIGURE 2C - POST OPERATIVE IMAGE AFTER 4 WEEKS OF CASE 1 


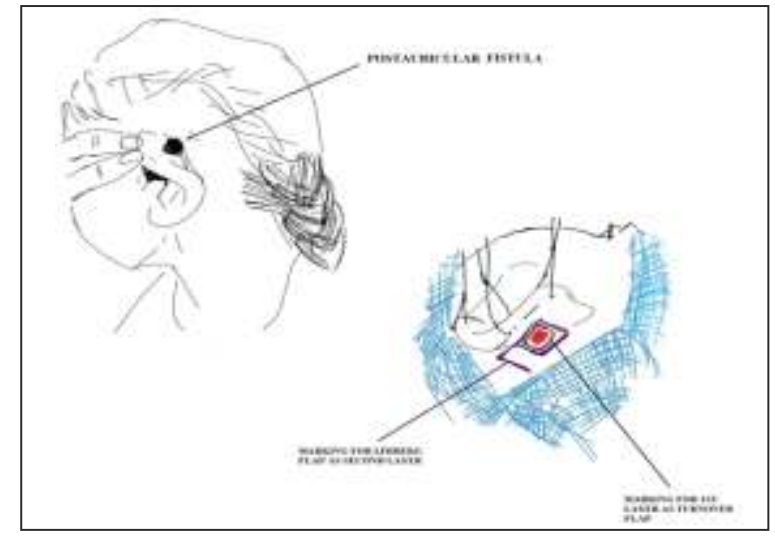

FIGURE 3- LINE DIAGRAM OF PLANNING AND FLAP MARKING OF CASE 2

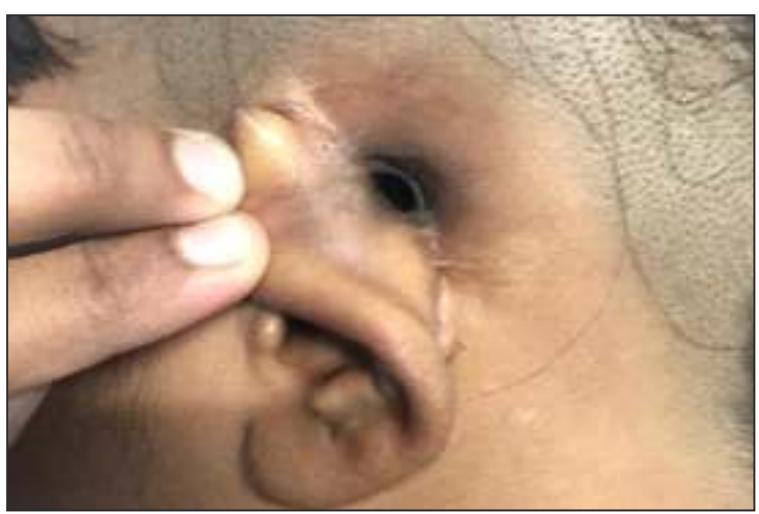

FIGURE 4A- IMAGE SHOWING POSTAURICULAR FISTULA RIGHT SIDE IN CASE 2

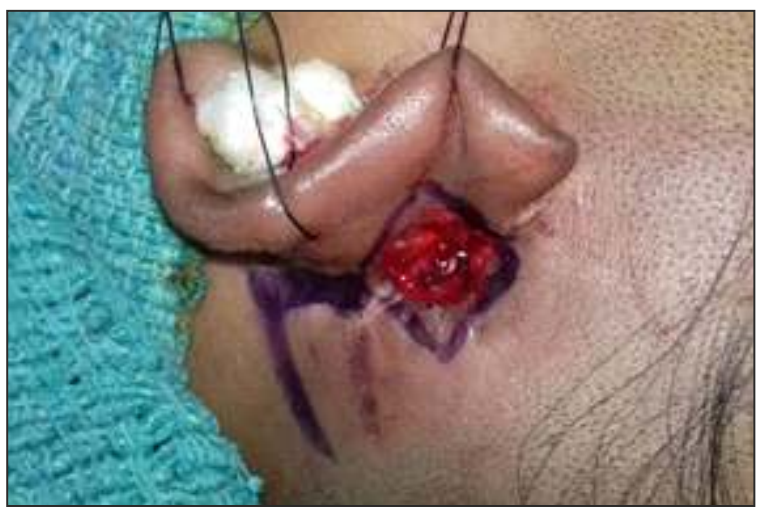

FIGURE 4B - IMAGE SHOWING PLANNING WITH $2^{\text {ND }}$ LAYER LIMBERG FLAP MARKING TO COVER THE RAW AREA LEFT FOLLOWING THE RAISING OF TURNOVER FLAP AS $1^{\text {ST }}$ LAYER

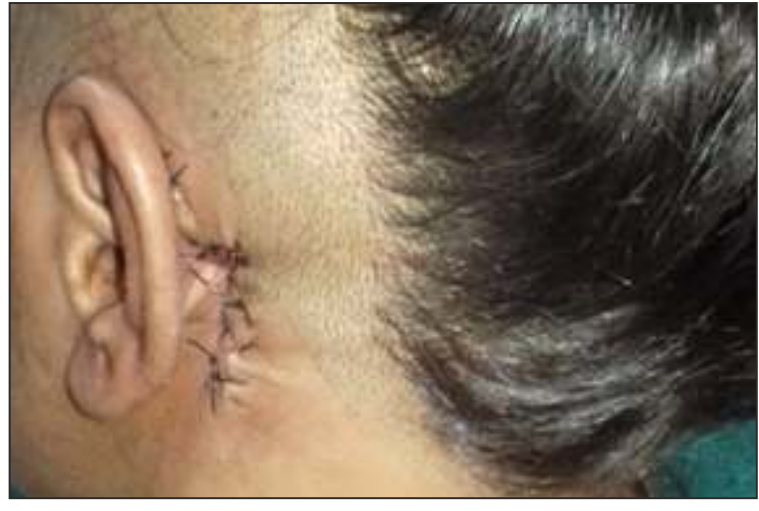

FIGURE 4C - POST OPERATIVE IMAGE AFTER 4 WEEKS OF CASE 2

\section{DISCUSSION:}

Post-auricular cutaneous mastoid fistulae are uncommon in occurrence so its management techniques are rarely reported. The commonest cause of these fistulas are either complication of chronic ear disease or ear surgery, or both. Several techniques have been described, some with mixed outcomes. Direct closure of these fistulas has been attempted with very high failure rates due to the necrotic skin edges eventually leading to enlargement of the fistula. Asherson et al described a technique of closure of Post auricular Chronic Mastoid Fistula by transposing Temporalis muscle into the complicating mastoidectomy wound with Zygomatic mastoiditis5. The techniques used for the closure of post auricular fistula includes simple closure, or using bone or cartilage graft, or muscle flap cover that are limited by one or the other issue. There are chances of high failure rate with simple closure due to necrotic skin edges, while the bone and cartilage grafts get infected and eventually resorbs. Grafts undergo resorption6. However Vira and Andrew successfully repaired the fistula using the cartilage and it was not compromised using that technique $^{10}$. Choo et al. Utilised a strip of Temporalis muscle to fill the mastoid bony defect in a case of post-auricular cutaneous fistula secondary to chronic suppurative otitis 
media, followed by direct skin closure7. Recently, Olusesi and Opaluwah, utilised post auricular fasciocutaneous periosteal advancement flaps with excision of burrow triangle for the closure of post auricular cutaneous mastoid fistula cuased by choleasteoma8. The Temporalis muscle flaps leaves aestheticaly unpleasant depression in the temporal region of the scalp that is frequently not accepted by younger patients. The fibro-muscular-periosteal flap used to cover the mastoid cavity in the technique described here is able to solve all these issues, by filling the cavity, and maintaining the open Tympanoplasty with mastoid obliteration. The bilobed flap from the mastoid and lateral neck regions have also been described for the complex defect around retroauricular sulcus and Mastoid owing to lax skin which allows free tension wound closure with a good aesthetical result8, ${ }^{9}$. Our technique described here provides physiological closure of mastoid fistula in two layers. Flaps are robust due to high vasculature of post auricular region. These procedures can also be done under local anaesthesia in older individual. Properly executed flap scar is well hidden and does not leave any depression like Temporalis muscle transfer. Technique is easy to learn and execute and maintain open Tympanoplasty. One of the drawback or the argument against this procedure is that allowing the epithelial surface of turnover flap to line the tract make it liable to the infection as the epithelial surface sheds keratin and secretes sebum. But in none of the cases mentioned above we have noticed any form of discharge, infection or the recurrence in the fistula even after 1 year of follow up.

\section{CONCLUSION}

A Combination of Turnover plus Pivot flap is found to be successful method for closure of post auricular fistula with acceptable aesthetic outcome

\section{CONFLICT OF INTERESTS : NONE}

NO ETHICAL APPROVAL REQUIRED: NO ETHICAL APPROVALIS REQUIRED.

INFORMED CONSENT: DULY INFORMED CONSENT
WAS OBTAINED IN ALLTHE CASES.

FUNDING SOURCE: NONE

ACKNOWLEDGEMENTS: NOT APPLICABLE

\section{REFERENCES}

1. Bhat KV, Udayashankar SG, Venkatesha BK, Kumar P. Bilateral atticoantral chronic suppurative otitis media presenting as bilateral cutaneous mastoid fistulas. Ear Nose Throat J. 2009;88(10):E1-3.

2. Müderris T, Berçin S, Sevil E, Kırış M. [Postauricular cutaneous mastoid fistula: a case report]. Kulak Burun Bogaz Ihtis Derg KBB J Ear Nose Throat. 2013;23(5):288-290. doi:10.5606/ kbbihtisas. 2013.51447

3. Wadhera R1, Gulati SP, Kalra V, Ghai A, Garg A. A large postauricular cutaneous mastoid fistula caused by a cholesteatoma. - PubMed - NCBI. Ear Nose Throat J. 2010 Apr;89(4):E33-

4. Accessed May 2, 2020.4. Luetje CM. Postauricular mastoid cutaneous fistula: a method of closure. Otolaryngol Head Neck Surg. 1980;88(1):90-92. doi:10.1177/019459988008800121

5. Asherson N. Post-operative Mastoid Fistula: Closure by use of Temporal Muscle Transplant. Proc $\mathrm{R}$ Soc Med. 1933;26(5):567-568.

6. Lee JH, Lee PK, Rhie JW, Ahn ST. Treatment of Postauricular Mastoid Cutaneous Fistula by Superficial Temporalis Fascia Transposition Flap. J Korean Soc Plast Reconstr Surg. 2004;31(1):133.

7. Choo JC, Shaw CL, Chong Y.C. S. Postauricular cutaneous mastoid fistula. J Laryngol Otol. $2004 ; 118(11): 893-894$. doi:10.1258 /0022215042703633

8. Olusesi AD, Opaluwah E. Postauricular advancement fascio-cutaneo-periosteal flap for closure of mastoid cutaneous fistula. Otolaryngol Pol. 2014;68(5):276-280. doi:10.1016/ j.otpol. 2014.02.001 
9. Pendolino AL, Pavone C, Zanoletti E. Fibromuscular-periosteal flap and bilobed flap for post-auricular cutaneous mastoid fistula closure. J Laryngol Otol. 2019;133(8):723-726. doi:10.1017/S0022215119001063

10. Darshni Vira, James C. Andrews. Postauricular Cutaneous Mastoid Fistula repair. Otolaryngology-Head and Neck Surgery.2012;147(2S): P218.doi.org:10.1177 /0194599812451426a296

\section{Declaration}

The study is in accordance with the ethical standards of the responsible committee on human experimentation (Institutional or Regional) and with the Helsinki declaration of 1975, as revised in 2000

\section{*Corresponding Author}

Dr. Naveen Kumar (MS, MCh)

Assistant Professor, Department of Plastic Surgery

Lady Hardinge Medical College and Associated Hospital, New Delhi -110001

Mob: 9968262759,

Email:drnaveenvmmc@gmail.com 


\section{OTOGENIC BRAIN ABSCESS MANAGEMENT STRATEGY : AN INSTITUTIONAL EXPERIENCE.}

Authors : Ravi Sankar Manogaran (1) , Saima Azim (2), Pearly PK(2), Amit Keshri(3), Neha Singh(2), Govind Bhuskute (2), Arulalan Mathialagan (2), Rajat Jain(2), Surendra Singh Baghel(2), Sanjay Behari (3).

Authors Affiliations : (1) Assistant professor, Neuro-otology unit (2) Senior Resident, Neuro-otology unit, (3) Associate professor, Neuro-otology unit (4) Head, Department of neurosurgery, SGPGIMS, Raibareli Road, Lucknow, Uttar Pradesh, India

\begin{abstract}
:
Otogenic brain abscess is a potentially lifethreatening complication of otitis media, which requires a high index of suspension for diagnosis and management. The present retrograde study is a compilation and analysis of 20 cases of otogenic brain abscess that has been managed at our institute from 2000 to 2018 . Although the prevalence has decreased significantly due to the use of antibiotics, the problem persists. Headache, fever and vomiting are the most common presenting symptoms. The advent of advanced imaging techniques has contributed a lot in making the diagnosis faster. In contrast to previous studies where the temporal lobe is the most common site, both cerebellar and temporal lobe involvement has been equally distributed. Pseudomonas was found to be the most common organism against Proteus mirabilis in most of the recent studies. Immediate therapy with intravenous antibiotics was found responsible for $32 \%$ of the sterile cultures. $12(60 \%)$ of the patients underwent interval mastoidectomy, of which seven patients underwent mastoidectomy at two weeks, and five patients were intervened at six weeks and rest eight were managed in the same sitting. No change was observed in these groups in terms of outcome after six weeks of follow-up. Although rare brain abscess continues to be a serious complication of otitis media which needs immediate attention with a multidisciplinary approach.
\end{abstract}

Keywords: Brain abscess; Otogenic infection; Otitis media; Magnetic resonance imaging; Computed tomography

\section{Introduction:}

Otitis media is a common condition that may rarely lead to intracranial complications, which may be life threatening. Although rare in acute, both acute and chronic otitis media may give rise to these complications. Intracranial complications secondary to otitis media include extradural abscess, subdural abscess, meningitis (with or without encephalitis), otogenic brain abscess and lateral sinus thrombophlebitis. Both immunocompetent and immunocompromised individuals have been noted to suffer from otogenic brain infections. The predisposing factors for brain abscesses include repeated upper respiratory tract infections, sinusitis, chronic suppurative otitis media, trauma, solid organ transplant recipients, acquired immunodeficiency syndrome (AIDS) patients, dental manipulations/ infections and post neurosurgical procedures (1). After meningitis, brain abscess represents the second most common intracranial complication of otitis media (2). Localised inflammation and infection of brain parenchyma defines brain abscess, which is a life-threatening clinical condition demanding immediate attention. It is reported that roughly $50 \%$ of the brain abscesses in adults and $25 \%$ in children are otogenic in origin (3). Though the incidence has significantly reduced due to the advent of antibiotics (4), nonetheless, 
it warrants early diagnosis and management. The availability of better imaging techniques like high resolution computed tomography, and magnetic resonance imaging has provided the platform for early diagnosis and intervention. The mortality rate of otogenic brain abscess has come down to $3 \%$ from 14 to $35 \%$ in the past (5). Intracranial spread occurs through bony defects caused by cholesteatoma, preformed fracture lines, haversian system of veins, the periarterial space of Virchow-Robbins, Trautmann's triangle, venous thrombophlebitis (6). Cerebellar abscess spreads occur mainly through Trautmann's triangle and temporal via tegmen. The treatment modalities for brain abscess per se are conservative or surgical, which includes burr hole aspiration or craniotomy. According to Ndubuisi et al. (7), mode of treatment does not affect the mortality rate. The most critical factors influencing mortality were the pre-admission coma score and presentation with seizure. Appropriate antimicrobial therapy is initiated, followed by surgical intervention. Depending on the extent of involvement of the brain compartments, the size, and numbers of abscesses, neurosurgical drainage is performed either through open craniotomy and drainage or by drainage through a burr hole (2). After drainage or in the same sitting mastoidectomy is done to avoid recurrence and remove the source of infection. Identification of microbial cause and antimicrobial susceptibility profile guided specific intravenous antibiotic treatment initiation was found to show better patient prognosis (8). In a study by Penido et al. (9), a 15year observation revealed that the most common organisms involved are proteus, pseudomonas, streptococcus and Haemophilus species. In the present study, 32\% of the culture was sterile, while pseudomonas was found to be the most common culprit. Although rare, brain abscess continues to be a serious and lifethreatening clinical condition that calls for immediate medical attention in order to reduce the resulting morbidity and mortality.

\section{Materials and method:}

A retrospective study was carried out at our institute that included all the cases of otogenic brain abscess that were admitted and managed from 2000 to 2018 . The cases where the outcome of the surgical intervention was not found after at least six weeks of follow up were excluded. Twenty cases met the inclusion criteria, and a detailed analysis was done regarding age, sex, symptoms, signs, imaging, site of an abscess, other otological complications, antimicrobials, surgical procedures and microbiology. Twelve of our patients underwent interval mastoidectomy, of which seven patients underwent mastoidectomy at two weeks, and five patients were intervened at six weeks, and rest eight were managed in the same sitting (Table 1).

\section{Table 1: Patient data}

\begin{tabular}{|l|l|l|l|l|l|l|}
\hline $\begin{array}{l}\text { S. } \\
\text { No }\end{array}$ & $\begin{array}{l}\text { Age } \\
\text { (yrs.) }\end{array}$ & Sex & Symptoms & Site of abscess & $\begin{array}{l}\text { Surgical Intervention } \\
\text { (Mastoid } \\
\text { exploration) }\end{array}$ & $\begin{array}{l}\text { Culture/ } \\
\text { Microscopy }\end{array}$ \\
\hline 1 & 14 & F & F, H & Rt Temporal lobe & Interval (6 weeks) & SA, Ss \\
\hline 2 & 15 & M & F, H, V & Lt Temporal Lobe & Interval (2 weeks) & S \\
\hline 3 & 50 & F & $\begin{array}{l}\text { H, V, } \text { T }^{\text {HH }} \\
\text { Palsy }\end{array}$ & Rt Temporal lobe & Same sitting & PA \\
\hline 4 & 26 & M & F, V, H & Lt Temporal Lobe & Same sitting & S \\
\hline 5 & 20 & F & F, V, H & Rt Temporal lobe & Same sitting & S \\
\hline 6 & 14 & F & F, H, V, AS & $\begin{array}{l}\text { Left Parieto- } \\
\text { Occipital }\end{array}$ & Interval (2 weeks) & S \\
\hline 7 & 34 & M & F, H & $\begin{array}{l}\text { Rt Cerebellar } \\
\text { Tubercular } \\
\text { Abscess }\end{array}$ & Same sitting & CNS \\
\hline 8 & 30 & M & F, H, V & $\begin{array}{l}\text { Multiple intra } \\
\text { cerebellar abscess }\end{array}$ & Same sitting & B \\
\hline 9 & 42 & M & F, H, V & Lt Cerebellar & Interval (2 weeks) & PA, PM \\
\hline 10 & 15 & M & F, H, V & Rt Cerebellar & Interval (2 weeks) & PA \\
\hline 11 & 28 & M & F, H, Vertigo & Rt Cerebellar & Interval (6 weeks) & CNS \\
\hline 12 & 15 & M & F, H & Rt Temporal lobe & Interval (6 weeks) & S \\
\hline 13 & 28 & M & F, H & Lt Temporal Lobe & Interval (6 weeks) & PA \\
\hline 14 & 24 & M & F, H & Rt Cerebellar & Same sitting & $\begin{array}{l}\text { PA, AC, Ss, } \\
\text { CNS. }\end{array}$ \\
\hline 15 & 12 & F & F, H & Lt Temporal Lobe & Interval (2 weeks) & SA (MSSA) \\
\hline 16 & 16 & F & F, V & Rt Cerebellar & Same sitting & S \\
\hline 17 & 8 & M & F, H, V & $\begin{array}{l}\text { Rt Cerebellar \& } \\
\text { Rt Temporal Lobe }\end{array}$ & Same sitting & S \\
\hline 18 & 12 & M & F, H, V, LOC & Lt Cerebellar & Interval (6 weeks) & S \\
\hline 19 & 12 & M & F, V, H, LOC & Rt Cerebellar & Interval (2 weeks) & B \\
\hline 20 & 28 & M & H & Left Temporal & Interval (2 weeks) & GPC, SA, Ss \\
\hline
\end{tabular}

PA- Pseudomonas aeruginosa, S- Sterile, CNSCoagulase negative staphylococcus, BBacteroides species (Gram negative bacilli), PMProteus mirabilis, AC- Anaerobic cocci, SsStreptococcus species, SA- Staphylococcus aureus, F-Fever, H-Headache, V-Vomiting, LOCloss of consciousness, AS-altered sensorium 


\section{Results:}

Male preponderance was observed with a male: female ratio of $2.3: 1$. $70 \%$ of the cases were males, rest $30 \%$ were females (Fig 1).

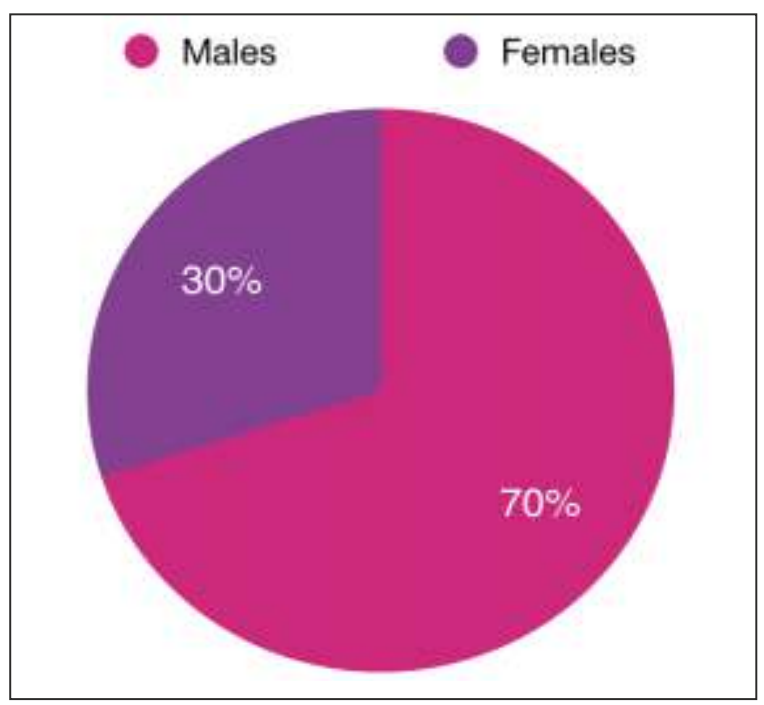

Fig 1:Sex Ratio

Mean age of the patients was 22.15 years, ranging from 8 years to 50 years. Out of these, $45 \%$ were below the age of 16 years (Fig 2).

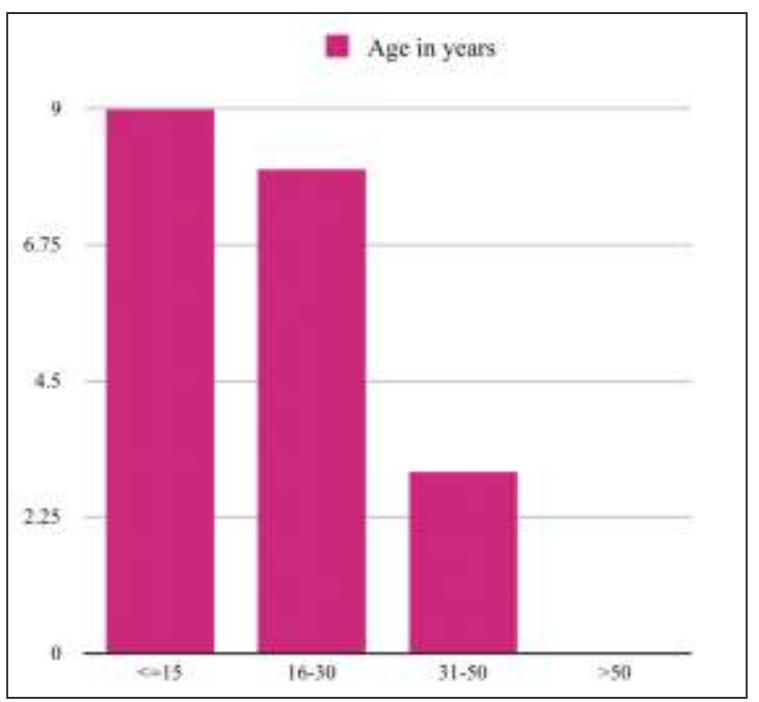

Fig 2: Age Distribution

$90 \%$ of the patients presented with fever, out of which $2(11 \%)$ were associated with chills and rigor, $2(11 \%)$ with loss of consciousness and $1(5.5 \%)$ with altered sensorium. $95 \%$ of the patients suffered from headache and $60 \%$ with vomiting. This was consistent with other studies where the headache was the most common symptom. Regarding concomitant complications of COM, one case presented with facial paresis and one with vertigo due to labyrinthine fistula.

High-resolution CT scans and MRI was done in all cases showing well-defined peripherally enhancing mass lesion. $95 \%$ of cases had a solitary abscess, while $1(5 \%)$ had multiple abscesses in the cerebellum. Earlier studies and observations have concluded that otogenic brain abscess is more commonly seen in the temporal lobe, but in this study, it was seen that temporal and cerebellar abscesses were equally distributed- $45 \%$ each. One case had an abscess in both the sites and one was located in parietooccipital lobe(Fig 3).

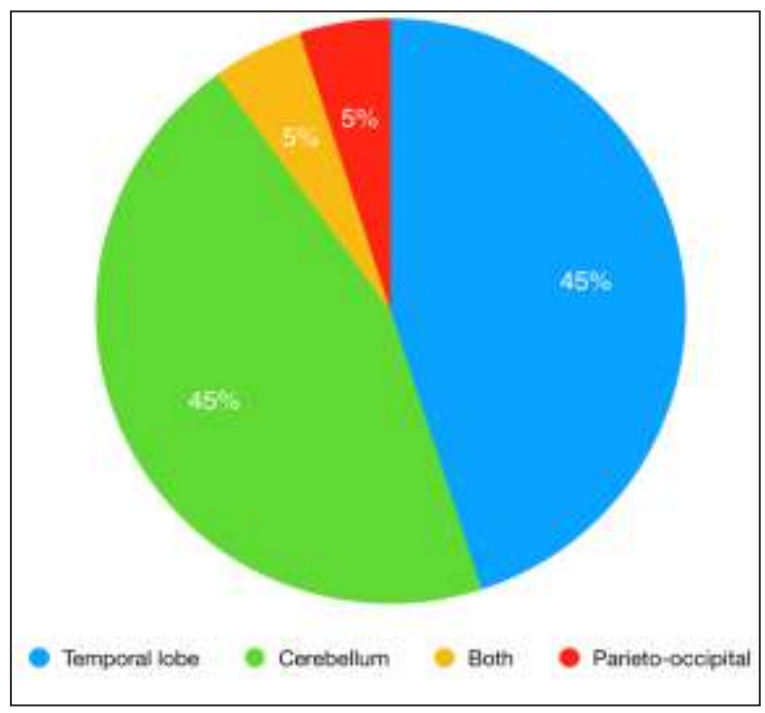

Fig 3: Site Of Abscess

If the bony walls of the middle ear cleft are intact, this points towards the fact that the brain abscess has occurred via venous thrombophlebitis. $25 \%$ of the cases had intact middle ear cleft intraoperatively, out of this only one was temporal lobe abscess, rest were cerebellar. Hence, we might conclude that venous thrombophlebitis more commonly leads to cerebellar abscess rather than the 
temporal lobe. In rest of the temporal lobe abscesses, tegmen plate was eroded, which was evident in the CT scan as well. The lateral semicircular canal was eroded in one case, in which the fistula test was positive and was having vertigo. One case with facial paresis had fallopian canal eroded in the mid vertical segment, which was decompressed in the same sitting. Incus was the most commonly eroded ossicle, followed by malleus. Cholesteatoma was found in $70 \%$ of the cases, and the rest had granulation tissue.

Most common organism found in culture/microscopy was pseudomonas followed by staphylococci. Proteus was found only in one case. Other organisms included streptococci and gram-negative bacilli (Fig 4).

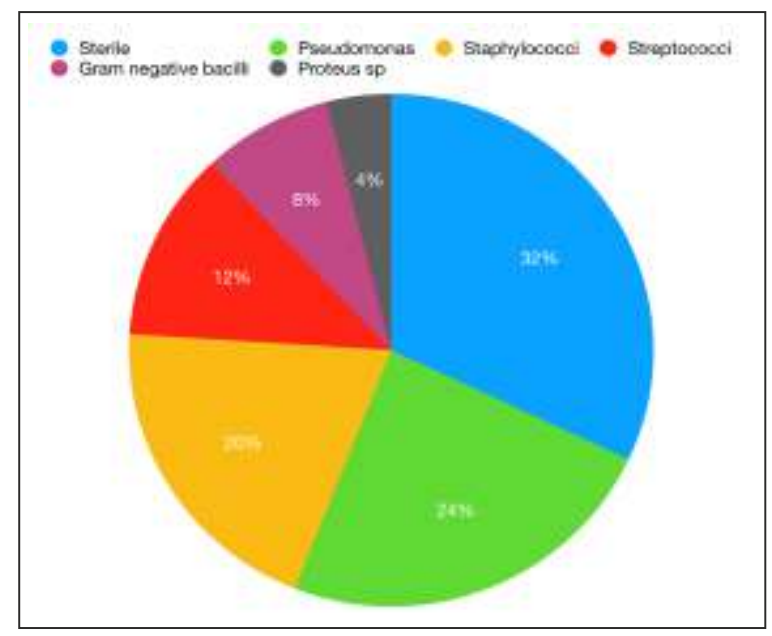

Fig 4: Culture/Microscopy.

\section{Discussion:}

The history of intracranial complications of otitis media goes back to $460 \mathrm{BC}$ when Hippocrates noted that acute pain in the ear and continuous high fever might lead to delirium and death (10). It was Morgagni who brought forward the fact that ear infection came first, and brain abscess was secondary (11). In the pre-antibiotic era, complications of otitis media were abundant with high morbidity and mortality. The management of otogenic brain abscess remained in the hands of otological surgeon until sulfonamides and penicillin began to be used in around 1942 (11). With the advent of the antibiotic era, intracranial complications of chronic otitis media have become scarce. The estimated incidence now is between $0.3 \%$ to 1.9 $7 \%(12,13)$, as compared to the pre-antibiotic era, where it occurred in 2.3 to $6.4 \%$ of cases (14).

Otogenic brain abscesses are mostly located in the temporal lobe and cerebellum, with the middle segment of the temporal lobe and lateral lobe of the cerebellum most profoundly affected. Formation of brain abscess undergoes four stages (1) wherein the first stage the bacteria in words into the brain tissue resulting in neutrophil astrocytes and microbial cell activation and edema in the second stage infection spread to the adjacent brain tissue involving macrophages lymphocytes and resulting in necrosis. Development of a vascularized capsule surrounding the lesion characterizes the third stage, which is responsible for the train enhancing lesion on $\mathrm{CT}$ scan. The final stage of a brain infection involves the destruction of the capsule and for the involvement of surrounding healthy brain parenchyma. The occurrence of brain abscess depends on the immune status of the patient type and virulence of microbes involved and use of antimicrobial agents (15).

In the present review, the cerebellum and temporal lobe were equally affected (45\%), with one case involving both and one parietooccipital lobe. The site of abscess varies in different studies from Murthy et al. (16) stating that cerebellar abscesses are four times more common than temporal to vice versa by Samuel J et al. (17). Usually, there is a single abscess; the chance of multiple abscesses varies from 19$33 \%$ (18). We had only one case presenting with multiple cerebellar abscesses.

Older studies state that otogenic brain 
abscesses are very rare in children; however, our observation does not support this finding. Out of 20 cases, 9 (45\%) were below 16 years of age.

The most common presentation of our patients was a headache, fever, and vomiting. Loss of consciousness was found in 10\%, altered sensorium in (5.5\%) and facial paralysis in 5\%. Our patients' presentations are more similar to the literature $(16,18)$. According to a review study done by Maria J. Duarte et al. (19), purulent otorrhoea was found in $5.7 \%$ to $92 \%$ of cases. In the present study, it was found in $65 \%$ of cases.

The management of otogenic abscess varies from conservative management with antibiotics to radical excision. The possibility for conservative management can be considered when there is no neurological deficit, abscess less than $2.5 \mathrm{~cm}$, multiple abscesses, and when there is an absolute contraindication for surgery. Guided aspiration can be considered when the abscess size is more than $2.5 \mathrm{~cm}$ in size or multiple abscesses abscesses near critical areas, and when there is a high chance of complications. Radical excision of the abscess cavity should be considered when there is a multilobulated abscess, posterior cranial fossa location (18). However, the timing of mastoidectomy is controversial. Some state that neurosurgical drainage should be done prior followed by mastoidectomy in the same sitting $(2,20,21)$, while others are convinced for interval mastoidectomy after six weeks (16). In the present review, eight patients underwent neurosurgical

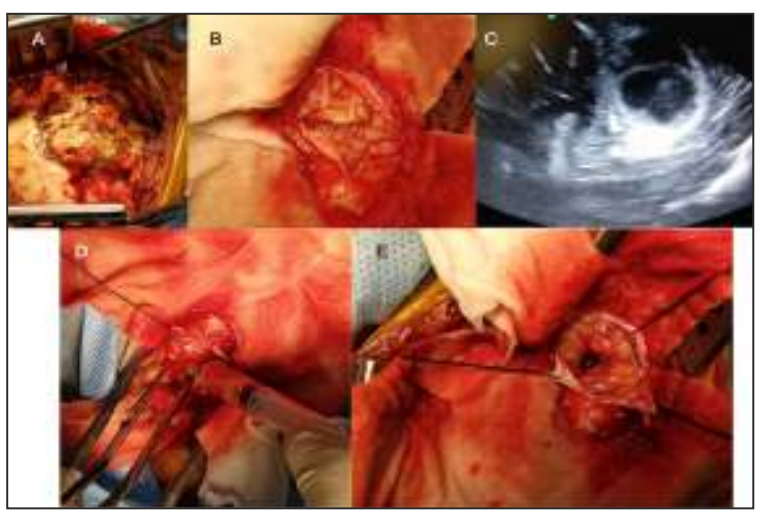

(Figure 5) and otological intervention at the same sitting.

Fig 5: Cerebellar abscess drainage. A) Mini craniotomy site (mastoid and occipital bone) B) Dural incision C) USG guided confirmation of abscess depth before aspiration D) Abscess drainage $E$ ) after complete aspiration.

Interval mastoidectomy was done in 12 (60\%) cases of which five cases and event at six weeks interval and rest 7 had surgery after 15 days. We consider for same sitting intervention when the general condition of the patient is fit for prolonged anesthesia. However, this is not always possible, where the patient will go for neurosurgical intervention first and then plan for interval mastoidectomy. Even though the ideal window period for interval mastoidectomy is six weeks, but most of our patients were from the low socioeconomic status and distant places, we reassessed the patients after their primary neurosurgical intervention at two weeks. If the patient was stable and fit for anaesthesia, we proceeded with mastoidectomy (Figure 6) at two weeks. We did not see any difference in their outcome.

Polymicrobial cultures with the high incidence of anaerobes are reported, most common being Proteus mirabilis (19). Most of the post of cultures in a series reported no organism growth after 48 hours of incubation. The use of intravenous antibiotics can be credited for the present results. Also, unlike many other studies where the most common gram-negative bacilli found was proteus, in a series, a change in trend was seen shifting to pseudomonas. We also noted the rise in coagulase-negative staphylococcus incidence in contrast to literature (18). This change due to increased prevalence of pneumococcal vaccination.

Figure 6: Mastoid cavity and middle ear reconstruction after canal wall intact mastoidectomy.

Current guidelines for the antibiotic coverage 
are a third-generation cephalosporin plus metronidazole with consideration of adding another drug to provide coverage for methicillin-resistant staphylococcus aureus (MRSA) for at least four weeks (21). This protocol was strictly followed in the present study. Although otogenic brain abscesses are rare, one should be vigilant for any clinical signs pointing towards it. Timely diagnosis and prompt treatment with antibiotics, abscess drainage followed by mastoidectomy is the basis for management. Interval mastoidectomy or that done in the same setting does not affect the outcome.

\section{Conclusion:}

The incidence and mortality of Otogenic brain abscess have markedly reduced owing to the use of antibiotics, imaging techniques and prompt intervention. Marked male preponderance is seen with headache as the most common symptom. Temporal and cerebellar lobes are equally involved, with pseudomonas as the most common organism. Burr hole aspiration versus craniotomy does not affect the outcome; neither does mastoidectomy that is done in the same sitting or at an interval. A high index of suspicion, early diagnosis, and vigilant intervention trails to a better outcome.

\section{References:}

1. Kandi V. Otogenic Brain Abscess: A Mini Review. Cureus. 2014Sep30;6(9).

2. Myers EN, Sennaroglu L, Sozeri B. Otogenic brain abscess: review of 41 cases. Otolaryngology-Head and Neck Surgery. 2000 Dec;123(6):751-5.

3. Ludman H. Complications of suppurative otitis media. Scott-Brown's otolaryngology. 1987;3:1-29.

4. Hafidh MA, Keogh I, Walsh RM, Walsh M, Rawluk D. Otogenic intracranial complications. A 7-year retrospective review. American journal of otolaryngology. 2006 Nov 1;27(6):390-5.

5. Szyfter W, Kruk-Zagajewska A, Borucki L, Bartochowska A. Evolution inmanagement of otogenic brain abscess. Otol Neurotol. 2012 Apr;33(3):393-5.

6. Borgohain R, Talukdar R, Ranjan K. Otogenic brain abscess: A rising trend of cerebellar abscess an institutional study. Indian Journal of Otology. 2015 Oct 1;21(4):286.

7. Ndubuisi CA, Ohaegbulam SC, Mezue WC, Chikani MC, Nkwerem SP, Ozor II. Management of brain abscess: Changing trend and experience in Enugu, Nigeria. Nigerian journal of surgery: official publication of the Nigerian Surgical Research Society. $2017 \mathrm{Jul} ; 23(2): 106$.

8. Viswanatha B, Vijayashree MS, Sumatha D. Unilateral attico antral ear disease with bilateral intracranial complications. Indian Journal of Otolaryngology and Head \& Neck Surgery. 2012 Mar 1;64(1):82-6

9. Penido ND, Borin A, Iha LC, Suguri VM, Onishi E, Fukuda Y, Cruz OL. Intracranial complications of otitis media: 15 years of experience in 33 patients. Otolaryngology-Head and Neck Surgery. 2005 Jan; 132(1):37-42.

10. Cawthorne T. The surgery of the temporal bone. The Journal of Laryngology \& Otology. $1953 \mathrm{Jul} ; 67(7): 377-91$.

11. Samuel CL, Chris DS, Michael JS. Intracranial complications of otitis media. In: Gulya AJ, Minor LB, Poe DS, editors. Glasscock Shambaugh Surgery of the ear. 6th ed. Connecticut: People's medical publishing house; 2010. p. 451.

12. Osma U, Cureoglu S, Hosoglu S. The complications of chronic otitis media: report of 93 cases. The Journal of Laryngology \& 
Otology. 2000 Feb;114(2):97-100.

13. Choi J, Choi Jl, Kim SD. Management of otogenic brain abscess using the transmastoid approach. Journal of Korean Neurosurgical Society. 2014 Mar;55(3):178.

14. Tonon E, Scotton PG, Gallucci M, Vaglia A. Brain abscess: clinical aspects of 100 patients. International journal of infectious diseases. 2006 Mar 1;10(2):103-9.

15. Viswanatha B, Nsaeeruddin K. Conservative management of otogenic brain abscess with surgical management of attico antral ear disease: A review. Indian Journal of Otolaryngology and Head \& Neck Surgery. 2012 Jun 1;64(2):113-9.

16. Murthy PS, Sukumar R, Hazarika P, Rao AD, Raja A. Otogenic brain abscess in childhood. International journal of pediatric otorhinolaryngology. $1991 \mathrm{Jul}$ 1;22(1):9-17.

17. Samuel J, Fernandes CM, Steinberg JL. Intracranial otogenic complications: a persisting problem. The Laryngoscope. 1986 Mar;96(3):272-8.

18. Mameli C, Genoni T, Madia C, Doneda C, Penagini F, Zuccotti G. Brain abscess in pediatric age: a review. Child's Nervous System. 2019 May 6:1-2.

19. Maria J. Duarte, Elliott D. Kozin et al. Otogenic brain abscesses: A systematic review. Laryngoscope Investig Otolaryngol. 2018 Jun; 3(3): 198-208.

20. Singh B, Maharaj TJ. Radical mastoidectomy: its place in otitic intracranial complications. The Journal of Laryngology \& Otology. 1993 Dec;107(12):1113-8.

21. Mathews TJ, Marus G. Otogenic intradural complications::(A review of 37 patients). The Journal of Laryngology \& Otology. 1988 Feb;102(2):121-4.

22. Arlotti M, Grossi P, Pea F, Tomei G, Vullo V, De
Rosa FG, Di Perri G, Nicastri E, Lauria FN, Carosi G, Moroni M. Consensus document on controversial issues for the treatment of infections of the central nervous system: bacterial brain abscesses. International Journal of Infectious Diseases. 2010 Oct 1;14:S79-92.

\section{*Corresponding Author :}

Amit Kumar Keshri MS

Associate professor, Neuro-otology unit,

Department of neurosurgery,

C-block, SGPGIMS,

Raebareli Road, Lucknow, Uttar Pradesh, India.

226014.

amitkeshri2000@yahoo.com

Orchid ID:

https://orcid.org/0000-0002-7834-5055 


\section{PLAIN RADIOGRAPHS OF MASTOID IN CHRONIC OTITIS MEDIA: NEED OR TRADITION?}

Authors; Sabeeh Beig (1), Satish Chand Sharma (2), Saifullah Khalid (3)

Authors Affiliations: (1) Senior Resident, (2) Professor, Department of ENT, (3) Assistant professor, Department of Radio diagnosis, JNMCH (AMU), Aligarh

\begin{abstract}
Objectives: To statistically evaluate the role of plain radiograph of mastoid in chronic otitis media (COM) atticoantral disease.

Methods: This cross-sectional study undertaken at a tertiary level teaching hospital included 32patients of COM (Atticoantral disease) who underwent pre-operative plain radiograph of bilateral mastoid \{Schuller's $\operatorname{view}(\mathrm{s} / \mathrm{v})\}$ and the radiological findings were compared with the operative findings and statistical analysis was done.
\end{abstract}

Results: Plain radiograph of mastoid(s/v) predicted some of the surgical landmarks of mastoid surgery viz. tegmen and sinus plates with a fair degree of accuracy. The positive predicted value for radiolucent shadow (which was taken as indicating bone destruction and thus presence of cholesteatoma ) was also high but at the same time, a low negative predictive value and a cohen's kappa test showing only a fair agreement underscores the point that absence of a radiolucent shadow does not rule out the presence of cholesteatoma.

Conclusions: We thus conclude that plain radiographs of mastoid are helpful in providing a prior knowledge of the surgical landmarks in mastoid surgery. Hence with this information, if a surgeon finds himself more at ease in operating a patient then a plain radiograph of mastoid should be done when CT scan facility is unavailable.However, citing the limited information that a plain radiograph of mastoid has to offer on other aspects of the disease, its use as a 'routine' investigation in chronic otitis media should be discouraged.

.Key Words: Plain radiograph mastoid,Schuller's View, Chronic Otitis Media, AtticoAntral, Cholesteatoma.

\section{INTRODUCTION}

Imaging is a universal investigation in cases of Chronic Otitis Media (COM).Computed Tomography (CT) and magnetic resonance imaging (MRI) are the preferred investigations in COM. However, facilities of CT and MRI are neither available everywhere nor affordable for every patient, more so in countries like India where a substantial population lives below poverty line and in low facility areas.

In this situation where only X-ray facility is available should plain radiographs of mastoid be done? If yes then what is the analytical evidence?

In this study, we have tried to find the utility of plain radiographs of mastoid by comparing radiological findings vis-a-vis operative findings.

\section{MATERIALS AND METHODS}

\section{Study Design:}

Cross-Sectional Analytical Study

\section{Study Setting:}

Tertiary Level Teaching Hospital

\section{Study Population:}

32 patients of COM (atticoantral disease) who presented to ENT outpatient facility of the 
hospital were included. Patients with a previous history of ear surgery, history of temporal bone fracture, those having a neoplastic or granulomatous disease of temporal bone and those considered unfit for surgery (e.g. pregnancy/ ischemic heart disease) were excluded. Diagnosis of COM (atticoantral disease) was made on clinical grounds.

\section{Study Instruments:}

Performa for history and examination, for radiologist to report findings, for surgeon to report intra operative findings

After a detailed history and examination and obtaining an informed consent these patients under went bilateral plain radiograph of mastoid \{Schuller's View(s/v)\}and findings were reported by a single experienced radiologist. The radiologist was asked to comment on the following points: (1) dural plate position (2) sinus plate position (3) dural plate integrity (4) sinus plate integrity (5) radiolucent shadow in the mastoid. This radiological reporting was then compared with the intraoperative findings.

\section{Data Management and Processing:}

Considering the intraoperative findings as the gold standard, sensitivity, specificity, and positive and negative predictive values were calculated for all the analysed points. In addition, a cohen's kappa value was also calculated while analysing radiolucent shadow.

\section{RESULTS}

Dural plate position was found normal in all the 32 casesintraoperatively and plain radiograph $(\mathrm{s} / \mathrm{v})$ predicted the same with $100 \%$ negative predictive value (NPV). For an anteposed sigmoid sinus the NPV was $96.88 \%$.Intraoperative finding ofbreach in dural plate wasradiologically detected in all the 5 cases but 5 false positive results were also given. Out of the 7 cases of sinus plate erosion only 2 could be detected on plain radiograph $(\mathrm{s} / \mathrm{v})$ giving an NPV of $82.14 \%$ but a PPV of just $50 \%$. In the 10 cases where a radiolucent shadow was reported, cholesteatoma was found in all the cases giving a $100 \%$ positive predictive value but at the same time an NPV of just $36.36 \%$ and a cohens kappa value of 0.263 .

TABLE 2 Correlating Dural Plate Position

\begin{tabular}{|c|c|c|c|c|c|c|c|c|c|c|c|}
\hline \multicolumn{4}{|c|}{ Dural Plate Position } & TP & $\mathbf{T N}$ & FP & FN & $\operatorname{Sn}(\%)$ & $\mathbf{S p}(\%)$ & \multicolumn{2}{|c|}{$\begin{array}{l}\text { Predictive Values } \\
(95 \% \text { CI) }\end{array}$} \\
\hline \multicolumn{2}{|c|}{$\mathbf{R}(\mathbf{S} / \mathbf{V})$} & \multicolumn{2}{|c|}{ Operative } & & & & & & & PPV(\%) & NPV $(\%$ \\
\hline $\mathbf{N}$ & Low & $\mathbf{N}$ & Low & & & & & & & & \\
\hline 32 & 0 & 32 & 0 & 0 & 32 & 0 & 0 & * & 100 & * & 100 \\
\hline
\end{tabular}

$\mathrm{R}(\mathrm{S} / \mathrm{V})$ =radiograph (schuller's view), $\mathrm{N}=$ normal, $\mathrm{TP}=$ true positive, $\mathrm{TN}=$ true negative, $\mathrm{FP}=$ false positive, $S n=$ sensitivity, $S p=$ specificity, $\mathrm{Cl}=$ confidence interval, $\mathrm{PPV}=$ positive predictive value, $\mathrm{NPV}=$ negative predictive value

TABLE 2 Correlating Sinus Plate Position

\begin{tabular}{|c|c|c|c|c|c|c|c|c|c|c|c|c|}
\hline \multicolumn{4}{|c|}{ Sinus Plate Position } & $T$ & & & $\overline{\text { FP }}$ & $\mathbf{F N}$ & Sn(\%) & Sp(\%) & \multicolumn{2}{|c|}{ Predictive Val ues $(95 \%$ CI) } \\
\hline \multicolumn{2}{|c|}{$\mathrm{R}(\mathrm{S} / \mathrm{V})$} & \multicolumn{2}{|c|}{ Operative } & & & & & & & & \begin{tabular}{|l|l} 
PPV(\%) \\
\end{tabular} & NPV(\%) \\
\hline [N & An. & 11 & An. & & & & & & & & & \\
\hline 32 & 0 & 3 & 1 & 0 & & & 0 & 1 & 0 & 100 & * & 96.88 \\
\hline
\end{tabular}

$\mathrm{R}(\mathrm{S} / \mathrm{V})=$ radiograph (schuller's view), $\mathrm{N}=$ normal, An. =Anteposed, $T P=$ true positive, $T N=$ true negative, $\mathrm{FP}=$ false positive, $\mathrm{S} n=$ sensitivity, $\mathrm{Sp}=$ specificity, $\mathrm{Cl}=$ confidence interval, $\mathrm{PPV}=$ positive predictive value, $\mathrm{NPV}=$ negative predictive value

TABLE 3 Correlating Dural Plate Integrity

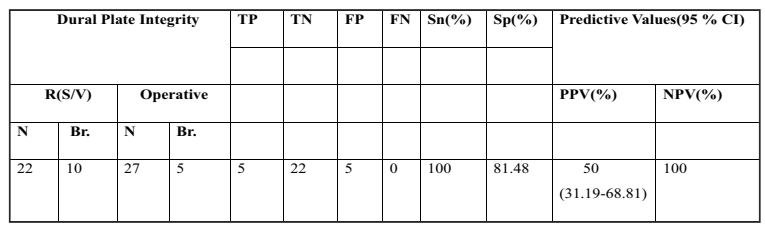

$\mathrm{R}(\mathrm{S} / \mathrm{V})$ =radiograph (schuller's view), $\mathrm{N}=$ normal, $\mathrm{Br}$. $=$ Breach, $\mathrm{TP}=$ true positive, $\mathrm{TN}=$ true negative, 
$\mathrm{FP}=$ false positive, $\mathrm{Sn}=$ sensitivity, $\mathrm{Sp}=$ specificity, $\mathrm{Cl}=$ confidence interval, $\mathrm{PPV}=$ positive predictive value, $\mathrm{NPV}=$ negative predictive value

TABLE 4 Correlating Sinus Plate Integrity

\begin{tabular}{|c|c|c|c|c|c|c|c|c|c|c|c|}
\hline \multicolumn{4}{|c|}{ Sinus Plate Integrity } & \multirow[t]{2}{*}{ TP } & \multirow[t]{2}{*}{$T$} & \multirow[t]{2}{*}{ FP } & \multirow[t]{2}{*}{ FN } & Sn(\%) & \multirow[t]{2}{*}{ Sp(\%) } & \multicolumn{2}{|c|}{ Predictive Values $95 \%$ CI) } \\
\hline \multicolumn{2}{|c|}{$\mathbf{R}(\mathbf{S} / \mathrm{N})$} & \multicolumn{2}{|c|}{ Operative } & & & & & & & PPV(\%) & $\mathbf{N P V ( \% )}$ \\
\hline N & Br. & $\mathbf{N}$ & Br. & & & & & & & & \\
\hline 28 & 4 & 25 & 7 & 2 & 23 & 2 & 5 & 28.57 & 92.00 & $\begin{array}{l}50(14.53- \\
85.47)\end{array}$ & $\begin{array}{l}82.14 \\
(73.95-88.17)\end{array}$ \\
\hline
\end{tabular}

$\mathrm{R}(\mathrm{S} / \mathrm{V})=$ radiograph (schuller's view), $\mathrm{N}=$ normal, $\mathrm{Br}$. =Breach, $\mathrm{TP}=$ true positive, $\mathrm{TN}=$ true negative, $\mathrm{FP}=$ false positive, $\mathrm{Sn}=$ sensitivity, $\mathrm{Sp}=$ specificity, $\mathrm{Cl}=$ confidence interval, $\mathrm{PPV}=$ positive predictive value, NPV=negative predictive value

TABLE 5 Correlating Radiolucent Shadow with Cholesteatoma

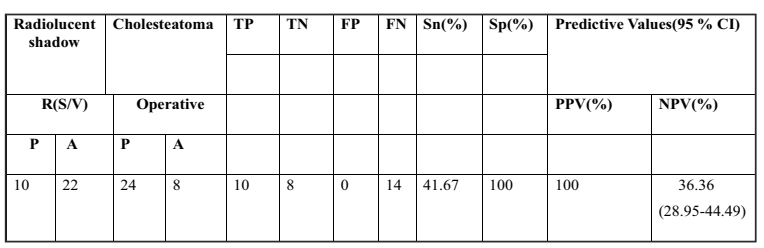

$\mathrm{R}(\mathrm{S} / \mathrm{V})$ =radiograph (schuller's view), $\mathrm{P}=$ present, $\mathrm{A}=$ absent, $\mathrm{TP}=$ true positive, $\mathrm{TN}=$ true negative, $\mathrm{FP}=$ false positive, $\mathrm{S} n=$ sensitivity, $\mathrm{Sp}=\mathrm{specificity,}$ $\mathrm{Cl}=$ confidence interval, $\mathrm{PPV}=$ positive predictive value, NPV=negative predictive value

TABLE 6 Analysing Interrateragreement between radiolucent shadow on plain radiograph(s/v) and intraoperative finding Cases in Agreement $=18$

\begin{tabular}{|l|l|l||}
\hline & Radiolucent Shadow & No Radiolucent Shadow \\
\hline Cholesteatoma & 10 & 22 \\
\hline No Cholesteatoma & 0 & 8 \\
\hline
\end{tabular}

Cohens Kappa Value(with 95\% Confidence Interval $)=0.263(0.067-0.459)$

Strength of agreement=Fair (0.01$0.20=$ slight agreement,0.21-0.40=fair a greement, $0.41-0.60=\mathrm{moderate}$ agreement, $0.61-0.80=$ substantial agreement, $0.81-100=$ almost perfect agreement)of cholesteatoma

FIG 1: Patient with right COM showing radiolucent shadow in the right mastoid ( It was found to be cholesteatoma intraoperatively

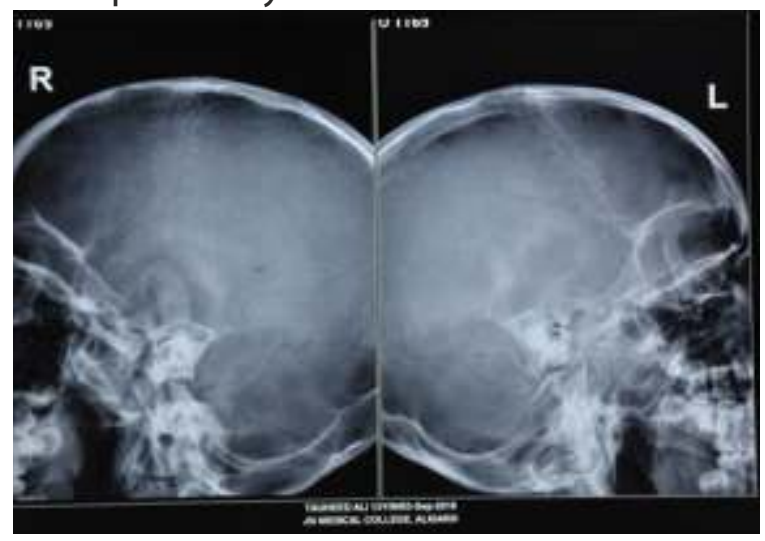

FIG 2: Same patient's (as in fig 1) postoperative radiograph.

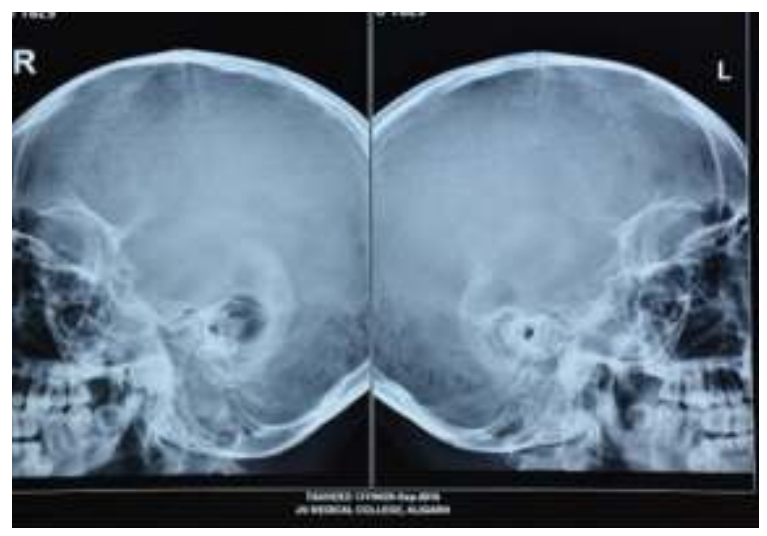

\section{DISCUSSION}

In the present study the operating surgeon did not come across any case of a low lying dura. Plain radiograph mastoid(s/v) predicted the finding with $100 \%$ negative predictive value which implies that if a low lying dura is not reported on a plain radiograph mastoid(s/v), it is unlikely that a low lying durawould be found intraoperatively.

Intraoperatively there was 1 case of an 
anteposed sigmoid sinus which was reported as normal by the radiologist while the rest were correctly reported and hence a negative predictive value of $96.88 \%$ was obtained.

Our findings of a low lying dura(0/32cases) is similar to T.Rai ${ }^{[1]}$ who found that only 1 out of their 50 cases had a low lying dura. Our finding is however in contrast to Liu Zhaohui et al. ${ }^{[2]}$ who reported a $21.8 \%$ incidence of low lying dura in their study.The incidence ofananteposed sigmoid sinus is $3.1 \%$ in our study which is similar to Tomura et al $(1.6 \%)^{[3]}$ but it differs from that reported by Zelikovich et al. $(36.5 \%)^{[4]}$.

Incidence of low lying dura and anteposed sigmoid sinus varies widely among previous studies. For low lying dura, it varies between $2 \%{ }^{[1]}$ and $21.8 \%{ }^{[2]}$ whereas for an anteposed sigmoid sinus it varies between $1.6 \%{ }^{[3]}$ and $36.5 \%{ }^{[4]}$. This wide variation can be attributed to the fact that there are no defined landmarks to label a case as having a low lying dura or an anteposed sigmoid sinus and hence reporting becomes highly subjective which is reflected in the wide range of above mentioned values.

Intraoperativelydural plate breach was found in 5 cases (15.6\%). This finding is similar to T.rai ${ }^{[1]}$ who reported an incidence of $12 \%$ but is in conflict with Suatkeskinet al ${ }^{[5]}$ who reports an incidence of $5 \%$.

The coherence with findings of T.Rai ${ }^{[1]}$ which is an India based study and the conflict with findings of SuatKeskin et $\mathrm{al}^{[5]}$, which is a Turkey based study is probably for the reason that in the Indian scenario, patients come to medical attention very late in the course of disease progression especially at the tertiary health care facility like the one in which the present study was conducted.

Plain radiograph mastoid(s/v) detected all the 5 cases of dural plate erosion with an additional 5 false positive results thereby accounting for $100 \%$ negative predictive value but only $50 \%$ positive predictive value. Hence if intact dural plate is reported, it is quite likely that the dural plate will be found intact intraoperatively but at the same time a positive result has only a $50 \%$ chance of being true.

Intraoperatively sinus plate erosion was found in $21.8 \%$ of cases. This is similar to the findings of T.Rai $(18 \%)^{[1]}$ Plain radiograph mastoid(s/v) detected sinus plate erosion with a negative predictive value of $82.14 \%$.

Presence of bone destruction with cholesteatoma was found intraoperatively in $75 \%$ of the cases. This is in line with the findings of O'reilly et al(79\%) ${ }^{[6]}$ and also Jackler $^{[7]}$, O Donoghue ${ }^{[8]}$, and Alzhoubi ${ }^{[9]}$ with all 3 of them reporting an incidence of $80 \%$.

Radiolucent shadow in mastoid on plain radiograph mastoid(s/v) in these study subjects of COM was considered to represent bone destruction and indicative of presence of cholesteatoma(Figures 1 and 2 ). Indeed, all 10 cases with a radiolucent shadow on plain radiograph $\mathrm{m}$ a s t o i d ( s/v) d i d h a v e cholesteatomaintraoperatively giving a $100 \%$ positive predictive value. However a negative predictive value of $36.36 \%$ together with a cohen's kappa value of 0.263 which is interpreted as only a 'fair' degree of agreement was also found. This underscores the point that absence of a radiolucent shadow does not rule out the presence of cholesteatoma. 


\section{CONCLUSIONS}

We thus conclude that plain radiographs of mastoid are to some extent helpful in providing a prior knowledge of the surgical landmarks in mastoid surgery. Hence with this information, if a surgeon finds himself more at ease in operating a patient then a plain radiograph of mastoid may be done when CT scan facility is unavailable. However, citing the limited information that a plain radiograph of mastoid has to offer on other aspects of the disease, its use as a routine investigation in chronic otitis media should be discouraged.

\section{LIMITATIONS OF THE STUDY}

This study was undertaken with a sample size of 32 subjects. Although statisticallyadequate, a larger sample size may lead to further insights and more authenticated findings applicable to a larger cohort.

\section{Clinical Significance:}

This study provides a statistical basis, discouraging routine use of plain radiographs in Chronic Otitis Media, a practice that is prevalent in the Indian scenario.

\section{Compliance with Ethical Standards}

Conflicts of Interest The authors declare that they have no conflicts of interest

Ethical Approval All procedures performed were in accordance with the ethical standards of the institutional ethics committee and with the 1964 Helsinki declaration and its later amendments or comparable ethical standards.

Informed consent An informed consent was taken from the patients or their guardians (in case of minors).

\section{REFERENCES}

1.RaiT. Radiological study of the temporal bone in chronic otitis media: Prospective study of 50 cases. Indian J Otol 2014;20:48-55.

2.Zhaohui L, Zhenchang W, Junfang X, Kun Z, Hong Z. HRCT study of anatomic variations of temporal bone. Chin Arc Otolaryngol Head Neck Surg 2006;2:97-101

3.Tomura N, Sashi R, Kobayashi M, Hirano H, Hashimoto $M$, Watarai J. Normal variations of the temporal bone on high-resolution CT:Their incidence and clinical significance. ClinRadiol 1995;50:144-8

4.Zelikovich El. Computed tomography of the temporal bone in diagnosis of otitis media chronicapurulenta.VestnOtorinolaringol 2004;4:25-9.

5.Keskin S, Çetin H, Töre HG. The Correlation of temporal bone CT with surgery findings in evaluation of chronic inflammatory diseases of the middle ear.Eur J Gen Med 2011;8:24-30.

6. O'Reilly BJ, Chevretton EB, Wylie I, Thakkar C, Butler $P$, Sathanathan N, et al. The value of CT scanning in chronic suppurative otitis media. J LaryngolOtol 1991;105:990-4.

7.Jackler RK, Dillon WP, Schindler RA. Computed tomography in suppurative ear disease: A correlation of surgical and radiographic findings. Laryngoscope 1984;94:746-52.

8.ODonoghue GM. Cholesteatoma: Diagnosis and staging by CT scan. J Otolaryngol 1987;12:157-60.

9.Alzoubi FQ, Odat HA, Al-Balas HA, SaeedSR. The role of pre-operative $C T$ scan in patients with chronic otitis media. Eur Arch Otorhinolaryngol 2009;266:807-9

*Corresponding Author:

Dr. Saifullah Khalid

Assistant professor, Department of Radio diagnosis,

JNMCH (AMU), Aligarh 


\section{THE COMPLICATIONS OF CSOM : OUR EXPERIENCE}

Authors: Anitya Srivastava (1), Ashish Chandra Agarwal (2)

Authors affiliations: (1)Senior Resident, (2) Assistant Professor, Department of ENT, Dr. Ram Manohar Lohia Institute of Medical Sciences, Lucknow, India.

\begin{abstract}
Context: Chronic Suppurative Otitis Media (CSOM) is a commonly encountered middle ear disease resulting in morbid complications and squeals. It is broadly classified into safe and unsafe type; in which unsafe CSOM is commonly associated with complications due to the bone erosion effect of cholesteatoma and super added infections. The rise in antibiotic use has reduced the incidence of complications but the current practice of unscientific administration of antimicrobial agents has made the microbiome resistant, ironically increasing the rate of certain complications. Aim: This study was conducted to profile the complications in unsafe CSOM. Material and Methods: A record based cross sectional study was conducted between January 2015 and October 2018 on 241 cases of unsafe CSOM at a tertiary care hospital in North India. Results: Out of 241 cases 14\% presented with complications. Of these $76.6 \%$ had extra cranial complication and $23.33 \%$ had intracranial complications. Conclusion: Mastoid abscess and meningitis were the most frequently encountered extra and intra cranial complications respectively. Judicious use of antibiotics will go a long way in reducing the morbidity due to the disease.
\end{abstract}

Keywords: CSOM; Extra cranial complications; Intra cranial complications.

\section{Introduction}

CSOM has been a common cause of middle ear disease since prehistoric times ${ }^{[1]}$ and is characterized by a long standing inflammation of the middle ear cleft. It is important to differentiate between the two types of CSOM viz. the safe and unsafe types; because unsafe type is commonly associated with life threatening complications ${ }^{[2]}$.

The rise in the use of antibiotics began in 1940s, and it has dramatically reduced the incidence of infective complications ${ }^{[3]}$. Due to unscientific use of antibiotics, many micro organisms have developed multi drug resistance, making antibiotics less effective and complications more common ${ }^{[4]}$. A large scale research is required to assess the current trend of complications in order to reduce the morbidity and mortality secondary to the disease.

\section{Material and Methods}

A record based cross sectional study was conducted in the department of ENT of a tertiary care hospital in north India, with an aim to profile the complications of unsafe CSOM. The duration of the study was 4 years and 9 months (January 2015 to October 2018). 241 cases diagnosed to have unsafe CSOM were included in the study. Patients having congenital ear diseases, malignancy of the ear, history of radiation to the head and neck region, diagnosed cases of tuberculosis and those having past history of taking anti tubercular therapy were excluded from the study.

Patient's data was recorded using retrospective charts review data collection method based on the articulated aims of the study. The data was analyzed using Microsoft Excel and SPSS version 20 statistical software. Descriptive statistics were used. Appropriate parametric and non parametric tests were applied to assess the association between various variables and were expressed in percentage. 


\section{Results and observations}

241 cases were studied during the study period and the age of the cases was between 9 years and 60 years. There were 114 males (47.3\%) and 127 females (52.69\%). 70 cases had bilateral ear disease (29.04\%), 80 cases had right ear disease (33.19\%) and 91 cases had left ear disease (37.75\%) [Table I].

Table I: Laterality of the involved ear.

\begin{tabular}{|l|l|l|}
\hline Right ear & 80 & $33.19 \%$ \\
\hline Left ear & 91 & $37.75 \%$ \\
\hline Both Ears & 70 & $29.04 \%$ \\
\hline
\end{tabular}

Amongst all the cases, $88 \%$ were without complications and $12 \%$ had complications [Figure I a]. Among those who presented with complications; 23 cases $(76.66 \%)$ had extracranial complications and 7 cases (23.33\%) had intracranial complications [Figure I b].

Figure la: Percentage of patients of unsafe CSOM presenting with complications.

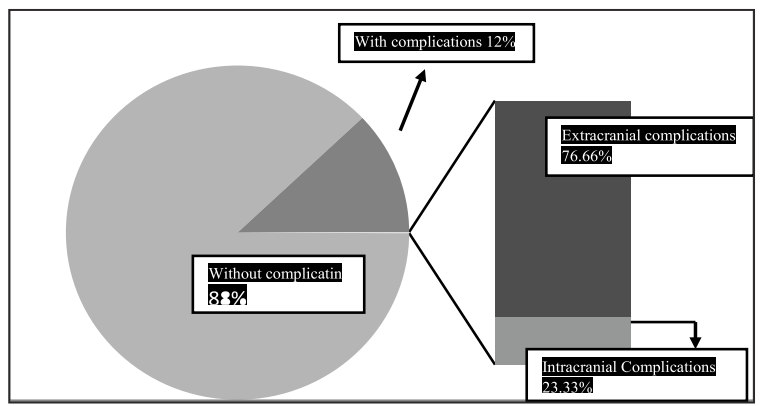

Figure Ib: Rate of different complications.

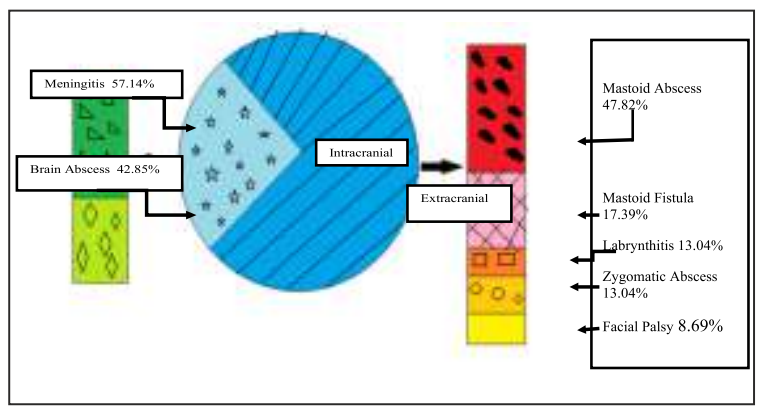

From figure I b, it can be noted that mastoid abscess was the most common extracranial complication and this was followed by a mastoid fistula, labrynthitis, zygomatic abscess and facial palsy. Meningitis was the most common intracranial complication and this was followed by a brain abscess.

\section{Discussion}

CSOM is common middle ear pathology and the unsafe type is frequently associated with complications. Presence of cholesteatoma along with a superadded bacterial infection results in the destruction of the bone and this leads to complications. Hematogenous spread of the pathology has also been documented ${ }^{[5]}$. Though the use of antibiotics has reduced the frequency and severity of complications, yet these are still encountered, probably due to the unscientific usage of anti microbial agents.

In our study, the male: female ratio was 1:1.1 and this was similar to some studies ${ }^{[1,6]}$ which have been done in the past. A study by Poursadegh et al ${ }^{[7]}$ reported male to female ratio of 1.39:1. A gender inequality can be an incidental finding as there is no knowledge of any anatomical difference in the structure of ear of males and females.

In our study, the age of the youngest patient was 9 years and oldest 60 years, the mean age was 26.8 years. 86 cases were between the age group of 20-30 years. Acquired cholesteatoma is commonly seen in patients less than 30 years of age ${ }^{[8]}$. Majority of the cases in our study had unilateral involvement and this was similar to a report by Boruah $D^{[8]}$. In a study by Goma et al ${ }^{[9]}$, bilateral involvement was noted predominantly.

In this study extracranial complications were more commonly encountered. Mastoid abscess was the most common amongst them, followed by a mastoid fistula. A study conducted by Sharma and Jaiswal et al $\left.{ }^{[10}\right]$ also had a similar results. This finding has also been supported by studies conducted by Wanna GB et al ${ }^{[3]}$, Viswanatha B et al ${ }^{[4]}$, Thappa $\mathrm{N}$ et al ${ }^{[11]}$. 
The present study had intracranial complications in 7 patients of unsafe CSOM. The majority had meningitis and this was followed by brain abscess. In a study by Thappa et al ${ }^{[1]}$ with 699 patients, brain abscess was reported as the most common complication. In our study, all the cases of brain abscess had temporal lobe involvement, which was at par with the results of J Samuel ${ }^{[12]}$ whereas according to studies done by Murthy et al and Dubey et al, abscess secondary to an otogenic infection was more frequent in the cerebellum ${ }^{[13,14]}$.

The incidence of intracranial and extracranial complications has decreased due to the administration of antibiotics. Yet, it is not uncommon to come across patients having extension of infection beyond the confines of the middle ear cleft, particularly in the developing world. The reasons could be multiple viz. poor personal hygiene and unawareness of the disease, inadequate health care facilities, unscientific usage of antibiotics and the presence of co-morbidities. An awareness about the disease, proper clinical evaluation, appropriate investigations, prescription of antibiotics as per culture sensitivity reports and surgical intervention at the earliest will ameliorate the morbidity associated with this condition.

\section{Conclusion}

Awareness at the level of community, state of the art health care facilities, judicious use of antibiotics and a good post treatment follow- up will go a long way in preventing the complications of CSOM.

\section{References}

1. Aljehani M, Alhussini R. The Correlation between Preoperative findings of High Resolution (HRCT) and Intraoperative findings of Chronic Otitis Media (COM). Clin Med Insights Ear Nose, throat. 2019;
12:50-55.

2. RaiT. Radiological Study of the temporal bone in chronic otitis media: Prospective study of 50 cases. Indian J Otol. 2014; 20:48-55.

3. Wanna GB, Dharamsi LM, Moss JR, Bennett ML, Thompson RC, Haynes DS. Contemporary management of intracranial complications of otitis media. Otol Neurotol. 2010;31:111-117.

4. Viswanatha B, Sarojamma, Vijayashree MS, Sumatha D. Unilateral attico antral ear disease with bilateral intracranial complications. Indian J Otolaryngol Head Neck Surg. 2012;64(1):82-86.

5. Mittal R, Lisi CV, Gerring R. Current concepts in pathogenesis and treatment of chronic suppurative otitis media. J Med Microbiol 2015;64:1103116.

6. O'Donoghue GM, Bates GJ, Anslow P, Rothera MP. The predictive value of High Resolution Computerized Tomography in Chronic Suppurative ear disease. Clin Otolaryngol Allied Sci. 1987; 12:89-96.

7. Poursadegh $M$, Hashemi $G$, Jalali $M$. Evaluation of anatomical variations of vestibular aqueduct dimensions in temporal bone CT scan. Med J Islam RepubIran. 2000; 14:199-202.

8. Boruah D, Sharma KB, Sanyal S et al. Role of HRCT in the evaluation of suppurative disease of middle ear and mastoid and there complication with surgical correlation. J Evolution Med. Dent. Sci. 2016;5:850-858.

9. Gomaa MA, Abdel Karim AR, Abdel Ghany HS, Elhiny AA, Sadek AA. Evaluation of temporal bone cholesteatoma and the correlation between High Resolution Computed 
Tomography and surgical finding. Clin Med Insights Ear Nose Throat. 2013;6:21-28.

10. Sharma N, Jaiswal AA, Banerjee PK, Garg AK. Complications of chronic suppurative otitis media and their management: A single institution 12 years experience. Indian J otolaryngol head neck surg 2015;67(4):353-360.

11. Thappa N, Srivatsva RP. Intracranial complication of CSOM, atticoantral type: experience at TUTH. J Neuroscience 2004; 1:36-39.

12. Samuel J, Fernandes CM, Steinberg JL. Intracranial otogenic complications: a persisting problem. Laryngoscope. 1986;96:272-278.

13. Murthy PS, Sukumar R, Hazarika P, Rao AD, Mukulchand, Raja A. Otogenic brain abscess in childhood. Int J Pediatr Otorhinolaryngol. 1991;22:9-17.

14. Dubey SP, Larawin V. Complications of chronic suppurative otitis media and their management. Laryngoscope. 2007;117:264-267.

\section{Source of support: Nil.}

\section{Acknowledgement: None}

Conflict of interest: None declared. The manuscript has been read and approved by all the authors, the requirements of authorship have been met and each author believes that the manuscript represents honest work.

\section{*Corresponding author:}

Ashish Chandra Agarwal MS (ENT), MRCS Ed

Assistant Professor, Department of ENT, Dr. Ram Manohar Lohia Institute of Medical Sciences, Lucknow, India

Email:ashishchandraagarwal@gmail.com 


\section{ROLE OF MACROLIDES (CLARITHROMYCIN) ON BIOFILMS IN CHRONIC RHINOSINUSITIS}

Authors: Mohd Aftab (1), Sachin Jain (2), Daya Shanker (3), Mohd Rizvan (4), Pankaj KumarTiwari (5)

Authors Affiliations: (1) Associate Professor, (2) Professor and Head, (3) Junior Resident, 94) Junior Resident, (5) Junior Resident, Department of ENT \& Head Neck Surgery, M.L.N. Medical College, Prayagraj, Uttar Pradesh, India

\begin{abstract}
Background: Rhinosinusitis, a group of disorders characterized by inflammation of the nose and paranasal sinuses can be classified as acute, sub-acute or chronic and recurrent based on the duration of inflammation. Biofilm with formation of a physical barrier prevent antibiotics from penetrating it. Macrolides achieve high intracellular concentration and have a spectrum of activity against Gram positive cocci. This study aims to describe effect of macrolide antibiotics (clarithromycin) on eradication of suspected biofilms in chronic rhinosinusitis.
\end{abstract}

Methods: Fifty ( 29 man and 21 women) patients of Chronic Rhinosinusitis were prospectively observed and data were collected.

Results: The average age of Chronic Rhinosinusitis onset was 28.6 years. Suspected biofilms was noted in all the patients. The case group showed a reduction of $25.8 \%$ in symptom score and $49.2 \%$ in endoscopic sign scores with clarithromycin.

Conclusions: The case group showed a reduction of bacteriologically as well as symptom score and endoscopic sign scores.

Keywords: Chronic Rhinosinusitis, Biofilm, Clarithromycin

\section{Introduction}

Rhinosinusitis is defined as a group of disorders characterized by inflammation of the nose and paranasal sinuses. Based on the duration of inflammation, rhinosinusitis is classified as acute
(< 4 weeks), subacute (4-12 weeks) or chronic ( $>12$ weeks), recurrent [ $>4$ episodes of Acute Rhino Sinusitis peryear].

CRS is classified into CRS with nasal polypand CRS without nasal polyp.Symptoms of CRS have been classified as major (facial pain or pressure, nasal obstruction or blockage, discoloured postnasal drainage, hyposmia and purulence in nasal cavity) or minor(headache, fever, dental pain and ear pain). ${ }^{1}$

Biofilms are a structurally complex, three dimensional community of bacteria anchored to a surface. Individual bacterial within a biofilm are connected by a self-extracted matrix consisting of negatively charged polysaccharide. Once organized, biofilms are capable of evading both the effects of antibiotics as well as host immunologic defense systems. ${ }^{2}$ Some CRS patients appear resistant to cure despite surgically opened sinus cavities and long-term culture-directed antibiotic therapy.

Several studies ${ }^{3,4,5,6}$ have investigated the relationship between biofilms and CRS. The most common bacterial biofilms in CRS are Staphylococcus aureus, Pseudomonas aeruginosa, coagulase negative Staphylococci, Streptococcus pneumoniae, Moraxella catarrhalis and Haemophilusinfluenzae.

Macrolides belong to the family of 14 or 15 membered lactone ring antibiotics. These antibiotics achieve high intracellular concentration and have a spectrum of activity against Gram positive cocci ${ }^{7}$

Macrolides can block the activation of 
transcription factor nuclear factor $\mathrm{kB}$ and inhibit the production of various inflammatory cytokines, including interleukin (IL)-8 and tumor necrosis factor- $a$ (TNF- $\alpha$ ). They can also suppress the secretion of airway mucus, induce the apoptosis of neutrophils, and even diminish the formation of bacterial biofilms. ${ }^{8,9}$

This study was planned to obtain the evidence of suspected biofilms in chronic rhinosinusitis and effect of macrolide antibiotics (clarithromycin) on eradication of suspected biofilms in chronic rhinosinusitis.

\section{Methods}

This prospective, Observational study was conducted in the Department of E.N.T., MotiLal Nehru Medical College and Swaroop Rani Nehru Hospital, Prayagraj from September 2018 to August 2019.

\section{Inclusion Criteria}

Age group of 18 - 45 years irrespective of Gender, patients with diagnosed chronicsinusitis [radiological examination and DNE(diagnostic nasal endoscopy)], two or more of the following symptoms (Anterior/ posterior mucopurulent nasal discharge, Nasal obstruction, Facial pain/ pressure/ fullness) persisting since $>12$ weeks, endoscopy signs: discolored mucus or edema within the Middle meatus or Ethmoid Region, evidence of Rhinosinusitis on CT Scan, patients who were willing to come for follow up and patients of CRS not responding to treatment even after three months with commonly used macrolides prescribed at $\mathrm{CHC}, \mathrm{PHC} \&$ by general physician were considered as a case of having suspected biofilm.

\section{Exclusion Criteria}

Patients having no other sinonasal pathology like polyposis malignancy, fungal rhinosinusitis, frontal mucocoele and deviated nasal septum, patients of comorbid conditions like diabetes mellitus, hypertension, psychological issues, liver disease, immunocompromised, patients with pregnancy or lactation, history of long term use of systemic steroid therapy and patient of CRS with nasal polyp

Clinical data including gender, age, symptoms, systemic disorders and related medications were collected. Patients were properly examined and selected for our study who fulfilled the criteria by International Advisory Board, $1997{ }^{10}$ andthe diagnosis of chronic rhinosinusitis was made.

Patients of age group 18 - 44 years with symptoms and signs of Chronic Rhino-sinusitis were randomized into two treatment groups.Group $A(n=25)$ were treated with macrolides antibiotics (Clarithromycin) and Group B $(n=25)$ were treated with a placebo.

Swab was taken in both the groups from middle meatus for study of bacteriological spectrum of suspected biofilm. The isolated pathogens were-examined microscopically to ensure the staining and morphologic characteristic of an organism. Further identification was done at species level by the Vitek-2 system.

After diagnosis of CRS with suspected bacterial biofilms. In Group A Oral Clarithromycin 500 mg BD was administered for 2 weeks followed by $250 \mathrm{mg}$ OD for next 6 weeks and in Group B placebo was administered.

Quality of life assessment pre-treatment as well as post-treatment was done by using Visual Analogue Score (VAS) at regular intervals of 0 , 2 weeks and 6 weeks. ${ }^{11}$

Nasal endoscopic scoring was also done before starting of treatment and at regular intervals after starting of treatment (i.e. at 0, 2 weeks, 6 weeks) according to Modified Lund-Kennedy Endoscopy Scoring system ${ }^{12}$.

\section{Results}

All fifty ( 29 man and 21 women) patients with 
mean age 28.6 years of suspected biofilms were found positive for aerobic as well as anaerobic bacteria.

Table-1: Comparison of microorganism profile of two study groups

\begin{tabular}{|l|c|c|c|}
\hline Pathogens isolated & Group-A & Group-B & Total \\
\hline Peptococcus & $9(36.0 \%)$ & $5(20.0 \%)$ & $14(28 \%)$ \\
\hline S. aureus & $16(64.0 \%)$ & $20(80.0 \%)$ & $36(72 \%)$ \\
\hline Total & $25(100 \%)$ & $25(100 \%)$ & \\
\hline
\end{tabular}

In Group A, a total of 16(64\%) were S. Aureusand $9(36 \%)$ were Peptococcus whereas in Group B, 20 ( $80 \%)$ were S. aureus and $5(20 \%)$ were Peptococcus. Though the proportion of Peptococcuswas slightly higher in Group A as compared to that in Group B.

Table No-2: Comparison of clarithromycin sensitivity in both study group

\begin{tabular}{|l|c|c|c|}
\hline Clarithromycin & Group-A & Group-B & Total \\
\hline Sensitivity & $20(80.0 \%)$ & $22(88.0 \%)$ & $42(84 \%))$ \\
\hline Resistant & $5(20.0 \%)$ & $3(12.0 \%)$ & $8(16 \%)$ \\
\hline Total & $25(100 \%)$ & $25(100 \%)$ & \\
\hline
\end{tabular}

$c^{2}=0.595 ; p<0.440$

On evaluating the sensitivity of Clarithromycin, it was found to be sensitive in $42(84 \%)$ cases, while $8(16 \%)$ cases were resistant $(2 \%$ S.aureus and $14 \%$ Peptococcus).

In Group A, mean endoscopic sign scores for discharge were $2.56 \pm 0.77,1.64 \pm 0.49$ and $1.40 \pm 0.71$ respectively at baseline, first and second follow-up intervals. As compared to baseline, there was a decline of $0.92 \pm 0.91$ $(35.9 \%)$ at first and $1.16 \pm 1.03(45.3 \%)$ at second follow-up intervals. $(p<0.001)$.

In Group B, Mean endoscopic sign scores for discharge were $2.44 \pm 0.77,2.52 \pm 0.59$ and $2.44 \pm 0.58$ respectively at baseline, first and second follow-up intervals. As compared to baseline, there was an increase of $0.08 \pm 0.81$ (3.3\%) at first follow-up while no change was observed at second follow-up.

At baseline in Group A, a total of 20 (80\%) cases was sensitive and while 5 (20\%) were resistant, in Group B, 22(88\%) cases were sensitive and $3(12 \%)$ were resistant against Clarithromycin.

Table 3: Evaluation of Change in Symptom scores as compared to baseline at different

\begin{tabular}{|c|c|c|c|c|c|c|}
\hline \multirow[t]{2}{*}{ Group } & \multirow[t]{2}{*}{$\begin{array}{c}\text { Follow-up } \\
\text { interval }\end{array}$} & \multirow[t]{2}{*}{ Mean \pm SD } & \multicolumn{2}{|c|}{ Improvement } & \multicolumn{2}{|c|}{$\begin{array}{c}\text { Significance of } \\
\text { change (Paired } \\
\text { 't'-test) }\end{array}$} \\
\hline & & & $\operatorname{Mean} \pm$ SD & $\begin{array}{c}\% \\
\text { Change }\end{array}$ & ' $t$ ' & 'p' \\
\hline \multirow[t]{3}{*}{ A } & Baseline & $40.64 \pm 3.03$ & - & - & - & - \\
\hline & First & $37.68 \pm 2.50$ & $2.96 \pm 3.06$ & $7.3 \%$ & 4.834 & $<0.001$ \\
\hline & Second & $30.16 \pm 1.80$ & $10.48 \pm 3.50$ & $25.8 \%$ & 14.965 & $<0.001$ \\
\hline \multirow[t]{3}{*}{ B } & Baseline & $39.44 \pm 2.99$ & - & - & - & - \\
\hline & First & $38.64 \pm 2.23$ & $0.80 \pm 1.83$ & $2.0 \%$ & 2.191 & 0.038 \\
\hline & Second & $37.84 \pm 2.66$ & $1.60 \pm 0.91$ & $4.1 \%$ & 8.764 & $<0.001$ \\
\hline
\end{tabular}

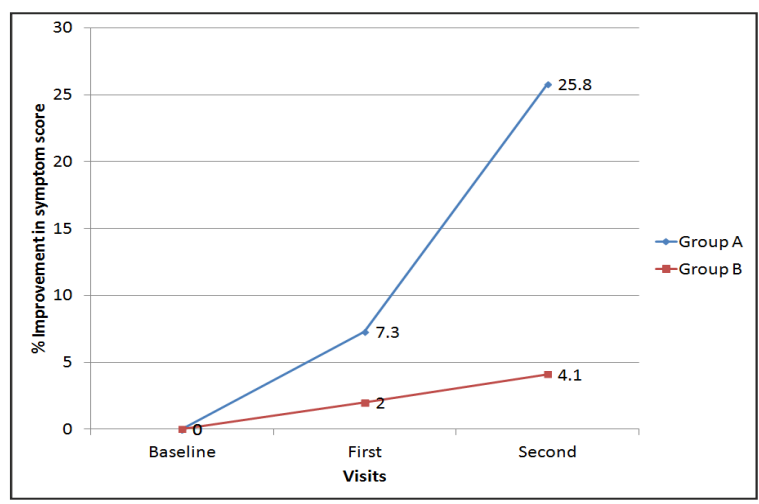

follow-up intervals in two study groups

Fig. 1 : \% Improvement in symptom scores at different time intervals in Groups A and B In Group A, mean symptom score was $40.64 \pm 3.03,37.68 \pm 2.50$ and $30.16 \pm 1.80$ respectively at baseline, first and second followup intervals respectively. As compared to baseline, there was a decline of $2.96 \pm 3.06(7.3 \%)$ at first follow-up and $10.48 \pm 3.50(25.8 \%)$ at second follow-up. Statistically, the change from baseline was significant at both the follow-up intervals $(p<0.001)$.

In Group B, mean symptom score was $39.44 \pm 2.99,38.64 \pm 2.23$ and $37.84 \pm 2.66$ respectively at baseline, first and second followup intervals respectively. As compared to 
baseline, there was a decline of $0.80 \pm 1.83(2 \%)$ at first follow-up and $1.60 \pm 0.91$ (4.1\%) at second follow-up. In statistical terms, the change from baseline was highly significant at both the follow-up intervals $(p<0.05)$.

\section{Discussion}

Chronic rhinosinusitis is a multidimensional disease having a huge economic burden, morbidity and quality of life deterioration. Evidence has shown that microorganisms play a crucial role in aggravating the symptoms and mucosal inflammation Boaseet al., 2013 ${ }^{13}$. The characterization of biodiversity of microorganisms in CRS could be done by carrying out microbiological assessment of potential specimen that could help in identifying and characterizing it.

In this context biofilms are an important source, for they have a high potential of diverse microbiological species at one place, moreover they represent the high possibility for easy isolation and identification of microbial organisms. Biofilms are highly organised microbial communities enclosed within a selfproduced extra cellular polymeric matrixHallStoodleyet al., 2004 ${ }^{14}$. There are limited studies on characterizing the biofilms in chronic rhinosinusitis patients.

Macrolides are broad spectrum antibiotics that include antibiotics like clarithromycin, azithromycin and erythromycin. They have been shown to have a successful role in inhibition of bacteria. Hence, the present study was carried out with an aim to identify the bacteriological spectrum in suspected biofilms of chronic rhinosinusitis and to assess the clinical efficacy of macrolide antibiotic (Clarithromycin) on these suspected biofilms. For this purpose, a total of 50 ( 29 man and 21 womens with mean age 28.6 years) chronic rhinosinusitis patients without polyps were enrolled in the study.

In present study, out of a maximum possible score of 60 , the VAS scores of patients ranged from 34 to 46 with a mean of $40.04 \pm 3.04$. These scores thus indicated a moderate burden of disease. Mean scores for discharge and edema were $2.50 \pm 0.76$ and $2.66 \pm 0.80$ respectively out of a maximum of 4 for each domain. Overall mean total sign score was $5.16 \pm 1.02$ which also reflected a moderate burden of disease for the two domains remaining in the study. Thus both sign and symptom scores were reflective of a moderate burden of disease. In present study, the bacteriological profile of suspected biofilms indicated a dominance of Staphylococcus aureus $(n=36 ; 72 \%)$.

In present study a significant improvement in signs was observed only in case group and it had a significant difference from control group from first visit itself. On final follow-up, the case group showed a reduction of $25.8 \%$ in symptom score and $49.2 \%$ in endoscopic sign scores. These results are similarly withLuoet $\mathbf{a l . 2 0 1 4}{ }^{15}$, who reported a reduction of $64.5 \%$ in symptom score and $49.5 \%$ in endoscopic sign scores. Deng et al.2018, ${ }^{16}$ in a randomized controlled trial found that symptomatic results are slightly better in long-term, low-dose with Clarithromycin group as compared to control group. Sarfaraz et al.,2008; ${ }^{17}$ Fan et al., 2014; ${ }^{18}$ Sireci et al., $2018^{19}$ and Wallwork et al., $2006^{20}$ also found similar results with Clarithromycin.

The findings of present study, thus show a promising role of clarithromycin in treatment of chronic rhinosinusitis without polyps both in terms of symptomatic response as well as antibacterial effect.

\section{Conclusions}

The present study was a novel to describe the bacteriological spectrum of biofilms of chronic 
rhinosinusitis patients and to assess the clinical efficacy of macrolide antibiotics (Clarithromycin) on these biofilms. This study also showed a significant curative effect of macrolide antibiotic (Clarithromycin) clinically and symptomatically as well as bacteriologically. The significance of this study is incidence of anerobes especially peptococcusfrom the suspected biofilm which were never reported before.

\section{References}

1. Benninger MS, Ferguson BJ, Hadley JA, Hamilos DL, Jacobs M, Kennedy DW, et al. Adult chronic Rhinosinusitis: Definitions, Diagnosis, Epidemiology, and Pathophysiology. Otolaryngology Head and Neck Surgery. 2003;129(3):S1S32.

2. Stewart PS. Costerton JW: Antibiotic resistance of bacteria in biofilms. Lancet 2001;358:135-138.

3. Hunsaker DH, Leid JG. The Relationship of B i ofilms to Chronic Rhinosinusitis.Current Opinion in Otolaryngology \& Head \& Neck Surgery. 2008;16(3):237-41.

4. Ramadan HH. Chronic Rhinosinusitis and Bacterial Biofilms.CurrentOpinion in Otolaryngology \& Head \& Neck Surgery. 2006;14(3):183-6.

5. Suh JD, Cohen NA, Palmer JN. Biofilms in Chronic Rhinosinusitis. Current Opinion in Otolaryngology \& Head \& Neck Surgery. 2010;18(1):27-30.

6. Cohen $\mathrm{M}$, Kofonow J, Nayak JV, Palmer JN, Chiu AG, Leid JG, et al. Biofilms in Chronic Rhinosinusitis: A Review. American Journal of Rhinology \& Allergy. 2009;23:255-60.

7. Cervin A, Wallwork B. Macrolide therapy of chronic rhinosinusitis. Rhinology.2007;45(4):259.

8. Zeng M, Li ZY, Ma J, Cao PP, Wang H, Cui $\mathrm{YH}$, Liu Z. Clarithromycin and dexamethasone show similar antiinflammatory effects on distinct phenotypic chronic rhinosinusitis: an explant model study. $B M C$ immunology.2015;16(1):37.

9. Tamaoki J. The effects of macrolides on inflammatorycells.Chest.2004;125(2):41 S-51S.

10. International Rhinosinusitis Advisory Board. Infectious rhinosinusitis in adults: classification, etiology and management. Ear Nose Throat J. 1997; 76:1-22.

11. VAS by Lund VJ and Mackay IS. Surgical management of sinusitis. Scott Brown's Otolaryngology 2008, 7th edition, ; Edward Arnold publishers, Page 1490; Table 117.9.

12. Psaltis AJ, Li G, Vaezeafshar R, Cho KS, Hwang PH. Modification of the LundKennedy endoscopic scoring system improves its reliability and correlation with patient-reported outcome measures. Laryngoscope. 2014; 124(10):2216-2223.

13. Boase S, Foreman A, Cleland E, Tan L, Melton-Kreft R, Pant $\mathrm{H}, \mathrm{Hu} F Z$, et al. The microbiome of chronic rhinosinusitis: culture, molecular diagnostics and biofilm detection. BMC Infectious Diseases 2013; 13:210.

14. Hall-Stoodley L, Costerton JW, Stoodley P. Bacterial biofilms: from the natural environment to infectious diseases. Nature Reviews Microbiol. 2004;2(2):95-108.

15. Luo Q, Deng J, Xu R, Zuo K, Li H, Shi J. 
Clinical effect of clarithromycin therapy in patients with chronic rhinosinusitis. Chinese Journal of Otorhinolaryngology Head And Neck Surgery. $2014 ; 49(2): 103-8$.

16. Deng J, Chen F, Lai Y, Xu R, Ou C, Fu Q, Shi J. Lack of additional effects of long-term, low-dose clarithromycin combined treatment compared with topical steroids alone for chronic rhinosinusitis in China: a randomized, controlled trial. International Forum of Allergy\& Rhinology. $2018 ; 8(1): 8-14$.

17. Sarafraz $M$, Khosravi $A D$, Ahmadi K. Clinical and Microbiological Evaluation of Long Term Clarithromycin in the Treatment of Chronic Rhinosinusitis. Journal of Medical Sciences 2008; 8(7): 669-72.

18. Fan $\mathrm{Y}, \mathrm{Xu} \mathrm{R}$, Hong $\mathrm{H}$, et al. High and low doses of clarithromycin treatment are associated with different clinical efficacies and immunomodulatory properties in chronic rhinosinusitis. Journal of Laryngology\& Otology. 2014;128:236-241.

19. Sireci $F$, Speciale $R$, Gallina S, Sorrentino $\underline{R}$, Canevari FR. Clarithromycin in the Management of Chronic Rhinosinusitis: Preliminary Results of a Possible Its New Use. Indian Journal Otolaryngology Head Neck Surgery. $2018 ; 70(1): 87-91$.

20. Wallwork B, Coman W, Mackay-Sim A, Greiff L, Cervin A. A double-blind, randomized, placebo controlled trial of macrolide in the treatment of chronic rhinosinusitis.Laryngoscope.2006;116(2 ):189-93
${ }^{*}$ Corresponding author:

\section{Dr. Daya Shanker}

Junior Resident,

Department of ENT \& Head Neck Surgery,

M.L.N. Medical College, Prayagraj,

Uttar Pradesh, India.

Phone (Mobile) No. +918923070901

Email: orljournal.ald@gmail.com 
BRONCHOSCOPIC CRYOTHERAPY IN MANAGEMENT OF POST TRACHEOSTOMY TRACHEAL STENOSIS: AN UNCONVENTIONAL NOVEL APPROACH

\author{
Name of Authors: Vikas Marwah', Vikas Gupta², Vikas Sharma ${ }^{3}$, Deepu Peter ${ }^{4}$, Deepak Shukla $^{5}$
}

\title{
Affiliations of authors:
}

(1) Associate Prof, Dept of Respiratory Medicine,(4) Resident, Dept of Respiratory Medicine, (5) Assistant Prof, Dept of Anesthesiology and Critical care, Military Hospital CTC, Pune, Maharashtra, India (2) Associate Prof, Dept of ORL-HNS, Command Hospital (Central Command), Lucknow, Uttar Pradesh, India (3) Assistant Prof, Dept of ORL-HNS, Military Hospital Kirkee, Pune, Maharashtra, India

\begin{abstract}
:
Post tracheostomy / Post intubation -tracheal stenosis is a relatively rare but a serious problem which warrants a precise diagnosis and a multimodality-multidisciplinary approach for successful outcome. Traditionally, depending upon the type and site of stenosis, such cases are managed by open surgical approach and occasionally by endoscopic approach with dilatation.

We report a case, a post traumatic quadriplegic on tracheostomy tube with suprastomal granulation and web like fibrous stenosis, which was managed successfully by bronchoscopiccryotherapy.Bronchoscopiccryot herapy can be considered as primary modality treatment in select group of cases.
\end{abstract}

Key words: bronchoscopy, cryotherapy, cryoadhesion, suprastomal granulation, tracheal stenosis

\section{Introduction:}

Endotracheal intubation and tracheostomy are commonly performed procedures on ICU patients. With increase in survivorship of ICU patients, post op ICU care is of paramount importance for improved quality of life. Patient with history of intubation / tracheostomy presenting with respiratory distress should be suspected to have develop tracheal stenosis.

Tracheal stenosis once occur, is a serious surgical problem. Tracheal resection and end to end anastomosis is considered the main stay treatment. However, with advent of endoscopic approaches, as good outcomes have been reported, the balance has been tilting towards them. In select situations endoscopic procedure have been tried for recanalization of obstructed airway. Procedures like interventional bronchoscopic dilation (mechanical or balloon), endoluminal treatment with electorcautery, lasers and stenting, use of cryotherapy have stood the test of time [1].

We present a case of post traumatic quadriplegia on prolonged tracheostomy tube who developed suprastomal granulations and web like fibrous stenosis leading to difficulty in phonation. He was successfully managed with flexible bronchoscopiccryotherapy under controlled sedation using dexmedetomidine.

\section{Case description:}

32 year old male, on long term fenestrated double lumen tracheostomy with speaking valve, after suffering a cervical spine injury in road traffic accident in December 2016. Posterior C1-2 plate and screw fixation was done for the cervical spine injury and was tracheostomized on the $7^{\text {th }}$ day of RTA. Diaphragmatic pacing was also done in view of bilateral diaphragmatic palsy. He was referred to our center with progressive difficulty in phonation since sept 2018. Fibreoptic laryngoscopy identified granulation in the 
subglottic region obstructing $>90 \%$ of the tracheal lumen (Fig 1).

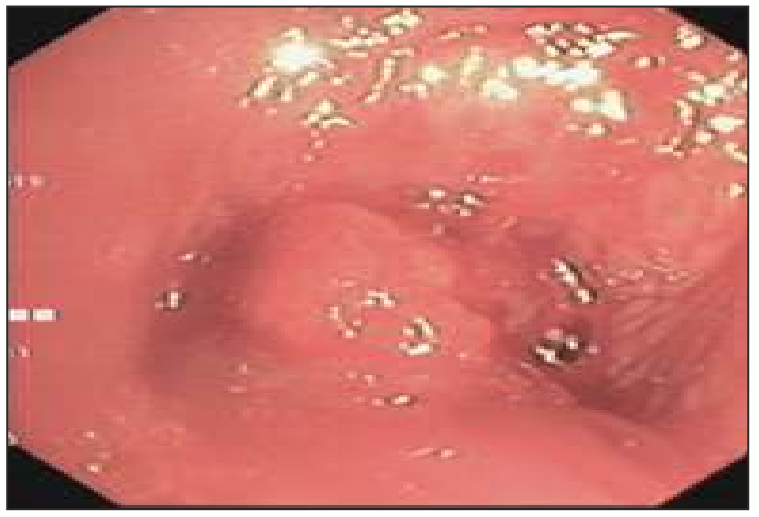

Fig1: Granulation tissue visualized in the tracheal lumen during bronchoscopy

A contrast enhanced computed tomogram revealed an enhancing soft tissue thickening superior to the tracheostomy tube at the level of stoma, predominantly in the anterior aspect, with cranio-caudal extension of $13 \mathrm{~mm}$ (Fig 2).

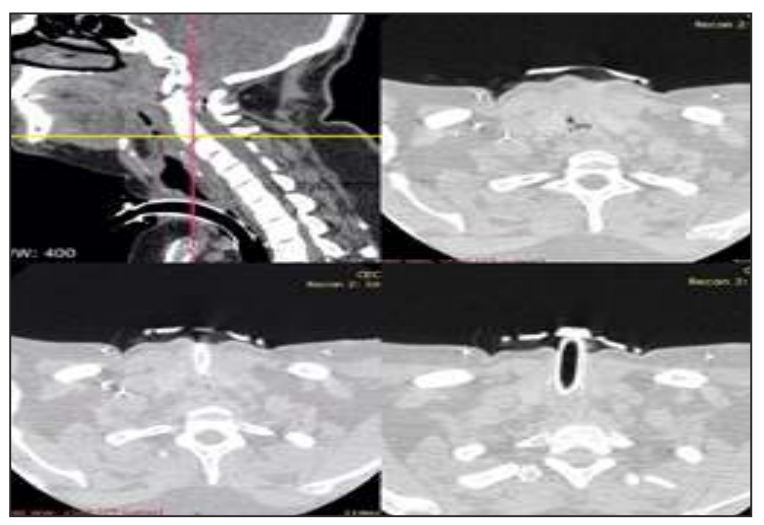

Fig 2: CECT showing suprastomal granulation tissue (black arrow) with almost completely occluded tracheal lumen (green arrow)

Patient was discussed in multidisciplinary clinic amongst Head Neck surgeon, Pulmonologist and Anaesthesiologist. In view of no neck extension available, it was decided to recanalize the obstructed airway by fibre optic bronchoscopy with cryotherapy and electro cautery for extraction of granulation tissue over multiple sittings. Sedation, during each of these sittings was achieved using an initial infusion of $50 \mu \mathrm{g}$ of fentanyl followed by loading dose $1 \mu \mathrm{g} / \mathrm{kg}$ of dexmedetomidine infused over 10 min and the loading dose was followed by infusion at a rate of $0.5 \mu \mathrm{g} / \mathrm{kg} / \mathrm{h}$ and ventilation was maintained through tracheostomy tube.

Friable granulation tissue attached to the anterior aspect of the trachea was visualised, which bled on touch. It was causing almost complete occlusion of the tracheal lumen. Bipolar electrocautery probe (Vio 200S, ErbeElektromedizin GmbH, Germany) was inserted through the working channel of the bronchoscope and de-bulking of the granulation tissue at 9'O clock, 12'O clock and 2'O clock position was done. Patient was again taken up for bronchoscopy after 03 days of the initial procedure. Sedation was again given using dexmedetomidine and fentanyl. Necrosed granulation tissue was visualised. The cryoprobe (Erbecryo2, ErbeElektromedizin $\mathrm{GmbH}$, Germany) was inserted through the working channel with nitrogen oxide as cryogen was used. The tip of the cryoprobe was kept directly over the granulation tissues. 02 activations for 10 seconds each were applied to the necrosed granulation tissue. The tissue was adherent to the cryoprobe after the second activation and it was extracted from the tracheal lumen by withdrawing the cryoprobe along with the bronchoscope (Fig 3).

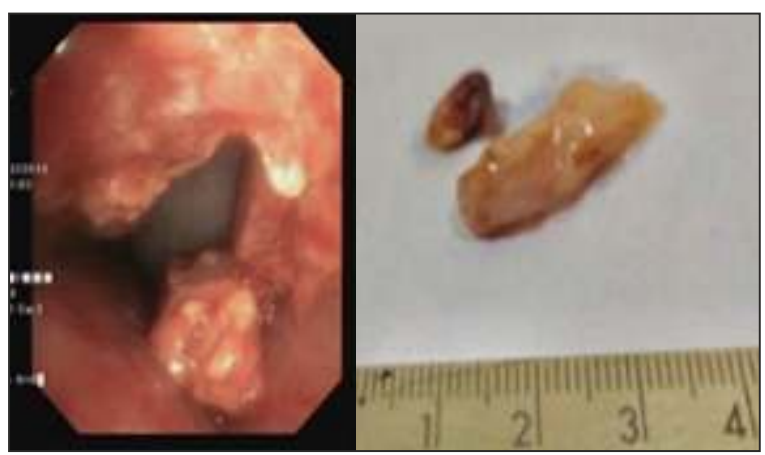

Figure 3: Suprastomal granulation tissue removed using the cryoprobe

There was only minimal bleeding during the second procedure. Bronchoscopic evaluation revealed adequate recanalization of the trachea and the tracheostomy tube could be visualised. 
Patient was administered systemic steroids along with inhaled steroid for three days.

Same procedure was repeated after 2 weeks for remaining granulation tissues. Patient after the procedure was able to phonate well and even tolerated capping of the tracheostomy tube. Patient is on regular follow up since then. Intraluminal is adequate, well mucosalised with no evidence of restenosis. He is being planned for decannulation. (Fig 4).

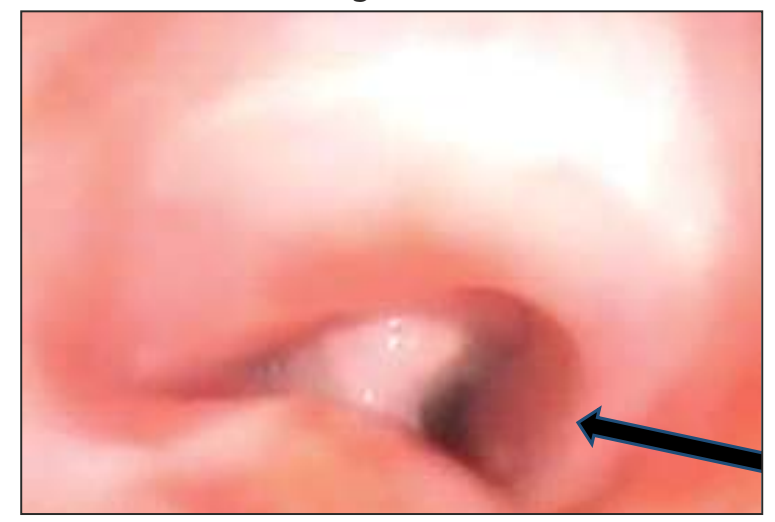

Fig 4: Follow up pic with adequately wide tracheal lumen, no granulations and tracheostomy tube visualised distally (arrow)

\section{Discussion:}

Tracheal stenosis occurring post intubation or post tracheostomy although rare, are still the most common cause [2]. Among all intubated patients, the reported incidence of stenosis ranges from 10 to $22 \%$, although, only $1-2 \%$ of the patients are symptomatic. Presently, estimated incidence of severe post intubation or post tracheostomy stenosis is 4.9 cases per million per year in the general population [3].

The site of stenosis depends, whether patient was intubated or tracheostomised. Intubated patient generally develop stenosis at the site of cuff. Tracheostomy patient develop stenosis due to a) abnormal wound healing with excessive granulation tissue around the stoma or over fracture cartilage site[3]. b) Mechanical leverage of the tube due to unsupported weight of ventilator circuit can cause pressure necrosis. c)
Rigidity of tracheostomy cannula causing friction and damage to mucosa [4].d) During coughing, the cannula thrusts repeatedly against the upper edge of the stoma and crushes down the anterior wall of the trachea, leading to suprastomal collapse and granuloma formation [5]. e) High cuff-pressure and failure to deflate cuff intermittently, also play an important role in the development of stenosis. Over inflation of non-elastic plastic cuff with pressure exceeding the mucosal capillary pressure $(30 \mathrm{~mm}$ of $\mathrm{Hg}$ ) of trachea, the mucosa that lies between the cuff of the balloon and the underlying cartilages develops ischemia. Long standing ischemia can leads to ulceration and chondritis of tracheal cartilages, followed by fibrotic healing, leading to progressive tracheal stenosis [6].

Patients remain asymptomatic unless there is significant stenosis reducing the tracheal lumen diameter to $50 \%$ to $75 \%$. The patient develops stridor if tracheal lumen is narrower than $5 \mathrm{~mm}$ in adults [7].

Traditionally, open surgical approach have been the main stay of treatment with maximum cure rates. However, with development of endoscopic endoluminal approach, which are less invasive and with comparative outcomes, these are also being employed in management of tracheal stenosis. Interventional bronchoscopic dilation (mechanical or balloon), endoluminal use of electorcautery, lasers, stenting, and use of cryotherapy have expanded treatment options [8].

In our patient, we opted for flexible bronchoscope assisted cryotherapy due to following reasons: a) Quadraplegic patient with cervical spine injury with plating and fixation of C1-2 cervical vertebrae leading to inability to extend neck prohibiting rigid bronchoscopic procedures. b) Diaphragmatic pacing in view of bilateral diaphragmatic palsy. c) Pre-existing 
tracheostomy with thin stenotic segment. d) Relatively thin fibrotic stenosis. e) Concerns over effects of general anaesthesia. f) Able to make patient phonate with no primary intention of decannulation.

Cryotherapy was first used on an endobronchial tumor in 1968 by Gage, who used a rigid applicator known as a cryoprobe. The use of cryotherapy became more widespread with the advent of the flexible cryoprobe in 1994 [9]. International guidelines in interventional pulmonology and American college of chest physicians acknowledged the use of cryotherapy in treating intrinsic airway lesions [10].

Cryotherapy is the insertion of cryoprobe through the working channel of the bronchoscope for the application of extremely low temperature and create a freeze thaw effect on tissues. It is based on the Joule-Thomson physical principle whereby a liquefied gas under pressure that exits through a small orifice undergoes rapid conversion and expansion to the gaseous form. This liquid-gas conversion is accompanied by a dramatic temperature drop that is captured in the cryoprobe tip. Tissue damage occurs when the cryoprobe is brought into contact with the target tissue. When using the cryoadhesion technique, the frozen probe tip is abruptly pulled away from adherent tissue during the rapid freezing phase. The goal is tissue removal, rather than tissue injury and cell death [11]. Most authors have used cryoadhesion technique for the removal of tissue only through a rigid bronchoscope under complete sedation. We did our procedure with a flexible bronchoscope, under conscious sedation with dexmedetomidine. Various authors have used dexmedetomidine for anaesthesia during bronchoscopy. They have reported excellent results with good patient tolerance of the procedure and improved patient comfort [12]. Our patient also tolerated the procedure and had a good post procedure recovery.

It is important to note that the cryosensitivity of a tissue depends on its intracellular water content and vascularity. Fat, cartilage, nerve sheath, connective tissue, and fibrosis are known to be cryoresistant, whereas tumor, granulation tissue, skin, mucous membranes, nerves, and endothelium are cryosensitive [13].

Cryotherapy has been used for multiple indications like malignant and benign central airway obstruction, foreign body removal or cryoextraction, endobronchial biopsy, and transbronchial biopsy. The advantages being: a) there is selective tissue destruction, Cryotherapy is less likely to affect the cartilage, collagen, or fat tissues in the airway; thus, the risk of perforation/ damage to airway is low. b) Chances of hemorrhage are low. c) Unlike laser which is generally used with rigid bronchoscope, cryotherapy can be used with flexible bronchoscope. e) There is no risk of airway fire when concurrently used with high oxygen (Fio2 $>0.4$ ) as compared to other modalities like electrocautery. f) It is comparatively inexpensive g) relatively simple to perform [11][14].

However no technology is without its set of complications. Commonly noted complications or drawbacks are a) Bleeding [15]. b) Inability to use in treating critical or emergent central airway obstruction, as there is increased inflammation after the procedure. Follow up bronchoscopy is required to clear necrotic tissue left behind [9]. c) Rapidly expanding cryogen leading to barotrauma and hypoxemia [14].

\section{Conclusion:}

Cryotherapy is an important tool that can be 
safely used with fibre optic bronchoscope to treat variety of conditions pertaining to central airway.We report successful use of cryotherapy in managing suprastomal granulation tissue caused by prolonged tracheostomy. Bronchoscopicelectrocautery followed by cryotherapy was performed in our patient under sedation with dexmedetomidine with favourable outcomes. Our experience suggests that a multimodality approach should be used for the management of granulation tissue and the same principle can be used effectively in the management of other malignant and nonmalignant central airway lesions.

Conflict of Interest: The authors declare that they have no conflict of interests.

\section{Declaration of Interest statement: None}

Funding Information: This work received no external funding

Informed Consent: Written informed consent was obtained from participant included in the study.

\section{References:}

1. Dalar L, Karasulu L, Abul Y, Özdemir C, Sökücü SN, Tarhan M, Altin S. Bronchoscopic treatment in the management of benign tracheal stenosis: choices for simple and complex tracheal stenosis. The Annals of thoracic surgery. 2016 Apr 1;101(4):1310-7.

2. Lorenz RR. Adult laryngotracheal stenosis: etiology and surgical management. Current opinion in otolaryngology \& head and neck surgery. $2003 \mathrm{Dec} 1 ; 11(6): 467-72$.

3. Zias N, Chroneou A, Tabba MK, Gonzalez AV, Gray AW, Lamb CR, Riker DR, Beamis
JF. Post tracheostomy and post intubation tracheal stenosis: report of 31 cases and review of the literature. BMC pulmonary medicine. 2008 Dec;8(1):18.

4. Grillo HC, Donahue DM, Mathisen DJ, Wain JC, Wright CD. Postintubation tracheal stenosis: treatment and results. The Journal of thoracic and cardiovascular surgery. 1995 Mar 1;109(3):486-93.

5. Monnier P (2010) Acquired Postintubation and tracheostomy related stenosis. In: Monnier P (ed) Pediatric airway surgery: management of laryngotracheal stenosis in infants and children. Springer Science \& Business Media, pp 183-198

6. Spittle N, McCluskey A. Tracheal stenosis after intubation. Bmj. 2000 Oct 21;321(7267):1000-2.

7. Majid A, Guerrero J, Gangadharan S, Feller-Kopman D, Boiselle P, DeCamp M, Ashiku S, Michaud G, Herth F, Ernst A. Tracheobronchoplasty for severe tracheobronchomalacia: a prospective outcome analysis. Chest. 2008 Oct 1;134(4):801-7.

8. Brigger MT, Boseley ME. Management of tracheal stenosis. Current opinion in otolaryngology \& head and neck surgery.2012 Dec 1;20(6):491-6.

9. Mathur PN, Wolf KM, Busk MF, BrieteWM, D a $\mathrm{t} \mathrm{z} \mathrm{m}$ a $\mathrm{n}$ $M$. Fiberopticbronchoscopiccryotherapy in the management of tracheobronchial obstruction. Chest. 1996 Sep 1;110(3):718-23.

10. Ernst A, Silvestri GA, Johnstone D. Interventional pulmonary procedures: guidelines from the American College of 
Chest Physicians. Chest. 2003 May 1;123(5):1693-4.

11. DiBardino DM, Lanfranco AR, Haas AR. Bronchoscopiccryotherapy. Clinical applications of the cryoprobe, cryospray, and cryoadhesion. Annals of the American Thoracic Society. 2016 Aug;13(8):1405-15.

12. Lekatsas G, Lambiri I, Prinianakis G, Michelakis S, Tzanakis N, Pitsidianakis G, Georgopoulos D. The use of dexmedetomidine as a sedative during flexible bronchoscopy. European Respiratory Journal. 2016Sep 48: PA764

13. Mazur $P$. The role of intracellular freezing in the death of cells cooled at supraoptimal rates. Cryobiology. 1977 Jun 1;14(3):251-72.

14. Inaty $H$, Folch $E$, Berger R, FernandezBussy S, Chatterji S, Alape D, Majid A. Unimodality and multimodality cryodebridement for airway obstruction. A single-center experience with safety and efficacy. Annals of the American Thoracic Society. 2016 Jun;13(6):856-61.

15. Hetzel M, Hetzel J, Schumann C, Marx N, Babiak A. Cryorecanalization: a new approach for the immediate management of acute airway obstruction. The Journal of Thoracic and Cardiovascular Surgery. 2004 May 1;127(5):1427-31.

Authors' contribution: Vikas Marwah: Conceptualisation, Methodology, Vikas Gupta: Supervision, Writing -Review \& Editing, Vikas Sharma: Data curation, Deepu Peter: Writing -Original draft, Deepak Shukla: Data curation

*Corresponding Author:
Name:Vikas Gupta

Associate Prof, Dept of ORL-HNS, Command Hospital (Central Command), Lucknow,

Telephone: +9177108899590

E-mail:vg.enthns@gmail.com

ORCIDID:https://orcid.org/0000-0002-

1739-3993 


\title{
UNUSUAL CASE OF RETROPHARYNGEAL HEMATOMA WITH USE OF ORAL ANTICOAGULANT THERAPY - CASE REPORT AND REVIEW OF LITERATURE
}

\author{
Authors: Srujan Vallur ${ }^{1}$, Vikas Gupta ${ }^{2}$, Abhijit Basu $^{3}$, Kiran Upadhyay ${ }^{4}$, Ritika Bhatia $^{5}$, Madhav N ${ }^{6}$
}

\section{Authors Affiliations:}

(1) Dept of ORL-HNS, 12 Airforce Hospital, Gorakhpur, (2) Associate Prof, (3) Assistant (4) Assistant Prof, (5) Senior Resident, (6) Resident, Dept of ORL-HNS, Command Hospital, Lucknow.

\begin{abstract}
Retropharyngeal space is a rare site of spontaneous haemorrhage and the formation of a hematoma in this location is a rarer complication of therapy with anticoagulants. Airway compromise can occur in rapidly increasing retropharyngeal hematoma. Emergent airway stabilisation is the key to a successful management of such cases, apart from reversal of causative factor.

We report a case of spontaneous retropharyngeal hematoma in an elderly female on anticoagulant therapy for Rheumatic heart disease, and has developed rapidly progressive swelling in neck post bout of violent cough. She was successfully managed with emergent airway access and reversal of causative factors.
\end{abstract}

Keywords: Retropharyngeal hematoma, Retropharyngeal space, Anticoagulant therapy

\section{Introduction}

The retropharyngeal space (RS) contains lymph nodes and is bounded anteriorly by the middle layer of deep cervical fascia and posteriorly by the alar fascial component of the deep layer of deep cervical fascia. It extends cranio-caudally from the skull base to the tracheal bifurcation. A midline raphe is formed by the attachment of the superior constrictor muscles to the alar fascia [1].

Retropharyngeal hematoma $(\mathrm{RH})$ is uncommon but potentially life threatening condition usually caused in adults by penetrating trauma through the posterior mucosal wall of the pharynx or cervical oesophagus. This rare entity may also occur as a result of different causes, including cervical spine trauma[2], intrathyroid bleeding[3], rheumatoid arthritis [4], EpsteinBarr virus infection [5], surgery [6], great vessel trauma, violent head movements, internal jugular vein puncture, parathyroid adenoma haemorrhage, and foreign body ingestion[7]. It may also occur spontaneously in patients with bleeding diatheses and in patients who are taking anticoagulation therapy[8]. Retropharyngeal hematoma is a significant cause of airway compromise and the most appropriate treatment from among the available options are, intubation, tracheotomy, and conservativewait and watch approach or surgical intervention by external drainage after securing airway [9][10][11]

We report a case of retropharyngeal hematoma that occurred spontaneously in a patient with a rheumatic heart disease with mitral stenosis who was taking anticoagulation therapy. We also review the literature on retropharyngeal hematoma.

\section{Case report}

60 years old lady, presented to emergency department of a peripheral hospital, with history of swelling over a neck of one day duration along with mild odynophagia. There was no history of fever, prior pain or swelling 
over neck. On going through her old medical documents she was found to be a known case of Rheumatic heart disease with mitral stenosis on systemic anticoagulant therapy (tab Warfarin) apart of medication for systemic illness. She denied any obvious history of sustaining trauma to neck. There was no history ingesting non vegetarian food, which could cause trauma to posterior pharyngeal wall due to bony spicule. She only gave h/o dry cough in bouts. At this juncture $\mathrm{RH}$ due to possibility of spontaneous intrathyroidal bleed as a result of bout of violent cough as an inciting factor was considered.

On examination, there was diffuse swelling over neck, anteriorly as well as laterally with slight predominance towards left (Fig 1). There was no stridor or noisy breathing. Her vital were within normal physiological limits, she was maintain $\mathrm{SPO}_{2}$ on room air.

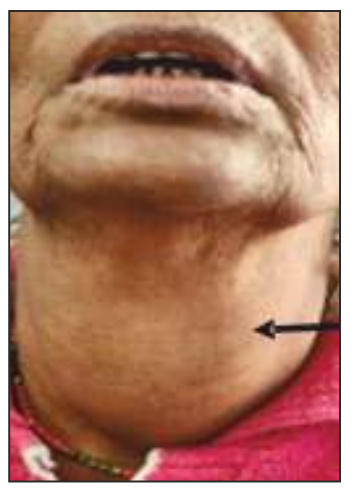

Fig 1: Diffuse swelling over neck, predominantly on left (arrow)

An urgent fibreoptic laryngoscopy (FOL) revealed ecchymosis and swelling in endolarynx involving posterior pharyngeal wall, aryetenoids, however bilateral vocal cords were mobile and glottis chink was adequate (Fig 2). An urgent complete blood counts with INR was done. INR was grossly deranged with a value of 10.1 .

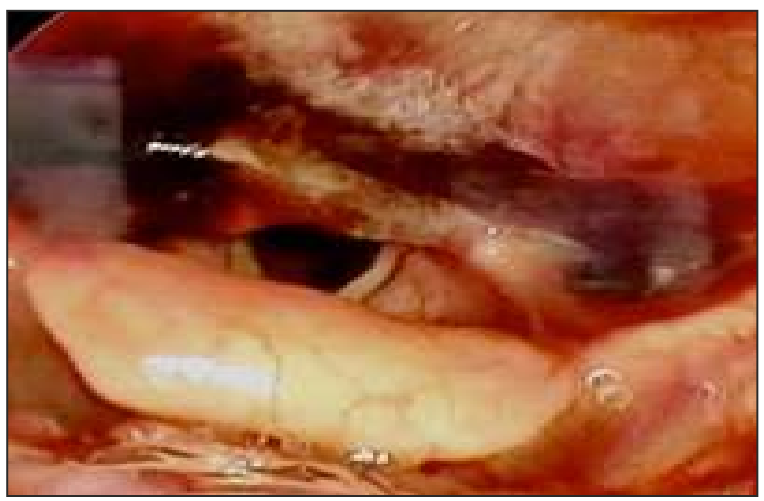

Fig 2: Submucosal ecchymosis and swelling involving posterior pharyngeal wall (arrow)Urgent USG neck followed by urgent CECT revealed collection in $\mathrm{RS}$ along with extension into parapharyngeal space, measuring $5 \times 2 \times 4 \mathrm{~cm}$ extending from skull base superiorly to level of glottis inferiorly (Fig 3). It was $14.4 \mathrm{~mm}$ at C2 vertebra level, $19.8 \mathrm{~mm}$ at C3,C4 level and $16.5 \mathrm{~mm}$ at C7 level. There was no collection inside thyroid capsule (Fig 3 There were no findings suggestive intracranial bleed, gastro-intestinal bleed, spontaneous mucosal bleed, haematuria or haemarthrosis.

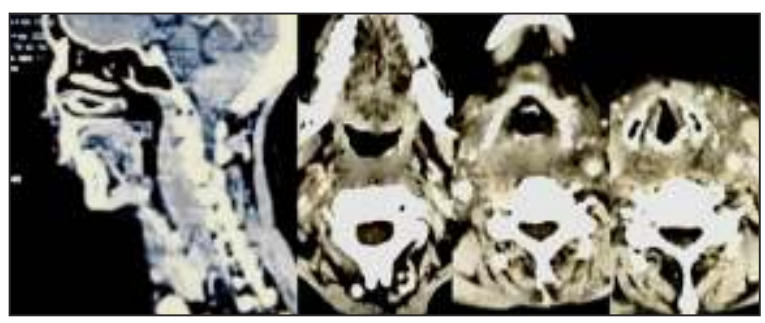

Fig 3: CECT- sagittal and axial view, showing collection in retropharyngeal space at different levels

In view of swelling extending to anterior neck, and adequate glottis chink on FOL, an urgent consultation with Intensivist was done, and it was decided to electively intubate her, to secure the airway. An informed written consent from patient and next of kin was taken. Apart of this local ice packs were applied, along with prophylactic broad spectrum antibiotics. She was also given Vit $\mathrm{K} 10 \mathrm{mg} / \mathrm{ml} \mathrm{IV}$ was administered daily. Fresh frozen plasma transfusion was also performed along with cessation of tab warfarin.She was later transferred to a tertiary care centre.

On arrival to our centre, patient was stable, on ETT with T-piece and room air. The swelling has reduced. Her INR has reduced to 3 . A conservative approach was decided. A repeat MRI was done to assess for present status of RH. Repeat MRI on $4^{\text {th }}$ post intubation day, revealed significant resolution of $\mathrm{RH}$ (Fig 4), with maximum thickness of $\mathrm{RS}$ of $6 \mathrm{~mm}$ at $\mathrm{C} 2,7.1 \mathrm{~mm}$ at C3, C4 level and 6.3mm at C7 level. 


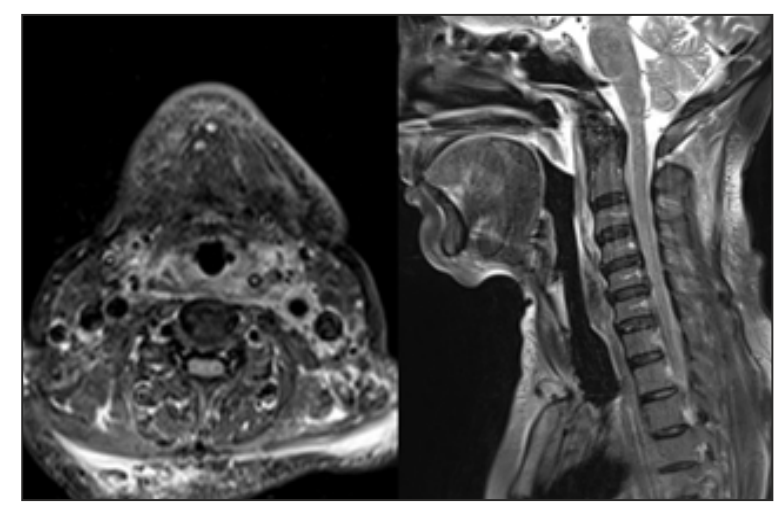

Fig 4: T2w images on MRI showing resolution of retropharyngeal collection.

Repeat FOL also revealed marked regression in swelling over posterior pharyngeal wall. Later her INR returned to normal limits. She was extubated successfully on $5^{\text {th }}$ post intubation day. She maintained $\mathrm{SPO}_{2}$ on room air. Cardiologist opinion was also taken for her systemic disease and re initiation of anticoagulants. On followup at 02 months, patient is asymptomatic.

\section{Discussion}

The retropharyngeal space is the area ofloose connective tissue that lies between the middle (buccopharyngeal) and the alar layers of the deep cervical fascia [12][13]. It extends from the base of the skull to the place where thetwo layers fuse at a variable level between the $\mathrm{C} 7$ and T4 vertebrae[13]. As a result, bleeding into the retropharyngeal space can extend from the skull base to the mediastinum. In addition, because the pretracheal, parapharyngeal, and retropharyngeal spaces are in communication with each other, a hematoma or an infection in one of these spaces can easily spread to the others.

Anticoagulation is routinely used to prevent thromboembolism in patients with atrial fibrillation and patients who undergo some cardiac surgical procedures, such as mechanical valve replacement. The agent most commonly used for this purpose is warfarin. Warfarin inhibits the vitamin-K-dependent enzymes needed for activation of coagulation factors II, VII, IX, and X. The half-life of warfarin is 35 hours, and its anticoagulant effect lasts 3 to 5 days [12]. Bleeding, the major complication of anticoagulation therapy can occur spontaneously or after a trivial trauma[8]. An elevated INR $(>4.5)$ is associated with a higher risk of bleeding [8]. Over anticoagulation can occur as a result of intercurrent medical conditions or interactions with some medications.

Retropharyngeal hematomas exhibit similar manifestations, including superior mediastinal obstruction (tracheal and oesophageal compression), ventral tracheal displacement on lateral cervical x-rays, and the subsequent appearance of subcutaneous bruising over the anterior neck and upper chest wall [5] [7]. However, because the clinical picture is often obscure at the outset, a high level ofsuspicion is essential for a diagnosis of retropharyngeal hematoma.

Stabilization of the patient's airway is paramount given the risk of rapid expansion of hematoma into the loose connective tissue lying between the pharynx and alar layer of the prevertebral fascia which can dramatically compromise the airway. A careful immediate intubation with either direct laryngoscopy or fiberoptic intubation can be performed with all efforts made to minimize airway trauma given the theoretical concern of hematoma rupture.Emergent tracheostomy can be considered as an alternative but generally not performed as long as patient can be intubated. Tracheostomy is also fraught with fear due to distorted anatomy as hematoma extends anterolaterally.Occasionally, if the swelling is not does not pose immediate threat to airway, patient may be carefully observed without airway access [3][14][15].

Irrespective of which decision is made, it should be made quickly because a delay in the initiation 
of airway management can increase the difficulty of intubation or tracheotomy and thereby magnify the chances of a poor outcome, including death.

Once airway is stabilized, attention can be turned to hematoma control. In most cases, observation and supportive treatment are adequate and suitable. Surgical exploration and evacuation of the hematoma are usually recommended forcases of expansile hematoma [7][8] [14][17]

There is no consensus on the management of a compromised airway caused by a retropharyngeal hematoma. On the basis of our experience, and literature review, we suggest that a small nonexpanding hematoma, not compromising the airway can be managed conservatively. Securing the airway with intubation or tracheotomy should be reserved for patients who are in serious respiratory distress; the choice between intubation and tracheotomy should be made on case to case basis.

Cross sectional imaging (computed tomography or magnetic resonant imaging with or without contrast) plays a vital role in initial as well as follow up of such patients. A deliberate decision to keep the patient on conservative management or surgical intervention can be taken depending upon imaging findings. In the adult, the average width of the retropharyngeal soft tissue at the level of $\mathrm{C} 2$ is $3.5 . \mathrm{mm}$ and at C6 is $14 . \mathrm{mm}$. Any increase in the width of the soft tissue shadow is suggestive of pathology in the retropharyngeal space. [3]

Penning reported that normal prevertebral soft tissue widths were $4.6 \mathrm{~mm}, 3.2 \mathrm{~mm}, 3.4 \mathrm{~mm}$, and $5.1 \mathrm{~mm}$ at $\mathrm{C} 1, \mathrm{C} 2, \mathrm{C} 3$, and $\mathrm{C} 4$ level in the neutral position, and $14.9 \mathrm{~mm}, 15.1 \mathrm{~mm}, 13.9 \mathrm{~mm}$ at C5, C6, and C7 level in neutral position [19].Rojas et al reported that the upper limits of normal range for thickness of prevertebral soft tissue were 8.5 $\mathrm{mm}, 6 \mathrm{~mm}, 7 \mathrm{~mm}, 18 \mathrm{~mm}$, and $18 \mathrm{~mm}$ at C1, C2, C3, C6, and C7, respectively. The upper limit of normal range was not determined for $\mathrm{C} 4$ and $\mathrm{C} 5$ levels due to variable position of the esophagus and larynx. Furthermore, they reported that mean prevertebral soft tissue thickness were 7 $\mathrm{mm}$ at $\mathrm{C} 4$ and $12.4 \mathrm{~mm}$ at $\mathrm{C} 5$ on multi-detector CT images [19].

Muñoz et al [20] reported that in spontaneously developed hematoma, nearly complete absorption was observed after 1 week.In our case, symptoms gradually alleviated and patient's general condition improved. She was later discharged after 1 week and advised to follow up regularly. Patient has thereafter been asymptomatic on follow up at 2 months.

\section{Conclusion}

Retropharyngeal hematomas due to anticoagulant therapy, are rare yet potentially life threatening emergency due the proximity to the upper airway. A high index of suspicion for $\mathrm{RH}$ should be kept in mind in patients presenting with rapidly progressive neck swelling on anticoagulant therapy even without obvious history of inciting factor. An expeditious management of airway is of paramount importance. Conservative or surgical evacuation of hematoma will depend on close monitoring of hematoma.

\section{Conflict of Interests}

We have no conflict of interests to declare.

\section{Consent}

A written informed consent has been taken from the patient for publication of pictures in medical journal.

\section{References}

1. Moore KL, Dalley AF, Agur AM. Clinically oriented anatomy. Lippincott Williams \&Wilkins; 2013 Feb 13. 
2. El Kettani C, Badaoui R, Lesoin FX, Le Gars D, Ossart M. Traumatic retropharyngeal hematoma necessitating emergency intubation. Anesthesiology: The Journal of the American Society of Anesthesiologists. 2002 Dec 1;97(6):1645-6.

3. Paleri V, Maroju RS, Ali MS, Ruckley RW. Spontaneous retro-and parapharyngeal haematoma caused by intrathyroid bleed. The Journal of Laryngology \& Otology.2002 Oct;116(10):854-8.

4. Thatcher J, George D. Retropharyngeal hematoma as a new cause of acute upper airway obstruction in rheumatoid arthritis. The Journal of rheumatology. 1987 Dec;14(6):1172-3.

5. Jones TM, Owen GO, Morar P. Spontaneous retropharyngeal haematoma attributable to Epstein-Barr virus infection. The Journal of Laryngology \& Otology. 1996 Nov;110(11):1075-7.

6. Daniello NJ, Goldstein SI. Retropharyngeal hematoma secondary to minor blunt head and neck trauma. Ear, nose \& throat journal. 1994 Jan;73(1):41-3.

7. Bloom DC, Haegen T, Keefe MA. Anticoagulation and spontaneous retropharyngeal hematoma. The Journal of emergency medicine. 2003 May 1;24(4):389-94.

8. Bapat VN, Brown K, Nakas A, Shabbo F. Retropharyngeal hematoma-a rare complication of anticoagulant therapy. European journal of cardio-thoracic surgery. 2002 Jan 1;21(1):117-8.

9. Baldassari CM, Howell R, Amorn M, Budacki R, Choi S, Pena M.
Complications in pediatric deep neck space abscesses. Otolaryngology--Head and Neck Surgery. 2011 Apr;144(4):5925.

10. Elsherif AM, Park AH, Alder SC, Smith ME, Muntz HR, Grimmer F. Indicators of a more complicated clinical course for pediatric patients with retropharyngeal abscess. International journal of pediatric otorhinolaryngology. 2010 Feb 1;74(2):198-201.

11. Park JH, Jeong EK, Kang DH, Jeon SR. Surgical treatment of a life-threatening large retropharyngeal hematoma after minor trauma: two case reports and a literature review. Journal of Korean Neurosurgical Society. 2015 Sep;58(3):304.

12. Sinert R, Scalea T. Retropharyngeal and bowel hematomas in an anticoagulated patient. Academic Emergency Medicine. 1994 Jan;1(1):67-72.

13. Al-Fallouji HK, Snow DG, Kuo MJ, Johnson PJ. Spontaneous retropharyngeal haematoma: two cases and a review of the literature. The Journal of Laryngology \& Otology. 1993 Jul;107(7):649-50.

14. Tsai KJ, Huang YC. Traumatic retropharyngeal hematoma: case report. Journal of Trauma and Acute Care Surgery. 1999 Apr 1;46(4):715-6.

15. Hefer T, Netzer A, Joachims HZ, Golz A. Upper airway obstruction--a rare complication after anti-coagulant therapy. Harefuah. 1993 Mar;124(6):3368.

16. Rosenbaum L, Thurman P, Krantz SB. Upper airway obstruction as a complication of oral anticoagulation therapy: report of three cases. Archives 
of Internal Medicine. 1979 Oct 1;139(10):1151-3.

17. Cohen AF, Warman SP. Upper airway obstruction secondary to warfarininduced sublingual hematoma. Archives of Otolaryngology-Head \& Neck Surgery. 1989 Jun 1;115(6):718-20.

18. Penning L. Prevertebral hematoma in cervical spine injury: incidence and etiologic significance. American Journal of Roentgenology. $1981 \mathrm{Mar}$ 1;136(3):553-61.

19. Rojas CA, Vermess D, Bertozzi JC, Whitlow J, Guidi C, Martinez CR. Normal thickness and appearance of the prevertebral soft tissues on multidetector CT. American Journal of Neuroradiology. 2009 Jan 1;30(1):13641.

20. Muñoz A, Fischbein NJ, de Vergas J, Crespo J, Alvarez-Vincent J. Spontaneous retropharyngeal hematoma: diagnosis by MR imaging. American journal of neuroradiology. 2001 Jun 1;22(6):1209-11.

\section{Source of support: NIL}

\section{Authors' contribution}

SVM and $A B$ prepared the manuscript. KU and RB did review of literature. NM involved in day to day care of patient. VG did supervision and editing of the final draft and is the consultant in charge of the patient.

\section{*Corresponding Author:}

Name: Vikas Gupta

Associate Professor, Dept of ORL-HNS,

Command Hospital, Lucknow

Telephone: 77108899590, E-mail:

vg.enthns@gmail.com ORCID: Vikas Gupta:

https://orcid.org/0000-0002-1739-3993 


\title{
SUPRASELLAR PITUITARY TUMOUR: UNEXPECTED SURGICAL OUTCOME AND LEARNING LESSONS
}

\author{
AUTHORS: Rajan Bhargava* (1) Mohit Kacker (2) Anjali Tiwari (3) Deepti Gupta (4) \\ AUTHORS AFFILIATIONS: (1) Consultant Otolaryngologist (2) Consultant Neurosurgeon (3) \\ Consultant Pathologist (4) Consultant Pathologist: Regency Hospital, Kanpur
}

\begin{abstract}
Suprasellar pituitary tumors are commonly operated by Endonasal Endoscopic Approach (EES) with very acceptable morbidity and complication rate. Occasionally tumor morphology or unexpected surgical trauma can lead to worse outcomes. We present a case of pituitary tumor with a large suprasellar cystic component invading the third ventricle who succumbed after an uneventful surgery. The possible reasons and learning thereof is being discussed in this report.
\end{abstract}

Keywords : Suprasellar tumors, EES, Complications

\section{INTRODUCTION}

EES approach to pituitary and anterior skull base lesions is a well established surgical technique. It was initially reported by Jankowski et al(1) more than twenty years ago. This was later popularized by many others including Sethi (2), Carrau et al(3).Extended approaches to suprasellar region were a natural advancement with the similar endonasal surgical corridor Cappabianca et al(4).

We report a case of a 32 year old male with a small enhancing sellar lesion and a large cystic surasellar component with ensuing hydrocephalus. He had clinical presentation of altered consciousness, left sided limb weakness and bilateral visual loss. He had also undergone a right ventriculoperitoneal (VP) shunt elsewhere which was nonfunctional. An uneventful endoscopic endonasal decompression of tumour and saucerisation of cyst with revision VP shunt on right side was done. Patient showed a good response initially followed by a stormy postoperative course with multiple complications resulting in his death after two weeks. The possible reasons for such a cascade of events are discussed with possible remedial measures.

\section{CASE REPORT}

A 32 year old man presented to us with holocranial headache, left sided limb weakness and bilateral visual loss with left being worse as compared to right. He had consulted many other specialists and had undergone right VP shunt elsewhere which was malpositioned and hence was nonfunctional. His examination revealed that he was arousable but sleepy with a power grade IV on left side. His pupils were semidilated and vision clinically was finger counting on right side at one meter and just finger perception on left side. In view of his clinical condition a decision to operate on him was taken on an urgent basis after getting appropriate workup and radiology. A CECT/MRI revealed small enhancing solid(sellar) and large cystic suprasellar lesion with obstructive hydrocephalus suggestive of a either a cystic solid craniopharyngioma or a pituitary tumour with a suprasellar cyst Fig(1\&2).

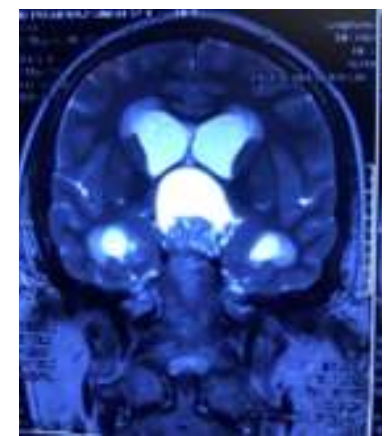

Figure 1

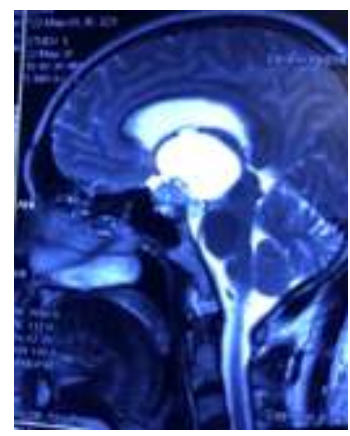

Figure 2 
A post shunt $C T$ showed malpositioned catheter which was nonfunctioning as mentioned earlier.Patient underwent removal of old VP shunt and placement of new Chabra shunt on the right side via same incision. This was done since ventricular end was short and valve of the shunt was blocked with blood clot and brain matter. At the same time, patient underwent endoscopic endonasal transsphenoidal tumour decompression. Thesolid, sellar portion of tumour was curetted which was brown,firm and non suckable. Thereafter, thin suprasellar cyst wall was saucerised and floor of third ventricle visualised.Repair of sellar floor was done with fat, fascia lata,Hadad flap and fibrin glue.

The patient did well in the initial postop phase with improved consciousness but with slightly increased urine output.Overnight, patient became very sleepy with increasing urine outputof $2700 \mathrm{ml}$ in 10 hours and a postop CT was advised.This revealed air and fluid in the area of suprasellar cyst, a well functioning right shunt and persistent hydrocephalus in the left ventricular system. It was decided to do a left VP shunt despite worsening of patient's symptoms who developed deterioration in sensorium, hyperpyrexia(105F)and severe tachycardia.A left VP shunt was done but no improvement in symptoms was seen with worsening sensorium and increasing urine output neccesasitating desmopressin administration .The patient could not tolerate extubation and had a generalised tonic clonic seizureand had to be reventilated.He never regained consciousness and had to be tracheostomized for ventilatory support but unfortunately died two weeks later due to chest sepsis.The histopathology of the tumour was pituitary adenoma which was surprising as radiological features pointed a diagnosis towards craniopharyngioma.The histopathology revealed a richly vascular tumour composed of moderately pleomorphic cells disposed in papillae, sheets, pseudorosettes and pseudoglandular pattern.Tumour cells had round to oval nucleus ,coarsely granular chromatin, occasional prominent nucleoli and moderate amount of eosinophilic granular cytoplasm. Areas of haemorrhage and cystic change were seen.On IHC tumour showed strong positivity for synaptophysin and PCK whereas EMA, LCA, prolactin, GH and GFAP were negative. $\mathrm{KI} 67$ showed low proliferative index less than $1 \%$. Hence the diagnosis of pituitary adenoma was made.
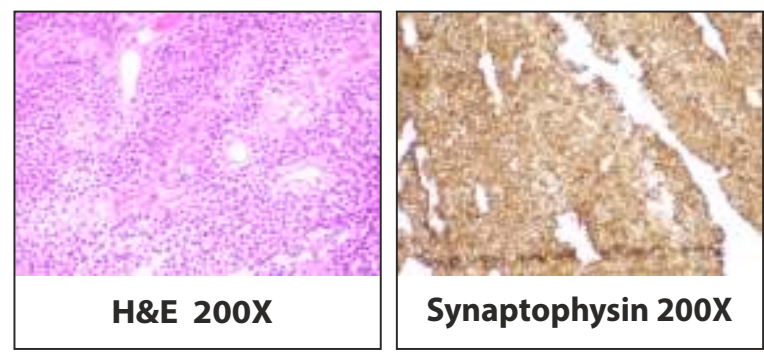

\section{DISCUSSION}

EES for lesions of pituitary and anterior skull base is an established surgical practice all over the world with an acceptable morbidity and mortality rate. A mortality rate of less than $1 \%$ has been the norm in most studies,Cappabianca et al (5).The complications arising out of such surgeries have been anatomically classified b e i n g $\mathrm{n}$ a s of a c i a l, sphenoidal,sellar,suprasellar,parasellar and endocrine, Cappabianca et al (5).The outcomes are dependent on both surgeon's hands and specific tumour features.A learning curve is definitely present in the overall outcome, Soliman et al(6). Our patient with a small sellar component and a large suprasellar cyst with invasion of third ventricle behaved more like a craniopharyngioma. With more than 100 such cases operated by our centre we felt fully equipped to take on this surgery.The surgical goals appeared to be accomplished with reasonable tumour decompression, uncapping of cyst and revision of shunt. His stormy postoperative phase with an initial recovery was 
a surprise to us.We are sharing our thoughts after doing a retrospective analysis in the course of the patient as a learning exercise.

Endoscopic decapping of large suprasellar cyst would inevitably lead to the entry of air and blood in the dead space in postoperative phase. This could have resulted in pressure on bilateral foramen of Monroe and persistent hydrocephalus. Hence we could have been safer in shunting both sides rather than believing that tumour decompression alone would suffice to improve hydrocephalus.The left sided shunt done as an after thought did not help because patient had deteriorated considerably by that time.Surprisingly literature is fairly silent on this.

Secondly our patient developed generalised tonic clonic seizures with reasonable biochemical parameters. Although EES is minimally invasive but where surgical manipulation is more than usual a prophylactic anticonvulsant can be considered.

Thirdly hyperpyrexia raises the possibility of acute hypothalamic injury during surgery especially in the manipulation of surasellar component.Literature deals with hypothalamic injury more in relation to craniopharyngioma rather than pituitary surgery as such. The situation in our patient was more like a craniopharyngioma rather than a classical pituitary tumour as interpreted from radiology.Tumour origin site along the pituitaryhypothalamic axis, invasion of third ventricleare a major determinant of hypothalamic injury and poor outcome with surgical mortality upto $21.5 \%$, Prieto et al (7). The shape of the suprasellar lesion and distortion of pituitary stalk on MRI were other pointers towards a likely hypothalamic injury during surgery, Prieto et al (7).

Finally a case has to made for prolonged ventilation if required although it raises the cost of care.In a study by Rock et al(8) unfavourable events such as prolonged ventilation were underreported.

Such lesions not only require meticulous surgical dissection but also an in depth understanding of complex anatomy and attendant risk factors which may hamper a good postoperative result.A case is also to be made of fairly exacting postoperative care to improve results.

\section{CONCLUSION}

EES although is an established surgical method for anterior skull base lesions but complications related are also not unknown. They are usually very safe but an occasional mortality can dampen the enthusiasm of the oprative team. Learning curve,tumour morphology,extent of resection, unfavourable anatomy, and postoperative care play a role in overall surgical outcome.

\section{BIBLIOGRAPHY}

(1) Jankowski R,Auque J,Simon C,Marchal JC,Nepner H,WayoffM, Endoscopic Pituitary tumour Surgery.Laryngoscope 1992;102(2):198-202

(2) Sethi DS,Prem K. Pillay, Endoscopic Pituitary Surgery-, a minimally invasive technique.Am J Rhinol 1996;10(3):141147

(3) Carrau RL,Jho ND, Koy, Transnasal -transsphenoidal endoscopic suegery of the pituitary gland. Laryngoscope1996;106(7):914-918

(4) Cappabianca P, Frank G,Pasquini E,et al . Extended endonasal trans-sphenoidal approaches to the suprasellar region, planum sphenoidale and clivus. In de Divitiis E, Cappabianca P, eds. Endoscopic Endonasal Transsphenoidal Surgery. Wein :Springer -Verlag;2003 
(5) Cappabianca P,Cavallo LM,De Divitiis E, , Surgical complications associated with the endoscopic endonasal trans sphenoidal approach for pituitary tumours. J. Neurosurg 2002;97:293-298

(6) Soliman MAR, Eaton S, Alkhamees AF et al ,Challenges, Learning Curve,and Safety of Endoscopic Endonasal Surgery of Sellar-Suprasellar Lesions in a Community Hospital World Neurosurgery 2020;138:940-954

(7) Prieto Ruth, Pascual JM, Barrios Laura, Letter to editor,Assessment of Postoperative complications in craniopharyngioma patients:An approach based on the heterogenous tumour-hypothalamus axis. Surgical Neurology International 2020;11(47)1-3

(8) Rock AK, Dincer A, Carr MT, et al Outcomes after craniotomy for resection of craniopharyngiomas in adults :Analysis of the national surgical quality improvement program(NSQID). J Neurooncol 2019;144:117-25

Conflict of interest: We have no conflict of interest to declare.

Source of support: Nil

\section{*Corresponding Author}

Dr Rajan Bhargava

Consultant ENT surgeon

Regency Hospital

Kanpur

Email id -rishabhbha@gmail.com 


\title{
DUPATTA STRANGULATION CAUSING TRACHEAL INJURY AND STENOSIS, A COMMON NORTH INDIAN SCENARIO: A CASE REPORT
}

\author{
Authors: Shahab Ali Usmani (1) Kinjal Shankar Majumdar (2) P. Achyuth (3) S.P. Agarwal (4)
}

Authors Affiliation: $(1,2,3)$ Senior Resident, (4) Professor, Department of Surgical Oncology AllMS, Rishikesh

\section{ABSTRACT:}

Closed tracheal injuries are rare but are more frequent in northern India. Ladies wear Dupatta (A Scarf) around the neck which causes strangulation injury when entangled in the rear wheel of motorcycle or rickshaw. Because of rarity of such cases, it is often difficult for physicians at periphery to diagnose it early adding to the morbidity. We report a12-years old girl who presented to us with severe stridor and grade III tracheal Stenosis following dupatta strangulation while she was riding motorcycle. She was previously treated with T-tube placement in the trachea for 6 months, which was removed a week back. The patient underwent urgent tracheostomy followed by CECT which showed $2 \mathrm{~cm}$ grade III tracheal tenosis below the cricoid cartilage. The patient underwent tracheal resection and anastomosis. The patient recovered well, without any change in voice and restenosis on bronchoscopy in 5 months follow-up.

\section{Key Words:}

\section{INTRODUCTION}

Tracheal injury due to strangulation with dupatta while riding motorcycle is uncommon in other parts of the world but is a common mechanism of injury in northern India where females use dupatta (a long scarf). The females mostly sit with both the legs on one side and dupatta getting stuck in the spokes of rear wheel of the bikes leading to fall and strangulation injury. The Cricotracheal separation of the upper airway following neck trauma is a rarity [1-3].The rarity of this type of injury often leads to a delay in diagnosis which may contribute to airway patency problems, vocal production, and swallowing [4].Presenting symptoms can be nonspecific and a high index of clinical suspicion may be required for early diagnosis and suitable management. We report a case where multiple surgeries were required for strangulation injury with dupatta leading to tracheal disruption and grade III stenosis leading to severe morbidity.

Keywords: tracheal stenosis, strangulation, tracheal injury

\section{CASE PRESENTATION:}

A 12-years-old female was referred to AllMS Rishikesh (A tertiary care center) with complaints of severe respiratory distress. She had a history road traffic accident 6 months ago, while riding on motorcycle and her dupatta got caught into the rear wheel of the motorcycle strangulating her neck. She immediately had respiratory distress and was rushed to a local hospital in her village. She was treated there for a week for local abrasions on neck and respiratory distress and when the condition did not improve, she referred to another center in the city. There she was evaluated, and urgent tracheostomy was done. The neck soft tissue injuries along with the tracheal injury and disjunction were reported. After stabilizing the patient, a Montgomery T-tube was put at the tracheostomy site, bridging the superior and the 
inferior segments. The T- tube was removed after 6 months. She was discharged after 2 days of observation in hospital in stable condition. After 2 weeks she again developed respiratory distress for which she was referred to higher center.

On examination in OPD at AlIMS, Rishikesh, she was having stridor at rest which was increasing on lying down. She was using accessory muscles of respiration, otherwise she was conscious oriented, and her vitals were stable. We immediately did air tracheogram [ figure 1] which showed significant stenosis of the tracheal segment below the cricoid cartilage. We did a urgent tracheostomy in view of respiratory distress. Tracheostomy was done through the stenosed segment to preserve the normal trachea. Post tracheostomy after stabilizing the patient we did a contrast enhanced CECT scan which showed grade 3 tracheal stenosis below the level of the cricoid cartilage of $2 \mathrm{~cm}$ in length and diameter of about $4 \mathrm{~mm}$. The lumen was obliterated and fibrotic [figure 2].

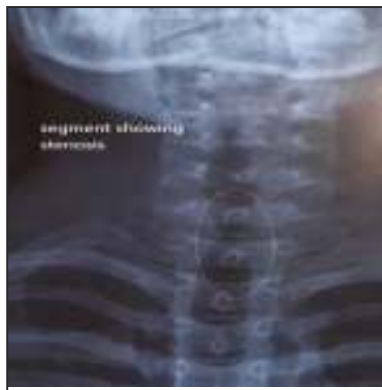

Figure 1

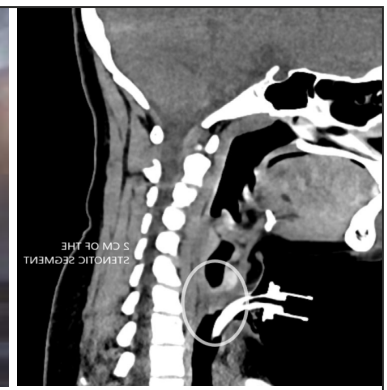

Figure 2
After stabilizing the patient and obtaining all routine investigations, we planned for resection of the stenosed segment and anastomosis.

The patient was anesthetized through the tracheostomy tube which was later changed to endotracheal tube. Laryngoscopy was done which showed a grade III trachea stenosis [figure 3]. On exposure of the trachea through the horizontal neck incision. The thyroid isthmus was cut in the midline and lobes were retracted laterally. We found $2.5 \mathrm{~cm}$ of the stenosed [figure 4].

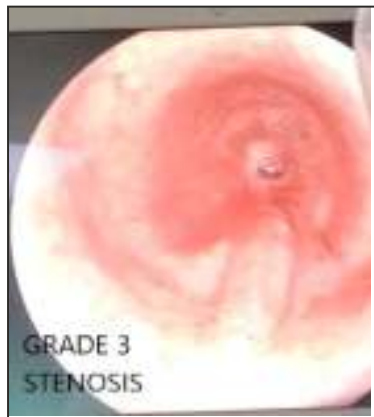

Figure -3

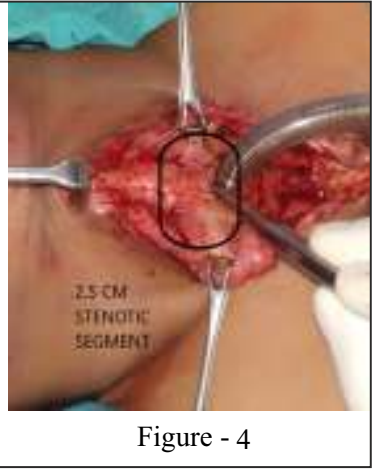

Figure -4
We excised the stenosed tracheal segment layer by layer to get normal segment without fibrosis. After resection, the segment was around $3.0 \mathrm{~cm}$ [figure 5] which was anastomosed primarily without tension with 4-0 PDS sutures using parachuting technique [figure 6].

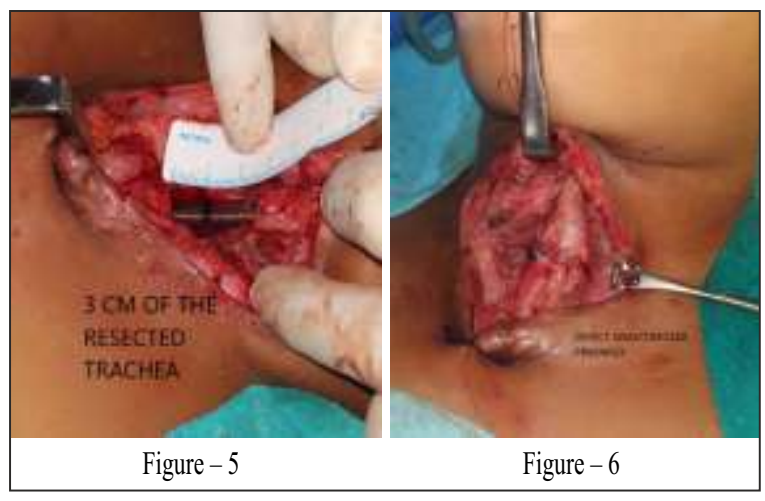

The knots of the anastomotic sutures lie outside of the trachea with $5 \mathrm{~mm}$ distance between each knot. The anastomosis is reinforced with thyroid gland and the strap muscles sutured over the trachea. A grillo suture from mandible to sternum was later applied to prevent extension of neck during post-operative period. The patient was kept in ICU with endotracheal tube, which was removed on post -operative day 1 . Post-operative day 2, laryngoscopy was performed to look for the status of the vocal cord and anastomotic segment. In which the vocal cords appeared mobile and anostosis was stable. The patient was observed in the ward for 3 days before discharge.Post-operative air tracheogram done on 4th post-operative day 


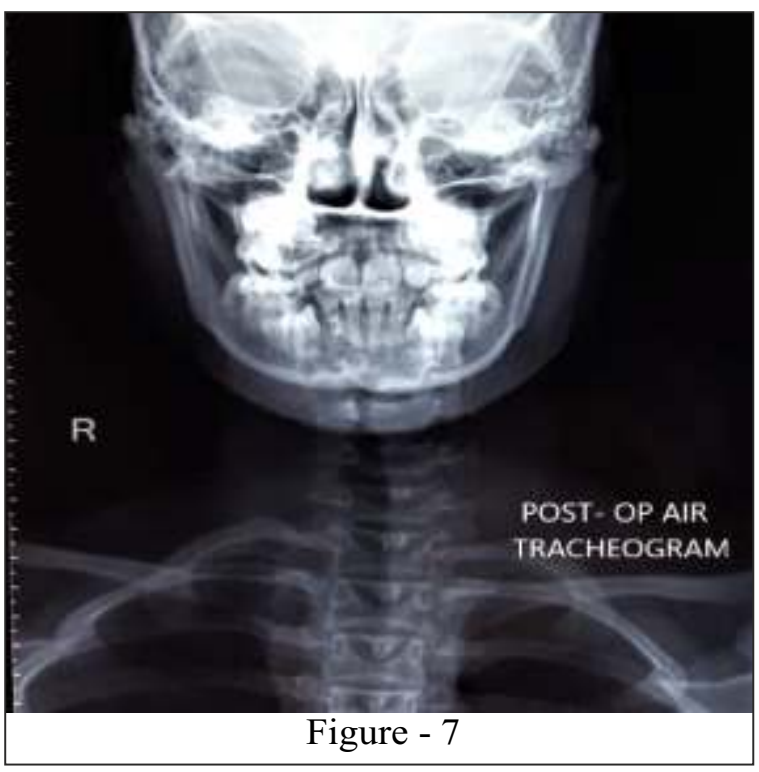

showed normal tracheal lumen [figure 7]. Patient is doing fine on follow up without any major issues 5 months post operatively.

\section{DISCUSSION:}

Closed tracheal injuries are rare but when associated with strangulation should be seen with strong suspicion of airway compromise. The most common symptom of laryngotracheal trauma is hoarseness. Other presenting symptoms can include dysphagia, pain, dyspnea, hemoptysis, and symptoms of airway obstruction such as stridor and tachypnea. Other signs include drooling and cervical subcutaneous emphysema and crepitation [5]. Strangulation injuries can also be associated with tracheal, laryngeal, esophageal injuries. There is a paucity of literature on management of such rare cases. In our case the patient was lucky to have survived both the accidental strangulation and the secondary stenosis. As she came to our hospital with grade III stenosis and just a pin hole opening left in the trachea. Moreover, she did not had any other esophageal, cervical and vascular injuries.

It was only in 1990 that Grillo demonstrated the feasibility of surgical treatment of tracheal stenosis for the first time and later, surgery for any type of tracheal disease requiring resection, including tumors, by resection of a portion of the trachea and its reconstruction by primary anastomosis [6,7].Resection and anastomosis are accepted as the treatment of choice for isolated tracheal stenosis [8]When the glottis is intact, segmental resection with cricotracheal or thyrotracheal anastomosis as a single stage procedure is found to be successful [9]. In our case as the stenosis was dense and $3.5 \mathrm{~cm}$ of the trachea was resected and anastomosed primarily without any tension. In 5 months of follow up there is patient did not have any anastomostic complication apart from local infection which was managed conservatively.

As these injuries are common in our part of the world, there should be public awareness for taking precautions while riding motorcycle and wearing Indian dresses with dupatta and sari. Any case of such strangulation injury should be evaluated for possible airway compromise. Early management and long term follow up should be initiated to reduce morbidity. Tracheal resection although challenging but has good long-term outcome.

\section{REFERENCES:}

[1] Chen F. H. and J. D. Fetzer, "Complete cricotracheal separation and third cervical spinal cord transection following blunt neck trauma: a case report ofone survivor," Journal ofTrauma, vol. 35, no. 1, pp. 140-142, 1993.

[2] Lee WT, Eliashar R, Eliachar I. Acute external laryngotracheal trauma: diagnosis and management. Ear Nose Throat J. 2006;85(3):179-184..

[3] Schaefer, S. D., The acute management of external laryngeal trauma: a 27-year experience. Archives of Otolaryngology, Head and Neck Surgery 118:598-604.

[4] Narci A., D.B.Embleton, A. Ayc, ic ek, F. 
Y"uceda"g, and S. C, etinkurs, un, "Laryngeal fracture due to blunt trauma presenting with pneumothorax and pneumomediastinum," ORL,vol. 73,no. 5, pp.246-248,2011.

[5]Juutilainen M, Vintturi J, Robinson S, Bäck L, Lehtonen $\mathrm{H}$, Mäkitie AA. Laryngeal fractures: Clinical findings and considerations on suboptimal outcome. ActaOtolaryngol 2008;128:213-8. [6] Grillo HC, Mathisen DJ, Wain JC. Management of tumors of the trachea.Oncology (Williston Park). 1992;6:61-7. discussion 68,70,72

[7] Grillo HC, Mathisen DJ. Primary tracheal tumors: treatment and results. Ann Thorac Surg. 1990;49:69-77.

[8]Grillo HC, The management of tracheal stenosis following assisted respiration, J. Thorac. Cardiovasc. Surg. 57 (1969) 52-71

[9] F.G. Pearson, L. Brito-Filomeno, J.D. Cooper, Experience with partial cricoid resection and thyrotracheal anastomosis, Ann. Otol. Rhinol. Laryngol.91 (1986) 322-328.

\section{Corresponding Author:}

Dr. Shahab Ali Usmani, MS (ENT), DNB, MRCS

Senior Resident, Department of Surgical Oncology,

AlIMS, Rishikesh

usmanishahab@hotmail.com 


\title{
INCIDENCE OF ORONASOPHARYNGEAL \& LARYNGEAL TUBERCULOSIS CASES IN PULMONARY TUBERCULOSIS CASES
}

\author{
Authors: Dr. Mohd Aftab (1), Dr. Sachin Jain (2), Dr. Pankaj Kumar Tiwari (3), Dr Ram Manohar Verma \\ (4), Dr. Daya Shanker (5).
}

Authors Affiliations: (1)Associate Professor, (2) Professor and Head, (3) Junior Resident, (4) Junior Resident, (5) Junior Resident, Department of ENT \& Head Neck Surgery, M.L.N. Medical College, Prayagraj, Uttar Pradesh, India.

\section{ABSTRACT}

Background: Tuberculosis is a major global health problem. Tuberculosis may be Pulmonary or Extrapulmonary. Oro-nasopharyngeal and Laryngeal tuberculosis are a form of Extrapulmonary Tuberculosis. Nasopharyngeal tuberculosis presents with neck mass, nasal obstruction, rhinorrhoea, epistaxis, Otalgia, hearing loss and cervical Lymphadenopathy. Common symptom of Laryngeal tuberculosis is hoarseness of voice. This study will increase awareness regarding Oro-nasopharyngeal / Laryngeal tuberculosis and will help in differentiating it from Oro-nasopharyngeal / Laryngeal carcinoma.

Objective: To find the incidence of Oronasopharyngeal and Laryngeal Tuberculosis among patients of PulmonaryTuberculosis.

Method: A total of 80 patients of Pulmonary Tuberculosis were selected and investigated for symptoms of Oro-nasopharyngeal and Laryngeal tuberculosis.

Results: Study revealed that $1.25 \%$ (1 patient out of 80 ) of total study subjects had Nasopharyngeal tuberculosis.

Conclusion: The study showed that the incidence of Oro-nasopharyngeal and Laryngeal tuberculosis among patients of PulmonaryTuberculosis was very less.

Keywords: Oro-nasopharyngeal, Laryngeal Tuberculosis, Pulmonary Tuberculosis,
ExtrapulmonaryTuberculosis.

\section{INTRODUCTION}

Tuberculosis (TB) is a major global health problem. It causes ill-health for approximately 10 million people each year and is one of the top ten causes of death worldwide. Tuberculosis has remained one of the world's deadliest communicable disease. ${ }^{\prime}$

Tuberculosis is the ninth leading cause of death worldwide and the leading cause from a single infectious agent, ranking above HIV/ AIDS. In 2016, globally there were as estimated 1.3 million Tuberculosis deaths among HIVnegative people (down from 1.7 million in 2000) and an additional 374000 deaths among HIV positive people.

No part of human body is immune to tuberculosis; it can affect the lung (Pulmonary tuberculosis) \& other sites (Extra pulmonary tuberculosis). Approximately $25 \%$ of case are extra pulmonary tuberculosis and of which head $\&$ Neck regions can be affected in up to $10 \%$ of these case with cervical lymph nodes most commonly involved. ${ }^{2}$ Tuberculosis of larynx was often misdiagnosed as carcinoma of larynx in patients with hoarseness and weight loss. It also presents with productive cough, pulmonary rales, and absence of cervical lymphadenopathy, which is commonly found in laryngeal carcinoma. Tuberculosis laryngitis is the most infectious form of disease, thorough physical examination and chest 
roentgenoraphic study should precede laryngoscopic examination of patients in whom tuberculosis may seem to be carcinoma of larynx. ${ }^{2}$

Tuberculosis can involve the nasopharynx primarily without affecting any other system termed a rare condition as nasopharyngeal tuberculosis or secondary to pulmonary or extrapulmonary involvement, when the portal of entry is upper respiratory tract and the route of spread is via hematogenous or lymphatic system.Majority of patients of nasopharyngeal tuberculosis presents with neck mass, nasal obstruction, rhinorrhoea, epistaxis, otalgiaor hearing loss, constitutional symptoms occurs in $12-30 \%$ cases of nasopharyngeal tuberculosis. ${ }^{3}$

However, nasopharyngeal tuberculosis is usually ignored because it has varied clinical manifestations and similar presentation with other common head and neck diseases. Nasopharyngeal tuberculosis may mimic nasopharyngeal carcinoma, both can present with cervical lymphadenopathy, nasal discharge, or nasal obstruction cervical lymphadenopathy together with the nasopharyngeal symptoms related to the mass or mucosal irregularity, makes the differential diagnosis from carcinoma difficult. Nasopharyngeal tuberculosis can co-exist with other conditions like laryngeal tuberculosis or oropharyngeal tuberculosis.

The diagnosis of oronasopharyngeal and laryngeal tuberculosis is often difficult and missed due to overlapping manifestations with carcinomas and other infections. This study was conducted to find out the incidence of Oronasopharyngeal and Laryngeal tuberculosis in Pulmonary tuberculosis cases. It will help in assessing the disease burden of oronasopharyngeal and laryngeal tuberculosis.

\section{MATERIALS AND METHODS}

This retroprospective study was conducted in S.R.N.Hospital, Prayagraj and TejBahadurSapru tuberculosis Hospital, Prayagraj. Patients were taken from duration (August 2018 to August 2019).This study was conducted after due clearance from institutional ethics committee. Patients were properly informed and written informed consent were taken from patients before participating in the study in an approved format. Patients selected for study were properly examined and history of contact, family history and duration of symptoms was taken and these patients were examined by Anterior rhinoscopy, diagnostic nasal endoscopy and direct fibreoptic laryngoscopy. Throat swab of patients for study were sent for bacteriological examination by (ZiehlNeelsen stain or BACTEC culture) and sputum examination by (Light Emission Diode Fluorescence Microscopy). Patients who were found positive for Acid Fast Bacilli from throat swab culture examination, were confirmed by histopathological examination of biopsied materials. For retrospective patients, case sheets of patients were collected from record keeping section, their addresses and phone number were obtained and called by letters and phones. After that their detailed history (family history, duration of symptoms) and investigations by which they diagnosed were taken.

\section{RESULTS}

This study was conducted on 80 patients and out of them distribution on the basis of chief complaints is as follows - 
Table 1 - Distribution of Study subjects according to chief complaints.

\begin{tabular}{|l|c|c|}
\hline \multirow{2}{*}{ Chief Complaints } & \multicolumn{2}{c|}{ Study Subjects } \\
\cline { 2 - 3 } & No. & $\%$ \\
\hline Cough \& Expectoration & 49 & $61.3 \%$ \\
\hline Breathlessness & 39 & $48.8 \%$ \\
\hline Chest Pain & 1 & $1.3 \%$ \\
\hline Haemoptysis & 8 & $10.0 \%$ \\
\hline Epistaxis & 1 & $1.3 \%$ \\
\hline Sore throat & 1 & $1.3 \%$ \\
\hline Cervical Swelling & 10 & $12.5 \%$ \\
\hline Change in Voice & 1 & $1.3 \%$ \\
\hline
\end{tabular}

Table-1 shows that maximum number of subjects (61.3\%) complained of cough and expectoration, less than half $(48.8 \%)$ complained of breathlessness, some of the subjects $(12.5 \%)$ complained of cervical swelling and nearly the same proportion (10.0\%) mentioned haemoptysis. Very few of the subjects $(1.3 \%)$ complained about chest pain, epistaxis, sore throat or change in voice.

Table 2 - Findings on Anterior Rhinoscopy

\begin{tabular}{|l|c|c|}
\hline \multirow{2}{*}{ Findings on Anterior Rhinoscopy } & \multicolumn{2}{|c|}{ Study Subjects } \\
\cline { 2 - 3 } & No. & $\%$ \\
\hline Change in nasal mucosa & 4 & $5.0 \%$ \\
\hline Nasal Discharge & 3 & $3.8 \%$ \\
\hline Turbinate Hypertrophy & 1 & $1.3 \%$ \\
\hline Deviated Nasal Septum & 7 & $8.8 \%$ \\
\hline No abnormality detected & 65 & $81.25 \%$ \\
\hline
\end{tabular}

Table-2 shows that maximum (81.25\%) of study subjects were found with no abnormality on anterior rhinoscopy, $8.8 \%$ of study subjects were found to have deviated nasal septum, 3.8\% had nasal discharge, $5.0 \%$ had changes in nasal mucosa while only $1.3 \%$ had hypertrophied turbinates.

Table 3 - Findings on Diagnostic Nasal Endoscopy

\begin{tabular}{|l|c|c|}
\hline \multirow{2}{*}{ Findings on Diagnostic Nasal Endoscopy } & \multicolumn{2}{|c|}{ Study Subjects } \\
\cline { 2 - 3 } & No. & $\%$ \\
\hline Changes in mucosa of nasopharynx & 5 & $6.3 \%$ \\
\hline Eustachian tube - not patent & 10 & $12.5 \%$ \\
\hline Thickened lateral and posterior wall of nasopharynx & 3 & $3.8 \%$ \\
\hline No abnormality detected & 62 & $77.5 \%$ \\
\hline
\end{tabular}

Table-3 shows that maximum (77.5\%) of study subjects were found with no abnormality on diagnostic nasal endoscopy, $12.5 \%$ of subjects had Eustachian tube not patent, $6.3 \%$ had changes in mucosa of nasopharynx, $3.8 \%$ had thickened lateral and posterior wall of nasopharynx. Majority of nasal changes resolved after consevative management with antiallergic and nasal decongestant drops.

Table 4 - Findings of Diagnostic Laryngoscopy

\begin{tabular}{|l|c|c|}
\hline \multicolumn{1}{|c|}{ Findings on Laryngoscopy } & \multicolumn{2}{c|}{ Study Subjects } \\
\cline { 2 - 3 } & No. & $5.0 \%$ \\
\hline Post nasal discharge & 4 & $1.3 \%$ \\
\hline Hyperemia of vocal cord & 1 & $3.8 \%$ \\
\hline Swelling in interarytenoid region & 3 & $3.8 \%$ \\
\hline Edema of epiglottis & 3 & $1.3 \%$ \\
\hline $\begin{array}{l}\text { Mucous plug over ant or / and post } \\
\text { commissure }\end{array}$ & 1 & $85 \%$ \\
\hline No abnormality detected & 68 & \\
\hline
\end{tabular}

Table-4 shows that maximum (85\%) of study subjects were found with no abnormality on Diagnostic Laryngoscopy, $5 \%$ of study subjects had post nasal discharge, $3.8 \%$ subjects had edema of epiglottis and equal proportion had swelling in inter-arytenoid region. Only 1.3\% subjects had hyperaemia of vocal cords and equal number had growth of aryepiglottic folds. Another $1.3 \%$ subjects had mucus plug over anterior or posterior commissure.

\section{Table 5 - Findings on throat swab for AFB}

\begin{tabular}{|c|c|c|}
\hline \multirow{2}{*}{ Findings on throat swab } & \multicolumn{2}{|c|}{ Study Subjects } \\
\cline { 2 - 3 } & No. & $1.25 \%$ \\
\hline AFB Positive & 1 & $98.75 \%$ \\
\hline AFB Negative & 79 & \\
\hline
\end{tabular}

Table- 5 shows that on doing investigation of throat swab for AFB , 79 patients (98.75\%) of study subjects were AFB negative, and only one patient $(1.25 \%)$ of study subject was found to be AFB positive. In case of AFB positive subject, biopsy specimen was taken from lateral and posterior wall of nasopharyx where thickening and growth was found and sent for 
histopathological examination. On histopathological examination, it showed diffuse infiltration from lymphocytes, epitheloid granuloma, langhans giant cells with caseous necrosis. This confirmed the diagnosis of nasopharyngeal tuberculosis.

\section{DISCUSSION}

In India where tuberculosis is so prevalent, nasopharyngeal tuberculosis is not very common and isolated nasopharyngeal tuberculosis is still uncommon.

Cristina S Nieves4 study states that, the most common symptom of nasopharyngeal tuberculosis was cervical lymphadenopathy and other symptoms may include chronic cough, epistaxis, nasal obstruction or nasal discharge, but in our study nasopharyngeal tuberculosis case did not present with cervical lymphadenopathy but epistaxis, chronic cough, nasal discharge were present. So our study states that the patient of nasopharyngeal tuberculosis may present with varied clinical manifestations.

The study of Jay J rohwedder2 on upper respiratory tract tuberculosis states that, the primary tuberculosis of the larynx does not occur. Laryngoscopic appearance of tuberculous laryngitis makes it difficult to exclude from laryngeal carcinoma. Vocal cord paralysis and cervical lymphadenopathy commonly present in carcinoma larynx, but these were not seen among patients of tubercular laryngitis. So when patients comes with complains of weight loss, productive cough, hoarseness of voice, proper examination of chest roentgenogram and sputum smear will avoid diagnostic confusion between tubercular laryngitis and carcinoma larynx. The study of $E$ Tas et al6 on upper respiratory tract tuberculosis states that, in modern days, tuberculosis of the upper respiratory system is rarely seen because of introduction of effective chemotherapy. The majority of cases reported with nasopharyngeal tuberculosis have come from nations where tuberculosis is endemic.

The study of Ann D King5 on Magnetic Resonance Imaging on features of nasopharyngeal tuberculosis states that, there are two patterns of nasopharyngeal tuberculosis, the first pattern shows a discrete polypoidal mass in adenoids and the second pattern shows a diffuse mucosal thickening of one or two walls of nasopharynx. It also states that there are three main patterns of involvement on direct examination of the nasopharynx [1] normal nasopharynx [2] irregularity and ulceration of mucosa [3] mass lesion that may be bulging of the wall or a polypoid mass. in our study there was thickening and mucosal irregularity present on lateral and posterior wall of nasopharynx.

In our study, irregular mucosal thickening on lateral and posterior wall of nasopharynx was found on diagnostic nasal endoscopy in nasopharyngeal tuberculosis case. Study of Tashnin Rahman8 on diagnostic nasal endoscopy showed a smooth congested growth in the superior wall of nasopharynx.

In our study on histopathological examination of throat swab positive patient for AFB showed epitheloid granuloma with caseous necrosis. Similar findings also found on histopathological examination in the study ofTashnin Rahman8.

In our study it was observed that only one patient $(1.25 \%)$ of pulmonary tuberculosis developed nasopharyngeal tuberculosis. which was comparable with study of Tashnin Rahman8

The study of ETas et al 6 states that the diagnosis of upper respiratory tuberculosis made by [1] clinical picture [2] histological findings [3] response to anti-tubercular treatment. Above study also states that caseous granuloma was present in all upper respiratory tuberculosis cases. In our study we sent throat swab of all 
cases to detect acid fast bacilli, and it was found positive in only one case. So throat swab for detection of acid fast bacilli is a useful microbiological test. On histopathologic examination of positive case, epitheloid granuloma and caseous necrosis was found.

In our study the AFB positive nasopharyngeal tuberculosis case belongs to adult age group (28 years). Study of Chonticha Srivanitchapoom7 on nasopharyngeal tuberculosis states that, nasopharyngeal tuberculosis commonly occurs in adults and there are two peaks of frequencies, (1) between 15 to 30 years (2) between 50 to 60 years.

\section{CONCLUSION}

India is an endemic country for pulmonary tuberculosis specially Eastern U. P, due to high population density, low socio-economic status and lack of education. In our study out of 80 cases of pulmonary tuberculosis, only one case found with tuberculosis of upper respiratory tract along with pulmonary tuberculosis. Nasopharyngeal and laryngeal Tuberculosis mimic symptoms with carcinoma. Therefore, a complete clinical, radiological and histopathological examinations are required to confirm the diagnosis.

Being an otorhinolaryngologist we should always keep in mind the possibility of Tuberculosis in the differential diagnosis of nasopharyngeal/laryngeal mass. In this way our study is helpful to keep eye on the cases of upper respiratory tract tuberculosis among cases of pulmonary tuberculosis and increases the awareness about upper respiratory tract tuberculosis. Further study is needed with large sample size with long duration of treatment/follow up as these are few limitations in our study to make definitive conclusion.

\section{REFERENCES}

1. Global Tuberculosis Report, 2017. World Health Organization.
2. J.J. Rohwedder, "Upper respiratory tract tuberculosis, Sixteen cases in a general hospital" Annals of Internal Medicine. 1974; 80(6): pp. 708-713.

3. R.K. Mishra, B.K. Prasad \& Sunil Mathur, Nasopharyngeal tuberculosis. Med. J. Armed Forces,India. 2015;71(2):S586-S589.

4. Cristina S. Nieves, MD, Rubiliza DC. Onofre, MD, Fortuna Corazon A. Aberin-Roldan, MD, Rene Louie C. Gutierrez, MD. Nasopharyngeal Tuberculosis in a patient presenting with upper airway obstruction. Philippine Journal of Otolaryngology-Head and Neck Surgery. 2010; Vol.25(1).

5. King $A D$, Ahuja $A T$, Tse GM, van Hasselt $A C$, Chan AB. MR Imaging Features of Nasopharyngeal Tuberculosis: Report of Three Cases and Literature Review. American journal of Neuroradiology 2003;24(4):279-82.

6. ETas, E Sahin, S Vural, HTurkoz, A Gursel. Upper Respiratory Tract Tuberculosis: Our Experience Of Three Cases and Review Of Article. The International Journal of Otorhinolaryngology. 2006;6(1).

7. Srivanitchapoom, C., \&Sittitrai, P. (2016). Nasopharyngeal Tuberculosis: Epidemiology, Mechanism of Infection, Clinical Manifestations, and Management. International Journal of O t o I a ry ngology, $2016 ; 1-6$. doi:10.1155/2016/4817429.

8. Rahman T, llapakurty B, Kakati K, Das AK, Kataki AC. Primary nasopharyngeal tuberculosis: A rare case presentation. National Journal of Medical Research. 2016;6(2):224-5. 


\title{
A RETROSPECTIVE STUDY ON CLINICAL AND EPIDEMIOLOGICAL PROFILE AMONGST POST OPERATED PATIENTS OF CHRONIC SUPPURATIVE OTITIS MEDIA (CSOM) AT A TERTIARY CARE CENTER.
}

\author{
Authors: Harendra Kumar Gautam (1), S.K. Kanuajia (2), Astha Singh (3), NS Saxena (4), Amrita \\ Srivastava* (5), Saumya KumarTiwari (6).
}

Author's Affiliation: (1) Associate Professor (2) Professor \& Head (3, 5) Senior Resident $(4,6)$ Assistant Professor, Department of ENT, GSVM Medical College, Kanpur, U.P. 208002

\section{Abstract}

Background: Chronic suppurative otitis media (CSOM) remains one of the most common ear diseases in the general population. The socioeconomic burden of CSOM is still very high both financially and non-financially for the society. There is a need for capacity building to reduce the burden as well as the associated risk. Aims and Objectives: The aim of this study was to study the clinical and epidemiological profile of post operated patients of chronic suppurative otitis media (CSOM) at a tertiary care center. Materials and Methods: This was a retrospective study of 265 patients of clinically diagnosed CSOM. The study was carried out at the ENT department, LLR hospital, GSVM medical college Kanpur during the period of 6 years from August 2013 to July 2019. Results: The data collected from the Clinicoepidemiological study of chronic suppurative otitis media carried out on 265 patients, showed that 197 patients had unilateral ear disease while 68 patients had bilateral ear disease. Among 265 patients, 126 (47.54\%) were male and 139 (52.42\%) were female. $44.15 \%$ patients were in age group 11 to 20 years of age. $72.82 \%$ patients belonged to lower socioeconomic status. Tubotympanic type constituted majority 207 (78.12\%) cases followed by atticoantral type in 58 (21.88\%) cases. Most patients presented with moderate hearing impairment 113 (42.64\%). Conclusion: CSOM is a preventable cause of hearing impairment. Early diagnosis and management can effectively reduce the socioeconomic burden and prevent deafness.

Keywords: CSOM, Socioeconomic status, Hearing impairment.

\section{Introduction}

Chronic suppurative otitis media (CSOM) remains one of the most common ear diseases having a prevalence of $5.2 \%$ in the general population. [1] Chronic otitis media (COM) equates with the term chronic "suppurative" otitis media that is no longer advocated, as COM is not necessarily a result of "the gathering of pus." However, the distinction remains between active COM, where there is inflammation and the production of pus, and inactive COM, where there is no inflammation and the production of pus. [2] Incidence of this disease is the higher in developing countries, because of malnutrition, overcrowding, poor hygiene, inadequate health care, and recurrent upper respiratory tract infection.[3] In the developing countries, there is differential prevalence among the different socioeconomic strata of the community.[4] The socioeconomic cost of CSOM is still very high both financially and non-financially for the society. There is a need for capacity building to reduce the burden as well as the associated risk. [5] It is the commonest childhood infectious disease worldwide [6] starting early in life, but in our environment, presentation may be in adult life. [7] CSOM is usually classified into two types: Tubotympanic and atticoantral depending on whether disease process affects 
pars tensa or pars flaccid of the tympanic membrane. [8].

The aims of managing the chronic discharging ear are early detection and timely, appropriate intervention to eradicate the disease permanently or to reduce its effects (i.e., ear discharge, hearing loss, and other complications) if eradication is not possible. [9]

\section{Material and Method}

This was a retrospective study of 265 patients of clinically diagnosed CSOM. The study was carried out in the Department of ENT of a tertiary-care Medical College and Hospital during the period of 6 years from August 2013 to July 2019.The relevant data were collected with regard to age and sex distribution, type of CSOM, laterality, type of discharge, associated complaints, duration between incidence and presentation, clinical presentation, radiological findings, management, and complications. Xray mastoid bilateral Schuller's view, HRCT Temporal bone and Culture and Sensitivity of discharge were carried out in selected cases.

\section{Results}

The data collected from the Clinicoepidemiological study of chronic suppurative otitis media carried out on 265 patients, revealed that 197 patients had unilateral ear disease while 68 patients had bilateral ear disease. The data were analyzed statistically and following observations were made. Among 265 patients, 126 (47.54\%) were male and $139(52.42 \%)$ were female. $44.15 \%$ patients were in age group 11 to20 years.[Tab-1]

Table 1: Distribution of patients according to age and gender.

\begin{tabular}{|l|l|l|l|}
\hline Age group (years) & Male & Female & Total \\
\hline $11-20$ & 56 & 61 & 117 \\
\hline $21-30$ & 33 & 34 & 67 \\
\hline $31-40$ & 24 & 38 & 62 \\
\hline $41-50$ & 10 & 4 & 14 \\
\hline $51-60$ & 3 & 2 & 5 \\
\hline Total & 126 & 139 & 265 \\
\hline
\end{tabular}

Figure 1: Distribution of patients according to age and gender.

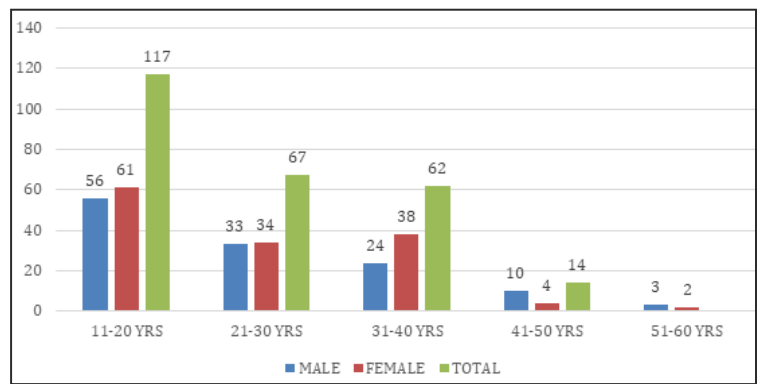

$72.82 \%$ patients belonged to lower socioeconomic status. [Tab-2]

Tab-2 Distribution of patients according to socioeconomic status.

\begin{tabular}{|l|l|}
\hline Socioeconomic condition patients & No. of Patients (\%) \\
\hline Upper & $12(4.52 \%)$ \\
\hline Upper middle & $20(7.54 \%)$ \\
\hline Lower middle & $40(15.09 \%)$ \\
\hline Upper lower & $83(31.32 \%)$ \\
\hline Lower & $110(41.50 \%)$ \\
\hline Total & $265(100 \%)$ \\
\hline
\end{tabular}

Figure 2: Distribution of patients according to socioeconomic status.

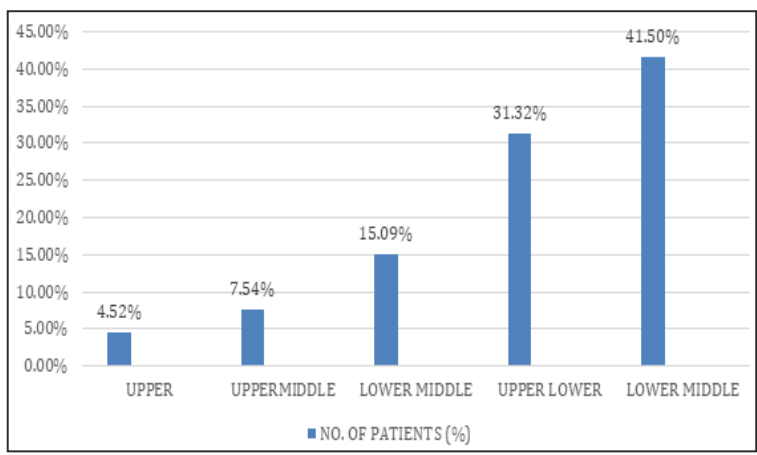

DISTRIBUTION OF PATIENTS ACCORDING TO SOCIOECONOMICTubotympanic type constituting majority $207(78.12 \%)$ cases trailed by atticoantral type $58(21.88 \%)$ cases.[Tab-3]

Table 3: Distribution of Patients according to type of CSOM.

\begin{tabular}{|l|l|}
\hline Type of CSOM & No. of Patients (\%) \\
\hline Tubotympainc type & $207(78.12 \%)$ \\
\hline Atticoantral type & $58(21.88 \%)$ \\
\hline Total & $265(100 \%)$ \\
\hline
\end{tabular}


Figure 3: Distribution of Patients according to type of CSOM.

DISTRIBUTION OF PATIENTS ACCORDING TO TYPE OF CSOM

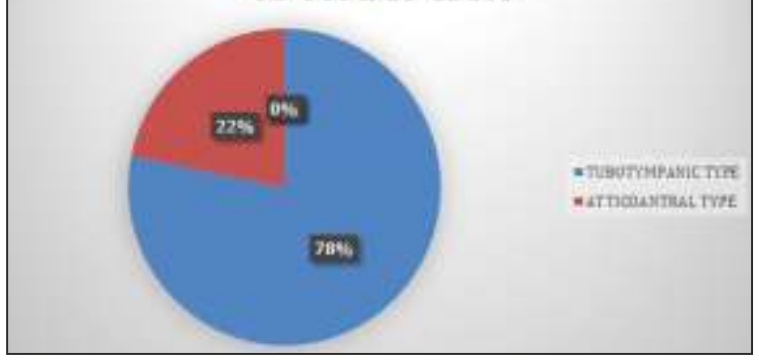

Most patients presented with moderate hearing impairment 113 (42.64\%), while mild hearing impairment was seen in 89 cases (33.58\%).[Tab-4]

Table-4: Distribution of patients according to hearing loss.

\begin{tabular}{|l|l|}
\hline Degree of Hearing Loss & No. of Patients (\%) \\
\hline Mild & $89(33.58 \%)$ \\
\hline Moderate & $113(42.64 \%)$ \\
\hline Severe & $47(17.73 \%)$ \\
\hline Profound & $16(6.03 \%)$ \\
\hline Total & $265(100 \%)$ \\
\hline
\end{tabular}

Figure 4: Distribution of patients according to hearing loss.

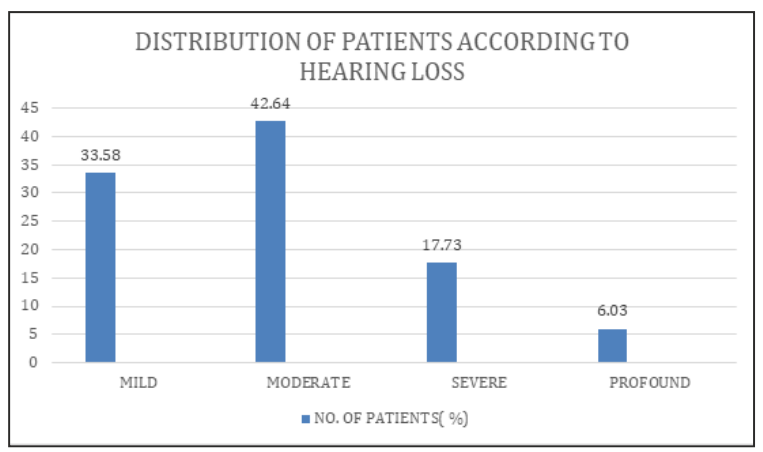

\section{Discussion}

Out of total 265 patients $44.15 \%$ were in age group of 11 to 20 years. Findings of this study is similar to study carried out by Gupta and Mittal, where majority of patients were of the age group of $10-20$ years. ${ }^{[10]}$
In our study $72.82 \%$ patients belonged to lower socioeconomic status, which was similar to Gupta and Mittal ${ }^{[10]}$ study where most patients belonged to poor socioeconomic status (SES class IV, V comprised more than three-fourth of patients). This may be attributed to unhealthy living conditions, unbalanced diet, and poor hygiene and the economic strains of the patients with regard to seeking health services.

Analysis of the gender distribution in this study revealed that CSOM was found to be more common in females 139 (52.42\%) than in males 126 (47.54\%). Consistent results were obtained by Sharma A et al ${ }^{[11]}$ and Nazir and Kadri, ${ }^{[12]}$ while a study by Patigaroo et al. ${ }^{[13]}$ and Moshi et al. ${ }^{[14]}$ showed a higher incidence in male population as compared to females.

In present study Tubotympanic type comprised majority 201 (75.84\%) cases followed by atticoantral type 58 (21.88\%) cases. Findings of this study are similar to study carried out by Kabdwal $\mathrm{N}$ et al. where out of a total of 80 patients, $61(76.25 \%)$ were of safe CSOM whereas 19 (23.75\%) were unsafe CSOM. ${ }^{[15]}$

In the study conducted by Aditya Singhal et al, most patients presented with moderate hearing impairment (43.75\%) and mild hearing impairment (31.25\%). ${ }^{[16]}$ This is similar to our study where most patients presented with moderate hearing impairment 113 (42.64\%), followed by mild hearing impairment 89 (33.58\%).

\section{Conclusion}

CSOM is a preventable cause of hearing impairment. Early diagnosis and management can effectively reduce the socioeconomic burden and prevent deafness. It is an infection commonly associated with poor socioeconomic status related conditions such as malnutrition, overcrowding, poor hygiene and recurrent URTI. 


\section{Reference}

1. World Health Organization. State of hearing and ear care in the South East Asia Region. WHO Regional Office for South East Asia. WHOSEARO. SEA/Deaf/9. Available at:http://www.searo.who.int/LinkFil es/Publications_HEARING_\&_EAR_ CARE.pdf. Accessed on 10 January 2010.

2. Browning GG, Kelly G, Swan IR, Canter R, McKerrow SW. In: Gleeson MJ, Bruton MJ, editors. ScottBrown's Otorhinolaryngology Head and Neck. London: Edward Arnold; 2008.

3. Kumar $\mathrm{H}$, Seth $\mathrm{S}$. Bacterial and fungal study of 100 cases of chronic suppurative otitis media. J Clin Diagn Res. 2011;5:1224-7.

4. Adhikari P, Joshi S, Kharel B. Chronic suppurative otitis media in urban private school children of Nepal. Braz J Otorhinolaryngol. 2009; 75(5):669-72.

5. Afolabi OA, Fadare JO, Omokanye HK, Olatoke F, Odi TO, Saka MJ, et al. Socioeconomic challenges of chronic suppurative otitis media management in state tertiary health facility in Nigeria. Egypt J Ear Nose Throat Allied Sci. 2014; 15(1):17-22.

6. Verhoeff $M$, van der Veen EL, Rovers MM, Sanders EA, Schilder AG. Chronic suppurative otitis media: a review. Int J Pediatr Otorhinolaryngol 2006; 70(1):1-12.

7. Okafor BC. The chronic discharging ear in Nigeria. J Laryngol Otol1984; 98(2):113-9.

8. Kumar H., Seth S. Bacterial and fungal study of 100 cases of chronic suppurative otitis media. J Clin Diag Res 2011;5:1224-7.

9. Acuin JM. Chronic suppurative otitis media: a disease waiting for solutions. Comm Ear Hearing $\mathrm{H}$ 2007;4(6):17-19.

10. Gupta R, Mittal M. A study on clinical and epidemiological profile of chronic suppurative otitis media (CSOM) at a tertiary care center. Int J Med Sci Public Health. 2016; 5(5):1021-4.

11. Sharma A, Banerjee $M$, Mehra M, Khandelwal P, Taneja V. Bacteriology and antibiotic sensitivity of chronic suppurative otitis media in a government hospital. Indian J Otol 2018; 24:214-8.

12. Asifa Nazir, S. M. Kadri. Aerobic bacteriology of chronic suppurative otitis media: a hospital based study. Int J Res Med Sci. 2014 Nov; 2(4):1521-1525.

13. Patigaroo SA, Wani SM, Anjum N, Islam $M$, Sumbrai $D$, Ahmad R. Drift in the bacteriology of chronic suppurative otitis media and methicillin-resistant Staphylococcus aureus as an 
emerging pathogen: an experience. Int J Med Sci Public Health 2016; 5:671-

14. Moshi NH, Minja BM, Ole-Lengine L, Mwakagile DS. Bacteriology of chronic otitis media in Dar es Salaam, Tanzania. East Afr Med J 2000; 77:20-2.

15. Kabdwal N, Varshney S, Bist SS, Bhagat S, Mishra S, Agarwal V. Pre and post-operative evaluation of hearing in chronic suppurative otitis media. Indian J Otol 2013; 19:164-8.

16. Aditya Singhal, Pooja Agrawal, Vijender Kumar Agrawal. Prevalence and determinants of chronic suppurative otitis media in school going children in Bareilly ( Uttar Pradesh). Int J Otorhinolaryngol Head Neck Surg. 2018Mar; 4(2):348-351.

\section{*Corresponding Author}

Dr. Amrita Srivastava

Assistant Professor

Department of ENT

GSVM Medical College

Kanpur 